\title{
Seaweed polysaccharides: Emerging extraction technologies, chemical modifications and bioactive properties
}

Paz Otero, M. Carpena, P. Garcia-Oliveira, J. Echave, A. Soria-Lopez, P. GarciaPerez, M. Fraga-Corral, Hui Cao, Shaoping Nie, Jianbo Xiao, J. Simal-Gandara \& M. A. Prieto

To cite this article: Paz Otero, M. Carpena, P. Garcia-Oliveira, J. Echave, A. Soria-Lopez, P. Garcia-Perez, M. Fraga-Corral, Hui Cao, Shaoping Nie, Jianbo Xiao, J. Simal-Gandara \& M. A. Prieto (2021): Seaweed polysaccharides: Emerging extraction technologies, chemical modifications and bioactive properties, Critical Reviews in Food Science and Nutrition, DOI: 10.1080/10408398.2021.1969534

To link to this article: https://doi.org/10.1080/10408398.2021.1969534

Published online: 31 Aug 2021.

Submit your article to this journal $₫$

Џ Article views: 166

Q View related articles $\longleftarrow$

View Crossmark data $־$ 


\title{
Seaweed polysaccharides: Emerging extraction technologies, chemical modifications and bioactive properties
}

\author{
Paz Otero \\ M. Carpena ${ }^{a}$ \\ P. Garcia-Oliveira ${ }^{a, b}$ \\ J. Echave ${ }^{a}$ \\ A. Soria-Lopez ${ }^{\mathrm{a}}$, P. Garcia-Perez ${ }^{\mathrm{a}}$ (D), M. \\ Fraga-Corrala,b \\ D, Hui $\mathrm{CaO}^{\mathrm{a}}$ \\ , Shaoping $\mathrm{Nie}^{\mathrm{c}} \mathbb{D}$, Jianbo Xiao ${ }^{\mathrm{a}, \mathrm{d}}$ \\ J. Simal-Gandara ${ }^{a}$ (D) and M. A. Prieto ${ }^{a, b}$
}

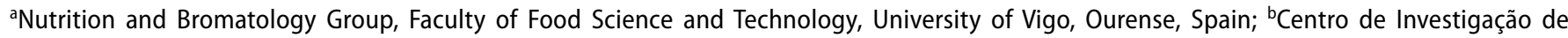
Montanha (CIMO), Instituto Politécnico de Bragança, Bragança, Portugal; 'State Key Laboratory of Food Science and Technology,

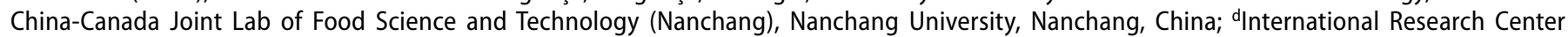
for Food Nutrition and Safety, Jiangsu University, Zhenjiang, China

\begin{abstract}
Nowadays, consumers are increasingly aware of the relationship between diet and health, showing a greater preference of products from natural origin. In the last decade, seaweeds have outlined as one of the natural sources with more potential to obtain bioactive carbohydrates. Numerous seaweed polysaccharides have aroused the interest of the scientific community, due to their biological activities and their high potential on biomedical, functional food and technological applications. To obtain polysaccharides from seaweeds, it is necessary to find methodologies that improve both yield and quality and that they are profitable. Nowadays, environmentally friendly extraction technologies are a viable alternative to conventional methods for obtaining these products, providing several advantages like reduced number of solvents, energy and time. On the other hand, chemical modification of their structure is a useful approach to improve their solubility and biological properties, and thus enhance the extent of their potential applications since some uses of polysaccharides are still limited. The present review aimed to compile current information about the most relevant seaweed polysaccharides, available extraction and modification methods, as well as a summary of their biological activities, to evaluate knowledge gaps and future trends for the industrial applications of these compounds.
\end{abstract}

\section{KEY TEACHING POINTS}

- Structure and biological functions of main seaweed polysaccharides.

- Emerging extraction methods for sulfate polysaccharides.

- Chemical modification of seaweeds polysaccharides.

- Potential industrial applications of seaweed polysaccharides.

- Biological activities, knowledge gaps and future trends of seaweed polysaccharides.

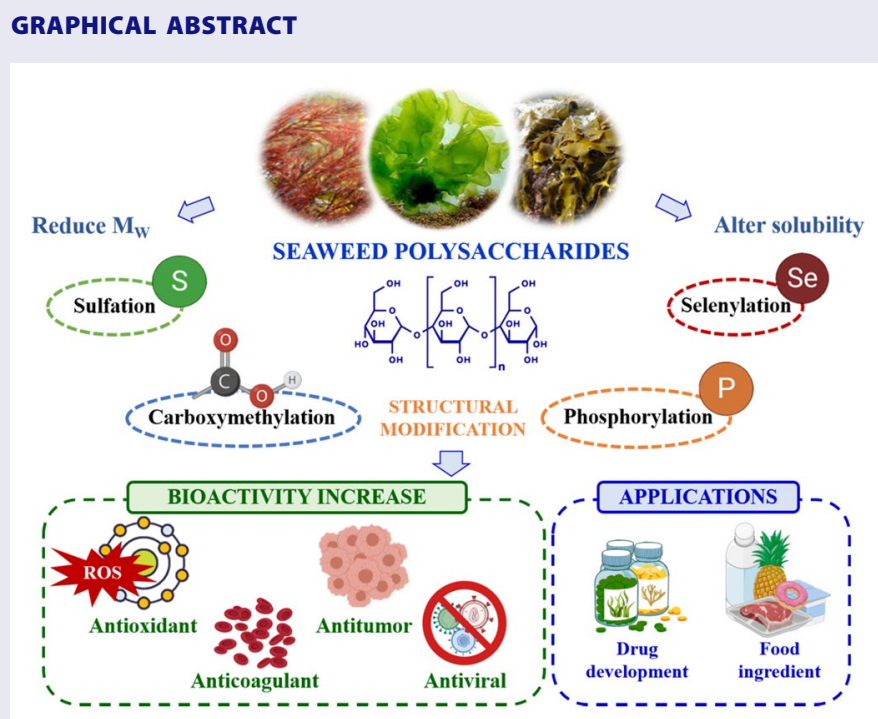

Several seaweeds' polysaccharides have gained the attention of industry due to their properties and bioactivities.

\section{KEYWORDS}

Algae polysaccharides; novel extraction methods; chemical modification biological activities 


\section{Introduction}

Macroalgae or seaweeds are plant-like organisms that generally occupy the benthic littoral zone. They are usually classified in green algae (Chlorophyta), brown algae (Phaeophyta) and red algae (Rhodophyta) (Otero et al. 2018). Nowadays, about thirty two million tons of macroalgae (wet weight) is processed worldwide, being the largest harvesting in the South East of Asia (Jönsson et al. 2020). The nutritional potential of the algae is widely recognized (Otero, López-Martínez, and García-Risco 2019). Seaweeds have been consumed for many years in countries like China, Indonesia and Philippines and have recently gained a considerable interest in Europe due to their multiple bioactive compounds with applications in the culinary and functional food industries. These organisms contain high value molecules like proteins, omega-3 polyunsaturated fatty acids, minerals, polyphenols, alkaloids, terpenes, pigments (chlorophylls, carotenoids and phycobilins) and polysaccharides (SP) (Pereira et al. 2021). This diversity of compounds are involved in biological activities like antioxidant, antimicrobial, anticancer, anti-allergic, antiviral and anticoagulant (Barkia, Saari, and Manning 2019; Kosanić, Ranković, and Stanojković 2015), showing also multiple applications in cosmetic and pharmaceutical industries (Alves et al. 2016).

Specifically, SP are the major components in seaweeds. They usually occur in the range of 5 to $75 \%$ of their dry weight (w/w, DW) depending on the species, age or season of harvesting, among other factors (Hentati et al. 2020). For example, the laminarin SP is usually found in the genus Laminaria up to 50\% (DW) (Patil et al. 2018). The importance of SP lies with the fact that many of them are sulfated polysaccharides (SFP), not present in terrestrial plants and linked to several health benefits like prebiotic effects and cholesterol excretion (Ciancia, Fernández, and Leliaert 2020). Their occurrence is specific for each macroalgae species (Hentati et al. 2020). For instance, green algae contain ulvan, brown seaweeds are rich in alginate, laminarin, fucans and fucoidans, while red macroalgae are composed by carrageenan, agar, floridean starch, but also other galactans. These differences in their chemical structure result in the different properties of SP (De Jesus Raposo, De Morais, and De Morais 2015). Generally, they possess several biological activities such as antioxidant, antimicrobial, antitumor, anticoagulant, anti-hyperlipidemic and anti-inflammatory. However, some SP do not entail a sufficient biological activity for cosmetic, food or nutraceutical applications. Degradation (generally, hydrolysis) and chemical modification (phosphorylation, sulfation or selenylation, among others) of SP has demonstrated to enhance their biological activities (Shi et al. 2017). For instance, different studies have proven that hydrolysis could improve the antioxidant capacity of SP from Enteromorpha species (Li et al. 2013; Shi et al. 2017). Other studies have shown that the introduction of carboxymethyl and hydroxamate groups improved the antioxidant and antimicrobial activity when compared to native SP from E. prolifera (Shao et al. 2017). In addition, structure and chemical composition of SFP is different according to the algae species. (Karnjanapratum and You
(2011) concluded that SFP differences in chemical composition are possible and may be due to differences in the growing conditions of seaweed and the employment of analytical methods and extraction procedures. However, the relation between the structure of algae SFP and their biological structure is not entirely clear (Bilan and Usov 2008). The chemical structure of SFP such as the degree of sulfation, sulfation position, molecular weight $\left(\mathrm{M}_{\mathrm{W}}\right)$ or glycosidic branching are factors that can affect their biological activities.

In seaweeds, SFP are mostly found as part of cellular walls, so extraction techniques are essential to obtain rich extracts of these bioactive molecules. Traditionally, solid to liquid extraction with hot water has been the most used method for extracting SP. However, in recent years, innovative extraction techniques have arisen to recover SP in a more efficient and clean way, usually followed by further purification and fractionation procedures (Xu, Huang, and Cheong 2017; Tang et al. 2020). SFP possess many applications, due to their hydrocolloid properties. Traditionally, they have been employed in the biomedicine field as gelling materials, as is the case of the agarose in bacterial cultures and electrophoresis gels (Beaumont et al. 2021). In addition, they are part of new diagnostic and therapeutic nanotechnology tools in development intended for human use. For instance, fucoidans have been used in biocompatible scaffolds for small drug, gene and protein deliveries, and for tissue engineering in regenerative medicine as well as for stabilizers of nanoparticles (Chollet et al. 2016). A recent study has been shown that marine carbohydrates, especially SFP, possess potent inhibitory effect on the low-pathogenic human coronaviruses HCoV-229E, HCoV-OC43, HCoV-NL63, and HCoV-HKU1 (Mohammed, Naveed, and Jost 2021). In this context, the growing applications of seaweed SP and deeper knowledge about their structure and functions will entail a simultaneous development and optimization of the employed extraction techniques. The aim of this article is to review the main SP obtained from seaweeds and most used extraction techniques, as well as to revise their structural characterization and modification methods that could allow improving their potential biological properties.

\section{Seaweeds-derived polysaccharides occurrence and types: structure and composition}

Algae SP can be classified according their source, as they are unique to green, brown or red algae but also depending on their sulfation degree (Tanna and Mishra 2019). In general terms, a greater polymerization and sulfation degree of these SP is related to a higher extent of their bioactivities, although it may also impact their hydrocolloidal properties (Kopplin et al. 2018). More sulfated SP include fucoidan and carrageenan, whereas the lower sulfated SP are ulvan and agar. Alginate and laminarin do not contain sulfate substitutions in nature (Jiao et al. 2011). Another relevant molecule is floridean starch, an storage starch-like molecule with markedly different characteristics to terrestrial plants starch and does not contain sulfate groups (Grünewald and 
Alban 2009). As SP are part of cell wall and matrix components, different taxonomic families of seaweeds show diverse SP types. Nevertheless, structure, composition and levels of these SP not only vary depending on the taxonomic origin but are also influenced but ecophysiological characteristics of the growth environment and time of harvest (Yaich et al. 2014). As such, a single species may display highly different content of P. Moreover, albeit each SP group share a common skeletal structure, their monosaccharide residues may greatly vary among species, which especially occurs in ulvan, carrageenan and fucoidan (Qi and Kim 2017). A broad perspective on the major addressed SP sources and composition is presented in Table 1.

\subsection{Polysaccharide's occurrence}

SP are generally found in high content (around 50\% DW), thus seaweeds have consistently been employed as a natural source of SP (Kraan 2012). In addition, macroalgae biomass is easily recovered from shored or cultured seaweeds. On top of that, due to globalization, some species (ex. Ulva sp., Codium sp., Gracilaria sp.) display invasive ecological behaviors and may also proliferate in abundance in eutrophicated waters, which has made SP extraction from them an alternative (Yaich et al. 2014). These facts make macroalgae the most feasible source of these SP over microalgae, although some other marine organism such as Spirulina sp., Chlorella sp., Dunaliella sp., Phaeodactylum sp. or Porphyridium sp. also contain significant levels of SP integrated in their cell wall and vacuoles (De Jesus Raposo, De Morais, and De Morais 2013). Here below a comparison about SP from the main three macroalgae groups (green, brown and red seaweeds) is carried out.

Green algae (Chlorophyta) are the macroalgae groups with less diverse SP content, yet the only one accounted to contain ulvan. This is the foremost extracted SP from Ulva species including $U$. lactuca, $U$. rotundata, $U$. rigida, or $U$. fasciata (Pangestuti and Kurnianto 2017). Although red algae are the main source of sulfated galactans, green algae have also been identified to have this SP in low quantities (e.g. around 5\% DW in the pacific algae of the genus Codium) (Farias et al. 2008). This is especially relevant, as no other sulfated galactans have been reported out of red algae and green algae. On the other hand, U. ohnoi has been described as a feasible source of starch, similar to that of terrestrial plants albeit present in low quantities (>10\% DW) (M. Prabhu et al. 2019).

Brown algae (Phaeophyta) pose a significant source of SP, like alginate, fucoidan and laminarin. Current alginate sources are $L$. hyperborea, $L$. digitata, L. japonica, A. nodosum, and $M$. pyrifera, as the amount of alginate is consistently higher than other brown algae species (Kraan 2012). For example, the alginate content in M. pyrifera, the largest consumed kelps in East Asia, can reach 30\% DW (Lorbeer et al. 2017) and the alginate content in $L$. digitata and in S. muticum is reported around $20 \%$ and $15 \%$ DW, respectively (Flórez-Fernández, Domínguez, and Torres 2019). On the contrary, fucoidan is a less extensively exploited SP, mainly obtained from Fucus vesiculosus (fucoidan content of $20 \%$
DW), from U. pinnatifida and from $L$. japonica (Bittkau, Neupane, and Alban 2020). Sargassum sp. is also a source of fucoidan, although it has generally much lower content, about 5\% DW (Jacobsen et al. 2019). While the levels of fucoidan and alginate generally remain constant throughout the year, the concentration of laminarin greatly shifted due to its energy storage role. Broadly, laminarin reaches its maximum content in autumn and the lowest in winter time in harvested seaweeds (Schiener et al. 2015). As its name hints, algae from the genus Laminaria are the richest source of laminarin, whose content is around $30-35 \% \mathrm{DW}$ in L. digitata, L. hyperborea and S. latissima (Kadam, Tiwari, and O'Donnell 2015).

Red algae (Rhodophyta) are the unique source of the sulfated galactans agar and carrageenans, but also the only natural source of floridean starch. These three SP may be concurrent, but generally agarophytes belong to the Gelidium, Gracilaria, Pterocladia, and Gelidiella genera, being Gracilaria species the first source (Sousa, Rocha, and Gonçalves 2020). In Gelidium and Gracilaria species, agar content is around $30-40 \%$ DW (Lee et al. 2017). Gelidium, Eucheuma, Gigartina and Eucheuma species are also the major global raw material to obtain carrageenans, especially $\lambda, \kappa$ and $\mathrm{t}$-carrageenans, which are the most valued by several industries due to their gelling properties ( $\mathrm{Li}$ et al. 2014). Other minor sources of carrageenans include Porphyra and Furcellaria species, which contain characteristically branched carrageenans labeled as porphyrans and furcelarans (Saluri et al. 2021). These algae are also harvested depending on their primary type of carrageenans. For example, Gigartina and Chondrus species are richer in $\lambda$-carrageenans (Jiao et al. 2011). Floridean starch is mainly obtained from species of the Florideophyceae family, including Gracilaria and Gracilariopsis genera (Yu et al. 2007).

\subsection{Main seaweed-derived polysaccharides}

\subsubsection{Ulvan}

Ulvan has a distinct heterogeneous composition, with repeated sequences of disaccharides as sulfated rhamnose, uronic acids (glucuronic or iduronic acids) and xylose (Lahaye and Ray 1996). Hence, the two most frequently repeated disaccharides are aldobiorunic acids, which are designated as type $\mathrm{A}(\beta$ - $\mathrm{D}$-glucuronic acid $\alpha-1 \rightarrow 4 \mathrm{~L}$-rhamnose 3 -sulfate) and type B ( $\alpha$-L-iduronic acid $\alpha-1 \rightarrow 4 \mathrm{~L}$-rhamnose 3-sulfate) ulvanobiuronic acids (Robic, Bertrand, et al. 2009). In minor proportion, ulvan is also composed of disaccharide aldobioses, called ulvanobioses. These consist of $\beta$-D-xylose $\alpha$ - $(1 \rightarrow 4)$ linked to L-rhamnose 3-sulfate, that may also display an additional sulfate group attached to the xylose $\mathrm{C}_{2}$ (Figure 1, Table 1). In general terms, ulvan is composed of around $65 \%$ ulvanobiuronic acid and 30\% uronic acids, with minor fractions of galactose, mannose and arabinose (Pangestuti and Kurnianto 2017). Sulfate content of this SP may range between 3 and $8 \%$ of DW and its rise is related to a higher anticoagulant activity (Robic, Gaillard, et al. 2009). However, its sulfation pattern is heterogeneous, with some regions exhibiting a sulfate group every 2 monosaccharides while other regions remain almost unsulfated 


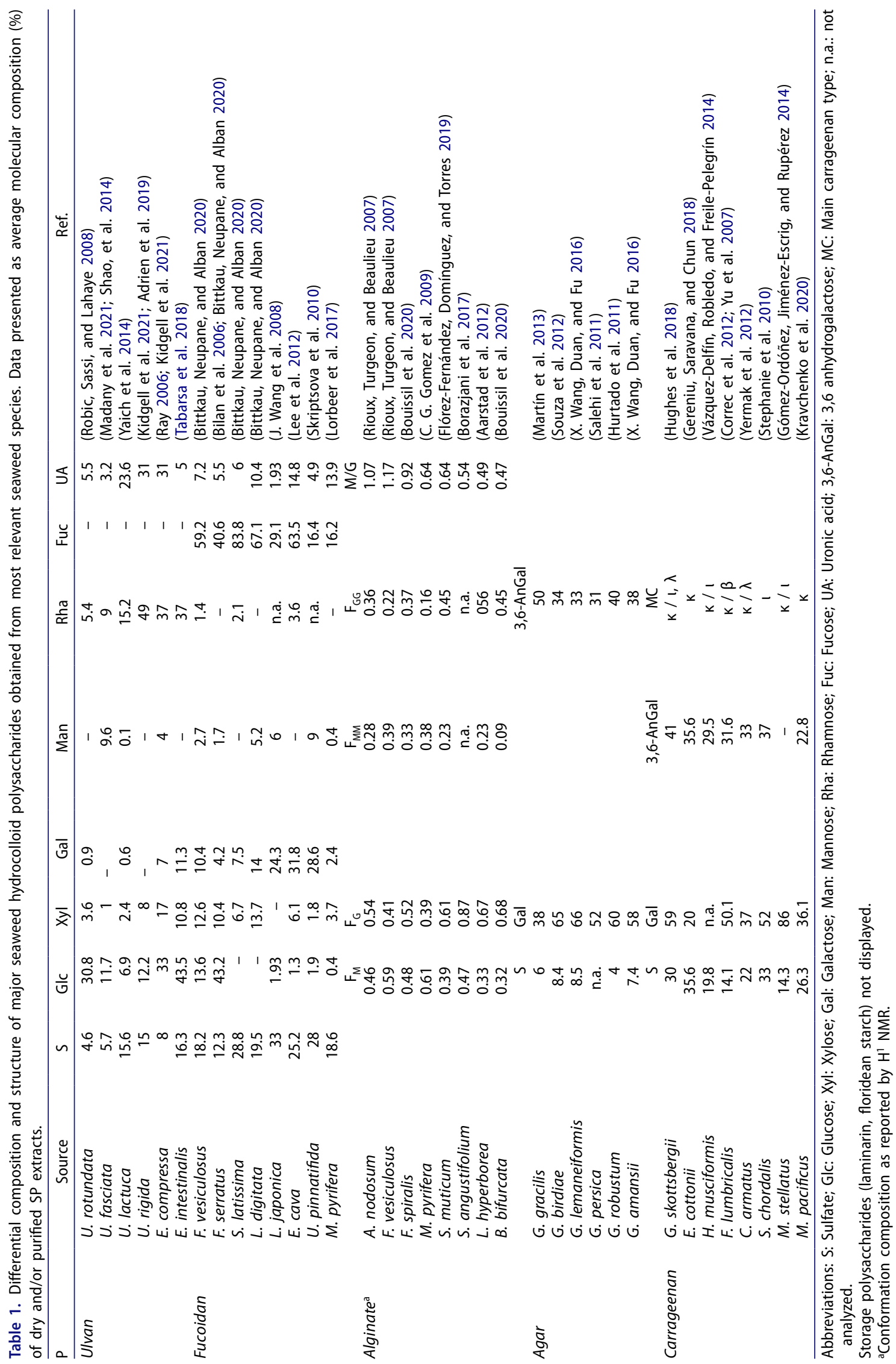


(Adrien et al. 2019). Studies on its structure revealed that depending on medium, salinity and $\mathrm{pH}$, ulvan subunits assemble and polymerize autonomously in different manners. At low $\mathrm{pH}$, the carboxyl groups of aldobiorunic acid groups ionize, while the sulfate groups remain stable, which alters its aggregation dynamics and leads to the dispersion of bead-like shaped aggregates with reduced solubility. Conversely, at high $\mathrm{pH}$, ulvan may form a very dense film, aggregating in a net-like shape (Robic, Gaillard, et al. 2009). Although all SP are hydrocolloids, ulvan has generally lesser affinity with water in comparison with others, making it a less viscose gelling agent in comparison with alginate or laminarin (Morelli and Chiellini 2010).

\subsubsection{Alginate}

Alginate is the main cell wall and cell matrix SP in almost all brown seaweeds, which are the primary source of this SP. It is an acidic molecule in nature. Alginate is essentially composed of two linearly linked monomers: $\alpha$-L-guluronate (G-blocks) $\alpha$ - $(1 \rightarrow 4)$ linked to $\beta$-D-mannuronate (M-blocks) (Cardoso, Costa, and Mano 2016), and these can appear as consecutive block sequences (G-G-G, M-M-M) or intercalated (M-G-M) (Figure 1). Depending on the order and proportion of these sequences and $\mathrm{M} / \mathrm{G}$ ratio, the resulting conformational structure will be different in $\mathrm{M}_{\mathrm{W}}$ and properties. Only G-blocks of alginate are believed to participate in intermolecular cross-linking with divalent cations (e.g. $\mathrm{Ca}^{2+}$ ) to form hydrogels (George and Abraham 2006). Thus, this is a feature that contributes to ease precipitation in alginate extraction. The composition (M/G ratio, mineralization), the sequence type and G-block length are critical factors affecting the physical properties of alginate and its resultant hydrogels. Therefore, higher guluronate proportions will yield more rigid alginate hydrogels (Rioux, Turgeon, and Beaulieu 2007). An species and tissue dependence is also stablished, as alginates from $A$. nodosum, $M$. pyrifera and species of the genus Laminaria have higher M-block indexes (yielding weaker gels), while alginates from cortex or older blades from L. hyperborea are accounted for significantly higher G-block composition (Draget 2009).

\subsubsection{Fucoidan}

Fucoidan belongs to the group of fucans and present in brown macroalgae and is characterized by containing L-fucose (fucopyranose) as its main backbone monosaccharide. Generally, fucose content is around $40 \%$ of the total monosaccharides of fucoidan, but in some species it may rise up to $80 \%$ (Table 1) (Bittkau, Neupane, and Alban 2020). The other monosaccharides commonly found in fucoidan include mannose, galactose, glucose, xylose, and glucuronic acid (X. Liu et al. 2020). The structure of fucoidan is usually highly heterogeneous (with numerous branches) and varies according to the algae species. However, it can be broadly differentiated based on their structure between the order Fucales and other brown macroalgae. Analyses carried on representative Fucales like
Sargassum and Fucus species showed that their central chains are composed of consecutive linked $\alpha-(1 \rightarrow 3)$ and $\alpha-(1 \rightarrow 4)$ L-fucose residues. On the other hand, fucoidan from other seaweeds, of which Laminariales are the main representative, have their central chains composed of $\alpha-(1 \rightarrow 3)$ linked L-fucose residues without any $\alpha-(1 \rightarrow 4)$ linkages (Ale, Mikkelsen, and Meyer 2011). The heterogeneity in fucoidan structure, attained by variations in sulfate content, constituent monosaccharides, and $\mathrm{M}_{\mathrm{W}}$, is highly influenced by both the biological source of fucoidan and the applied extraction methods as the latter may also hydrolyze in diverse patterns certain residues (Garcia-Vaquero et al. 2017). A large number of studies found in the bibliography about fucoidan sources and structure has allowed to elucidate that sulfation commonly takes place at $\mathrm{C}_{2}$ of $\alpha-(1 \rightarrow 3)$-linked and $\mathrm{C}_{2}$ or $\mathrm{C}_{4}$ of $\alpha$-(1 $\rightarrow 4)$-linked L-fucose residues (S. H. Wang et al. 2020). Sulfation degree is also heavily altered among species, with sulfate groups substituting L-fucose residues on $\mathrm{C}_{2}$ or $\mathrm{C}_{4}$ and in rare cases on $\mathrm{C}_{3}$ (Shen et al. 2018). For example, fucoidan produced from Fucus species tends to have higher levels of $\alpha-(1 \rightarrow 3)$ and $\alpha-(1 \rightarrow 4)$-linked L-fucose residues, whereas from $A$. nodosum also shows $\alpha-(1 \rightarrow 3)$-linked L-fucose residues with a sulfate group at the position of $\mathrm{C}_{2}$. In addition, fucoidan produced from S. stenophyllum consisted of a backbone composed of $\beta$ - $(1 \rightarrow 6)$-D-galactose and $\beta$-( $1 \rightarrow 2)$-D-mannose residues, which revealed that sulfated galactose could be the other major sugar of fucoidan in some species (Duarte et al. 2001). A model of fucoidan structure with possible alterations is showed in Figure 1.

\subsubsection{Laminarin}

Laminarins are low $\mathrm{M}_{\mathrm{W}}$ storage SP of chain-linked $\beta$-( $1 \rightarrow 3)$-D-glucan, with occurring 6 -O- branching of $D$-glucan in the main chain. Furthermore, some repeated $\beta-(1 \rightarrow 6)$ intra-chain links are also present (Cui et al. 2021). Laminarin is also characterized by being smaller (in average) when compared to other SP, showing a polymerization degree in the range of 20-25 glucose moieties. While it is mostly an homopolymer, two types of laminarin chains can be distinguished, based on the monosaccharide found in their reducing end: $M$ chains and $G$ chains. $M$ chains end with a $\beta$-( $1 \rightarrow 3)-D$ mannitol, whereas $G$ chains end with glucose as the reducing end (Figure 1). In the case of Laminaria and Fucus species, $40-75 \%$ of these reducing end groups are linked to one of the primary hydroxyl groups of D-mannitol (Kadam, Tiwari, and O'Donnell 2015). The structural features of laminarin vary with algal species, for example, its structure can vary according to the $M: G$ chain ratio (in some cases $M$ chains are absent), the polymerization and branching degree and the proportion of $\beta-(1 \rightarrow 3)$ and $\beta-(1 \rightarrow 6)$-glycosidic bonds (Jin et al 2014). For example, laminarin isolated from E. bicyclis is composed of a linear chain of these $\beta-(1 \rightarrow 3)$ but also $\beta-(1 \rightarrow 6)$ linkage in a ratio of $2: 1$ of $\beta-(1 \rightarrow 3)$-D-glucans (Shin et al. 2009). Laminarin is one of the SP with the 

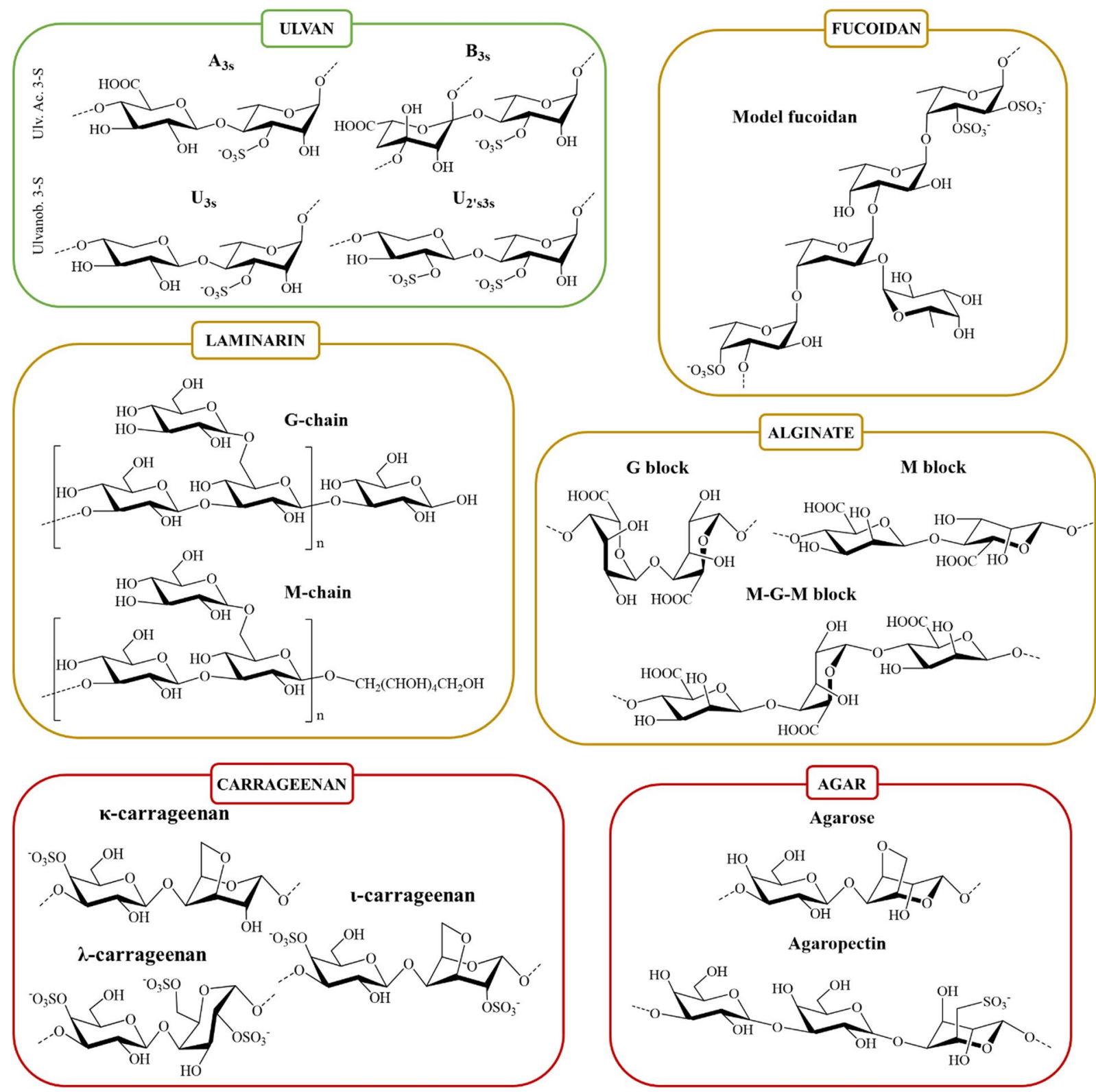

Figure 1. Oligosaccharide subunits conforming ulvans, fucoidan and alginate. Ulv. Ac. 3-S: Ulvanobiuronic acid 3-sulfate; Ulvanob. 3-S: Ulvanobiose 3-sulfate; G-block: $a$-L-guluronate; $M$ : $\beta$-D-mannuronate.

strongest affinity for water due to its abundance in alcohol groups in the glucan monomer, while it does not contain sulfate in its structure. One of its characteristics is its ability to form web-like structures that consequently contribute to its wound-healing properties (Tanna and Mishra 2019). This structure may change as a result of modifications e.g. sulfation, as the introduced anions alter the overall chain charge and result in the appearance of hydrogen bonds that lead laminarin to form helix conformations (Zargarzadeh et al. 2020).

\subsubsection{Agar}

Agar is one of the most valued and exploited SP, as it is accounted for excellent hydrocolloidal properties due to its composition. Agars are linear SP built up of alternating $\beta$-( $1 \rightarrow 3)$-D-galactopyranose and $\alpha$-( $1 \rightarrow 4)$-linked L-galactopyranose residues with intermittent sulfate groups at $\mathrm{C}_{6}$ (Rodríguez et al. 2009). Moreover, $\alpha-(1 \rightarrow 4)$-linked 3,6-D-anhydrogalactopyranose may also appear, which the higher levels of this residue confer enhanced hydrocolloid properties. For this backbone structure composition agar, together with carrageenan, are classified as sulfated galactans. The $\beta$ - $(1 \rightarrow 3)$-linked residue is the $\mathrm{D}$-enantiomer while the $\alpha-(1 \rightarrow 4)$-residue is the L-enantiomer, which can also appear linked next in the chain and constitutes one marked difference with carrageenans ( $\mathrm{Yu}$ et al. 2007). Depending on sulfation degree and pattern, anionic charge of the polymer will be altered, which has led to refer to the more neutral agar SP as agarose and the higher sulfated agaropectin (Armisén and Galatas 2009). Agarose is defined 
by the presence of 3,6-D-anhydrogalactopyranose, which strengthens agarose gel viscosity making it more desirable for gelling applications (Sousa, Rocha, and Gonçalves 2020). Moreover, agaropectin is also characterized for higher presence of acetate and pyruvate substitutions. These differences impact its structure and properties, as agaropectin-rich agar display lower water solubility (Y. Zhang et al. 2019).

\subsubsection{Carrageenan}

With a similar structure to agar, carrageenan is composed of linear $\beta$ - $(1 \rightarrow 3)$ - and $\alpha$ - $(1 \rightarrow 4)$-linked D-galactopyranose disaccharides. However, it presents substitutions in $\mathrm{C}_{4}$ with ester sulfate groups and $\alpha$-( $1 \rightarrow 4)$-linked 3,6-D-anhydrogalactopyranose (Cheong et al. 2018). Sulfation and 3,6-anhydrogalactopyranose proportions and patterns thus define the diverse groups of carrageenan (J. Liu et al. 2015). Six types of structures of carrageenan are known, which are $\mu, \nu, \lambda, \kappa, \iota$ and $\theta$-carrageenan. In general terms, $\mu \& \kappa$-carrageenan share the same $\beta$-(1 $\rightarrow 3)$-galactopyranoside, but the $\alpha$ - $(1 \rightarrow 4)$ galactoside is a sulfated galactopyranoside in $\mu$, while in $\kappa$ this is substituted for a 3,6-D-anhydrogalactopyranose. This same relation, with different alcohol and ester sulfate substitutions, is observed between $v /$ l-carrageenan and $\lambda / \theta$-carrageenan (Jiao et al. 2011). Ester sulfate abundancy ranges between $25 \%$ and $35 \%$ among carrageenan types, with $\kappa$-carrageenan showing the lowest sulfation while $\lambda$-carrageenan exhibits the highest, as it has three ester sulfate groups for each disaccharide monomer ( $\mathrm{Li}$ et al. 2014). This is relevant as the anionic sulfate groups bind to positively charged groups on proteins in food, for example, resulting in the thickening and stabilizing properties of carrageenan (McKim et al. 2019). Nonetheless, technological properties of carrageenan are directly reliant on their structure and proportion of disaccharides. For example, higher abundance of $\kappa$ and $\mathrm{t}$-carrageenans results in better gelling carrageenan due to their conformational changes and lesser sulfation degree (Gomez-Zavaglia et al. 2019). Natural carrageenan appear as hybrid polymers like $\mu / \kappa$-hybrids, $v / \mathrm{t}$-hybrids, $\kappa / \mathrm{t}$-hybrids and so on, being these proportions related to the source species (Jiao et al. 2011). $\kappa, \downarrow$ and $\lambda$-carrageenan are considered as the most relevant carrageenan due to their industrial applications (Cheong et al. 2018) and their structure is presented in Figure 1.

\subsubsection{Floridean starch}

Floridean starch is not a sulfated nor a cell-wall SP, but one of the few amylopectin containing SP with an energy storage role. It is composed entirely of amylopectin and in contrast with vegetal starches, it is a short-chain, highly branched SP more akin to animal glycogen than land plants starch (Martinez-Garcia, Stuart, and van der Maarel 2016). Its polymeric structure consists of $\alpha-(1 \rightarrow 4)$-D-glucoses with $\alpha$ - $(1 \rightarrow 6)$-branching chains, which appear as clusters and abundancy of $\alpha-(1 \rightarrow 6)$ branches is directly correlated with shorter chain length (Shimonaga et al. 2008). Because of this linkage pattern, structure and absence of amylose, floridean starch is regarded as an starch-like molecule with low caloric value while sharing many physico-chemical properties with vegetal starches (Olatunji 2020).

\section{From traditional to emerging extraction technologies of seaweeds' polysaccharides}

Several properties of SP such as film-formation and also biological activities have favored the development of diverse extraction systems to obtain these compounds for their further use in industrial applications (L. P. Gomez et al. 2020). To obtain these compounds in large quantities and high purity may involve different stages, represented in Figure 2. Briefly, the first stage involves the preparation of the macroalgae, which includes process like washing to eliminate salt and impurities, freeze-drying, or grinding to obtain a homogenous powder. Next, the samples could be submitted to a pretreatment to eliminate compounds that may interfere with the SP extraction, such as pigments or lipids (Dobrinčic et al. 2020). Following this stage, the macroalgae are extracted using different techniques (explained below).and afterwards, algae biomass is submitted to further treatments to separate the compounds of interest. In the case of alginates and carrageenans, it is usually employed alkali treatments (Abdul Khalil et al. 2018; Imbs et al. 2016; L. P. Gomez et al. 2020). The next step is to add ethanol to precipitate the SP present in the supernatant and to purify them by dialysis, filtration and chromatographic techniques (Dobrinčić et al. 2020). The composition and amount of SP not only are influenced by raw material (species, season, or place of harvest), but also by factors concerning extraction conditions and techniques (traditional or innovative techniques). Thus, it is necessary to optimize the parameters of the extraction techniques (traditional and innovative techniques) to improve their yields.

\subsection{Traditional techniques}

Traditional techniques like heat-assisted extraction (HAE) and Soxhlet extraction are commonly used in both research and industry. HAE is a solid to liquid extraction technique that typically involves heat and/or agitation to improve the solubility of the compounds of interest in the solvent utilized (Garcia-Vaquero, Rajauria, and Tiwari 2020). Among the consulted bibliography, the extraction of SP from macroalgae is generally performed using hot water as solvent (Bhardwaj et al. 2020), but some studies have employed other solvents (Deghrigue Abid et al. 2019) and also acidic solutions (Menshova et al. 2015; Yaich et al. 2017; Imbs et al. 2016) (Table 2). Extraction temperature varies from room temperature to $\geq 100^{\circ} \mathrm{C}$ and extraction time usually ranges from several hours up to $48 \mathrm{~h}$ (Table 2). On the other hand, Soxhlet extraction is characterized by the continuous flow of solvent through the sample, which enhances the extraction yield in comparison to HAE (Garcia-Vaquero, Rajauria, and 


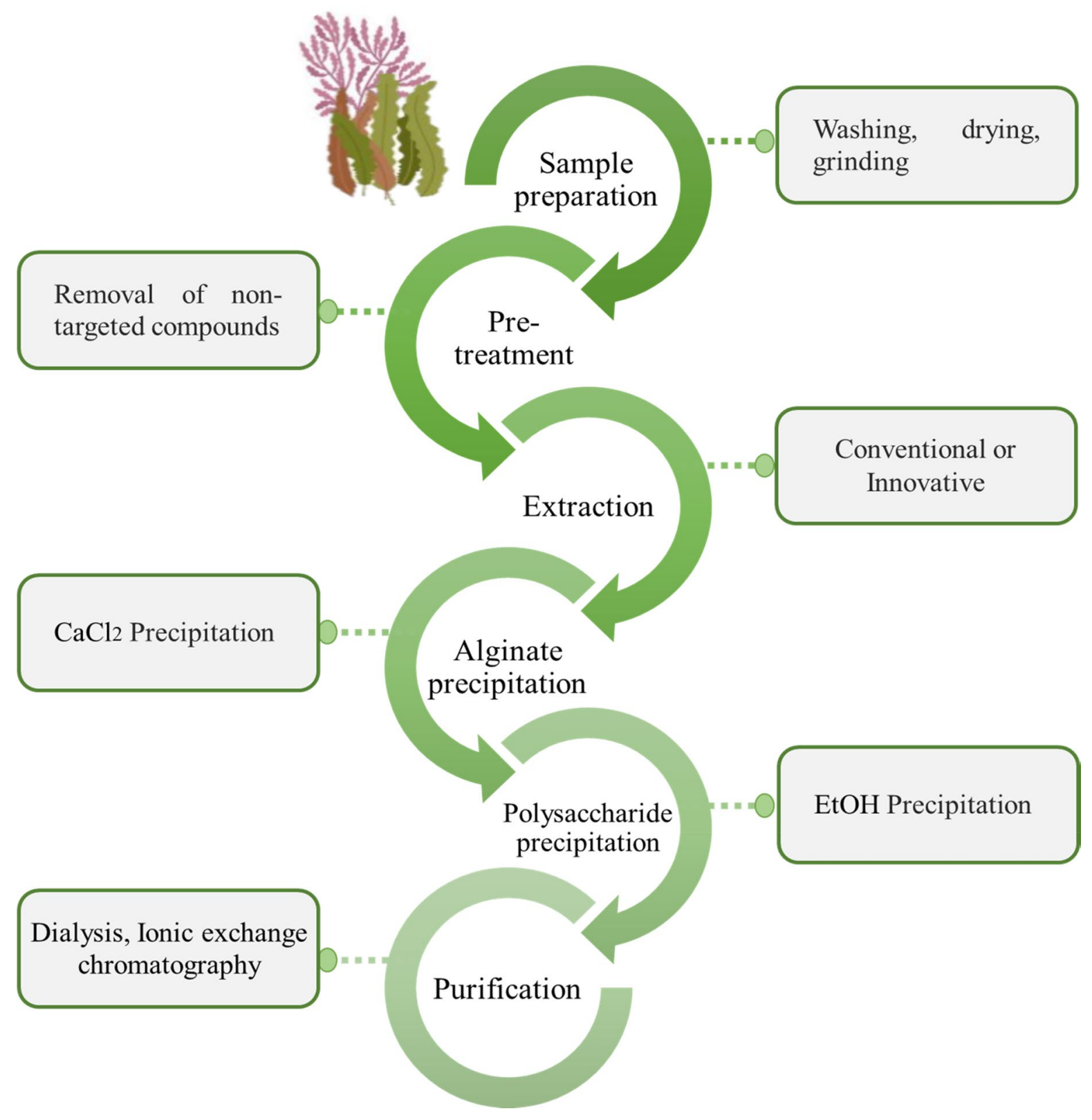

Figure 2. Schematic mechanism of polysaccharide extraction from macroalgae.

Tiwari 2020). However, few studies have shown to employ this system. In fact, it is usually used as a preliminary treatment before the extraction of macroalgae to remove non-targeted compounds present in the samples (Ammar et al. 2015; Bittkau, Neupane, and Alban 2020; Deghrigue Abid et al. 2019). As in the HAE, hot water is the most used solvent. However, in some cases and in order to precipitate alginates, calcium chloride was also added (Ammar et al. 2015; Bittkau, Neupane, and Alban 2020). The continuous flow also significantly reduces the extraction time, which ranged between 2 and $3 \mathrm{~h}$ (Table 2). Nowadays, several drawbacks of traditional techniques have been widely highlighted, such as large amount of solvents (sometimes toxic), long procedure times, high temperatures, degradation of compounds, etc. (L. P. Gomez et al. 2020; Garcia-Vaquero, Rajauria, and Tiwari 2020). To solve these problems and improve the efficiency of the extraction, innovative technologies for the extraction of SP are currently being evaluated.

\subsection{Innovative techniques}

The most currently employed innovative techniques for SP extraction are microwave-assisted extraction (MAE), ultrasound-assisted extraction (UAE), pressurized liquid extraction (PLE) and enzymatic assisted extraction (EAE) and pulse-electric field extraction (PEF). In general terms, these techniques present less drawbacks than conventional ones, but still, may have limitations.

\subsubsection{Microwave-assisted extraction (MAE)}

Currently, this technique is considered one of the most efficient innovative systems. MAE employs microwaves to 
heat the samples, evaporating the intracellular fluids. This causes an increase in pressure and the consequent cell breakage liberation of intracellular compounds into the solvent. Compared to conventional techniques, MAE reduces the amount of solvent needed and improves the efficiency. In addition, it is easy to combine it with other extraction technologies. Nevertheless, the main drawback of this technique is that thermo-labile compounds may be altered or degraded (Dobrinčić et al. 2020; Garcia-Vaquero et al. 2017).

As in the case of HAE, water (Alboofetileh, Rezaei, Tabarsa, Rittà, et al. 2019; Ren et al. 2017) and acidic solutions (Yuan et al. 2018; Okolie et al. 2019; Garcia-Vaquero et al. 2020) are the most employed solvents, but other solvents have been reported (Shang et al. 2021; Cao et al. 2018) (Table 2). Generally, the extraction temperature is around $90^{\circ} \mathrm{C}$, although it may oscillate in the range between 38 and $168^{\circ} \mathrm{C}$, while microwave's potency varies between 500 and $1000 \mathrm{~W}$. Finally, MAE is usually performed during a few minutes, but longer times have been also reported (Table 2).

\subsubsection{Ultrasound-assisted extraction (UAE)}

Another example of innovative techniques for extraction of SP is the UAE, which is based on the application of ultrasound waves above $20 \mathrm{kHz}$ to create bubbles and zones of high and low pressure. The growth and collapse of those bubbles leads to the breakdown of cell walls and particles, favoring the contact between the sample and the solvent. UAE is considered a suitable technique for an industrial scale, due to its simplicity, low-cost equipment and its rapidity. In addition, it operates at low temperatures, which allows the preservation of thermo-labile compounds and is feasible to be combined with other extraction methods, especially with MAE (Ciko et al. 2018; Y. Wang et al. 2021).

Usually, water or acidic solutions are the most employed solvents for UAE (Kadam et al. 2015; S. H. Wang et al. 2021; Youssouf et al. 2017), but other solvents have been investigated. UAE is often carried out at room temperature (RT) (Hmelkov et al. 2018; Kadam et al. 2015; Okolie et al. 2019), although temperatures between $50-90^{\circ} \mathrm{C}$ have been also used (Rahimi, Tabarsa, and Rezaei 2016; Youssouf et al. 2017). Among bibliography, extraction frequency employed is generally $20 \mathrm{kHz}$, (Okolie et al. 2019; Alboofetileh, Rezaei, Tabarsa, Rittà, et al. 2019) but higher frequencies have been selected (Rahimi, Tabarsa, and Rezaei 2016; Hmelkov et al. 2018) Regarding extraction time, this technique also employs short times, generally less than $1 \mathrm{~h}$ (Table 2 ).

\subsubsection{Pressurized liquid extraction (PLE)}

Pressurized liquid extraction (PLE) is also known as accelerated solvent extraction or subcritical water extraction, when water is used as solvent (Jacobsen et al. 2019). This technique is based on the use of water or other solvents at high temperatures and pressures, maintaining the solvent in the liquid state. The operation conditions usually vary between $50-200^{\circ} \mathrm{C}$ for temperature and $35-200$ bar for pressure (Otero et al. 2020; Navarro del Hierro et al. 2020; Ciko et al. 2018; Abdul Khalil et al. 2018). Some advantages of PLE include the use of less amount of solvent, short times or high efficiency (Saravana et al. 2016). However, the use of high temperatures may lead to undesired reactions or degradation of compounds and its application at industrial scale is still limited, since it requires expensive equipment and high amount of energy (Jacobsen et al. 2019).

Considering the compiled studies, water is the most used solvent in PLE for the recovery of SP, both alone or in combination with co-solvents, such as acids, deep eutectic solvents or ionic liquids, in variable concentration (Gereniu, Saravana, and Chun 2018; Saravana et al. 2016; Alboofetileh, Rezaei, Tabarsa, Rittà, et al. 2019) (Table 2). For temperature and pressure, operating conditions ranged between $60-180^{\circ} \mathrm{C}$ and $20-103$ bar, respectively. Regarding time, the extraction was performed between 5-25 min (Table 2).

\subsubsection{Enzymatic assisted-extraction (EAE)}

This technique consists in the use of digestive enzymes to degrade the complex cell wall of seaweeds and release the cytoplasmic content, improving the extraction rate. Some of the enzymes employed for SP extraction include proteases, such as Alcalase or Flavourzyme, or carbohydrases like Viscozyme or Celluclast (Dobrinčić et al. 2020) (Table 2). In EAE, temperature, $\mathrm{pH}$ and solvent (water or buffer) and ratio enzymes/sample are important factors that affect its efficiency and should be carefully considered for an optimized extraction (Abdul Khalil et al. 2018). Due to the nature of enzymes, this technique is considered highly specific, eco-friendly, and nontoxic. However, its industrial application is limited due to the high price of some type of enzymes (Dobrinčić et al. 2020; Garcia-Vaquero et al. 2017).

\subsubsection{Pulse-electric field (PEF)}

This extraction method is based on the application of intense electric pulses to disrupt the linkages between cell wall SP molecules and thus creating pores in its structure. Main parameters are the distance between electrodes and intensity. It is considered a green extraction method since no polluting solvents are generally required (Polikovsky et al. 2016). There are very few reports on the use of PEF for SP extraction. Foremost, PEF extraction on seaweeds has been focused on minerals, polyphenols and protein recovery (Robin et al. 2018). Nonetheless, a very recent study assesses the extraction of starch from U. ohnoi by PEF and revealed that it could be a feasible extraction procedure for this type of SP, among other components (M. S. Prabhu et al. 2019).

\subsection{Comparison of extraction techniques}

Due to the great variety of matrices in the literature with different experimental conditions (solvents, time, instrumental parameters, etc.), and the variety of target SP, as reflected in (Table 2), the comparison among extraction techniques has resulted in a difficult task. The comparison was focused in evaluating the most efficient techniques in terms of 


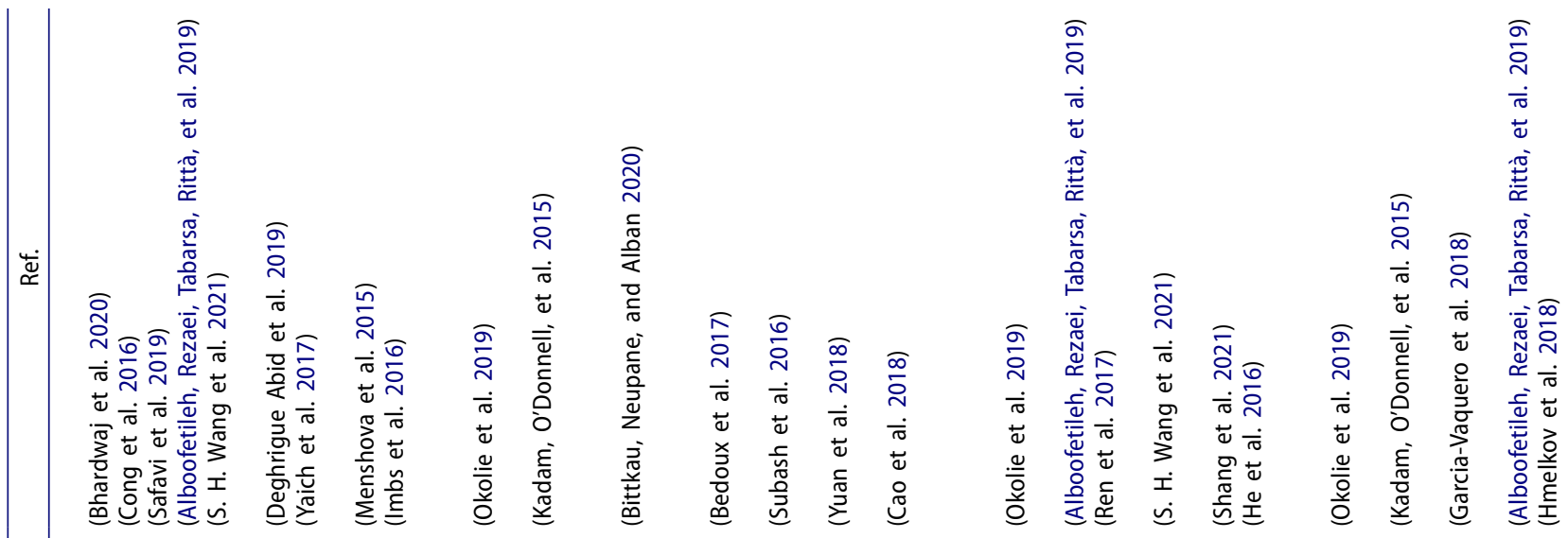

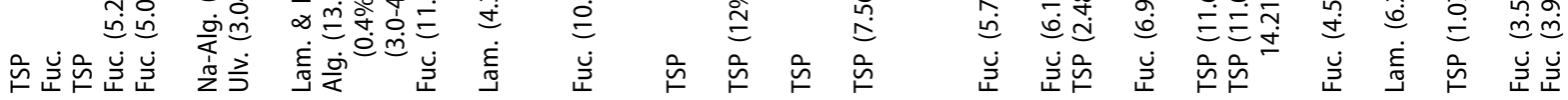

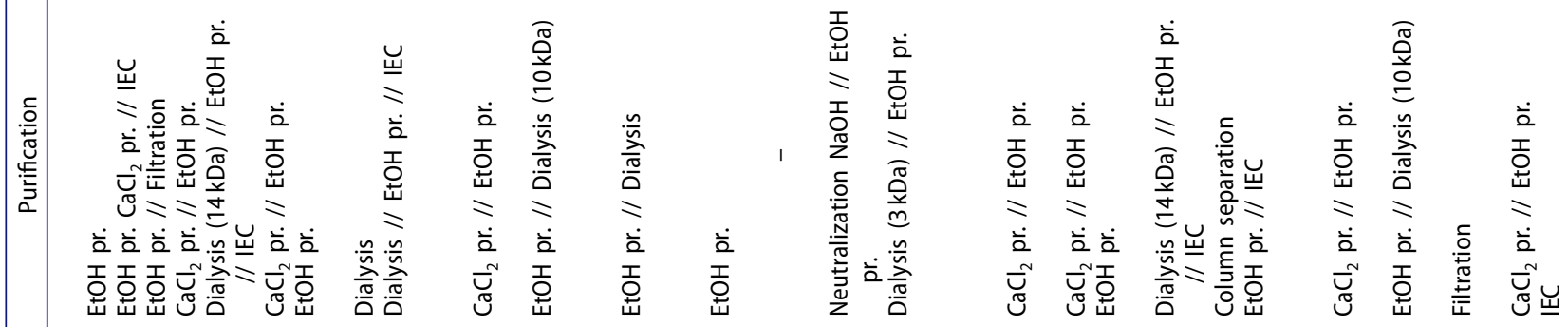

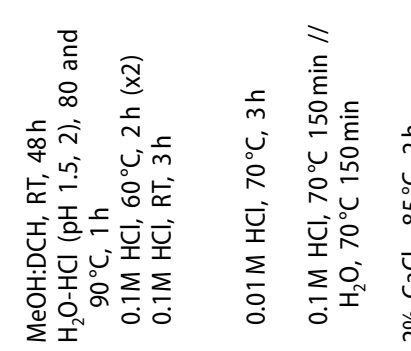

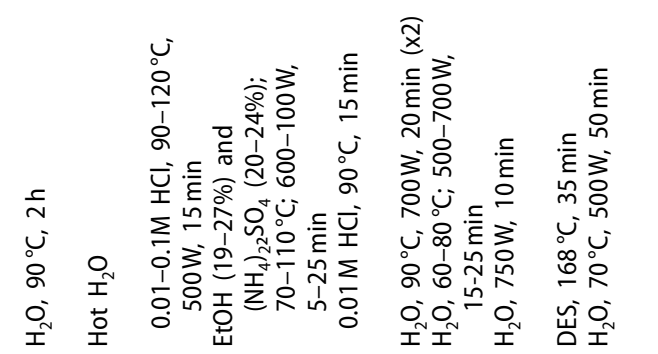

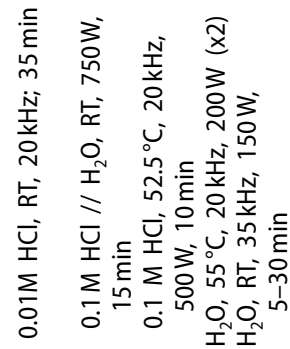

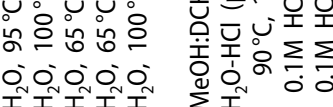

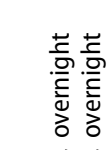

梂

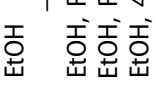

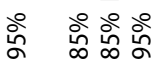
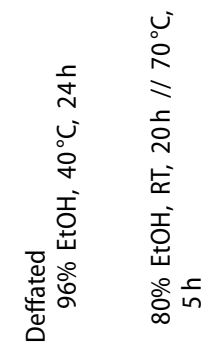

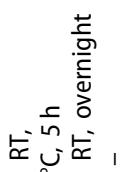
돈유온 ㅇํㅇㄷํ ๖े<smiles>[CH]1[CH]C1</smiles>

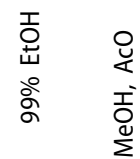

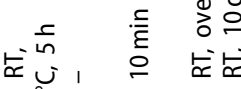

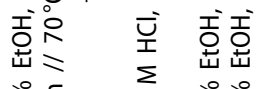

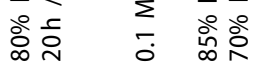
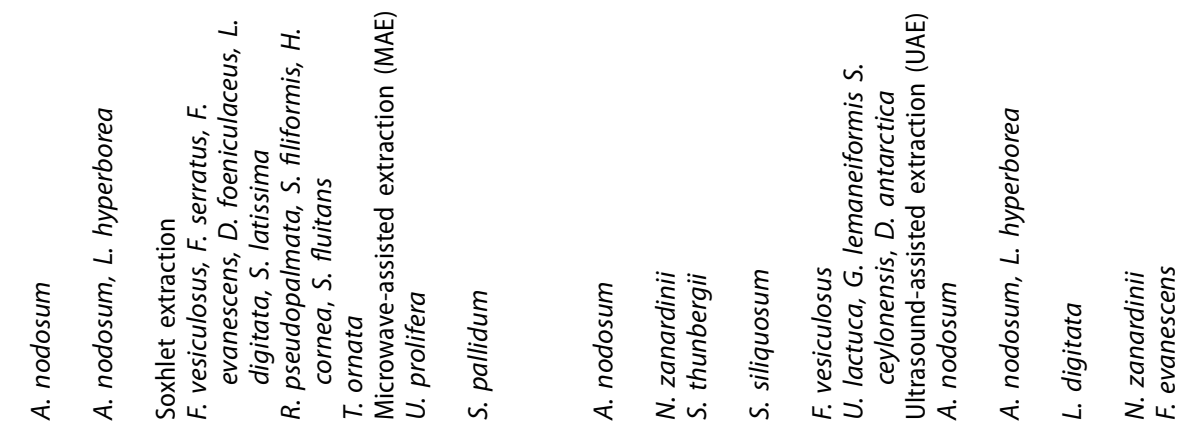

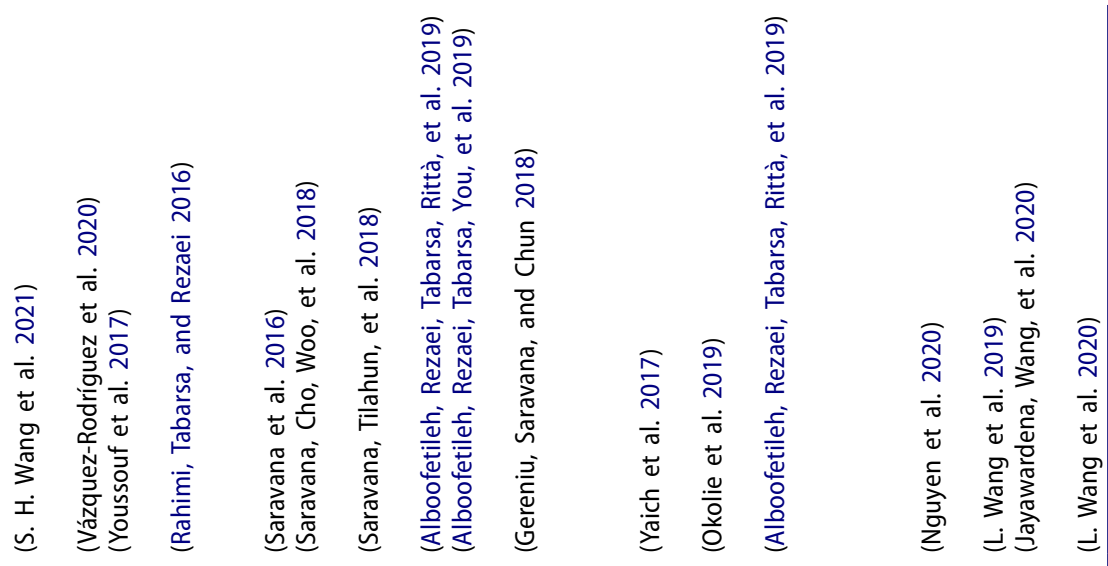

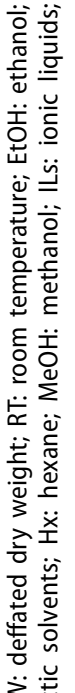

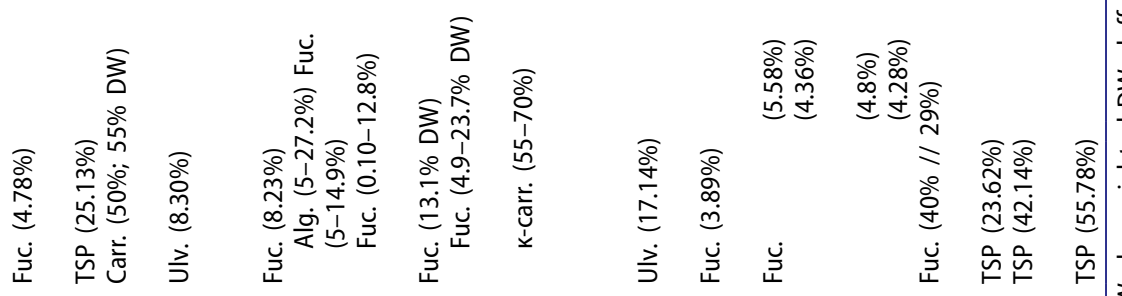

ᄒ

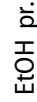

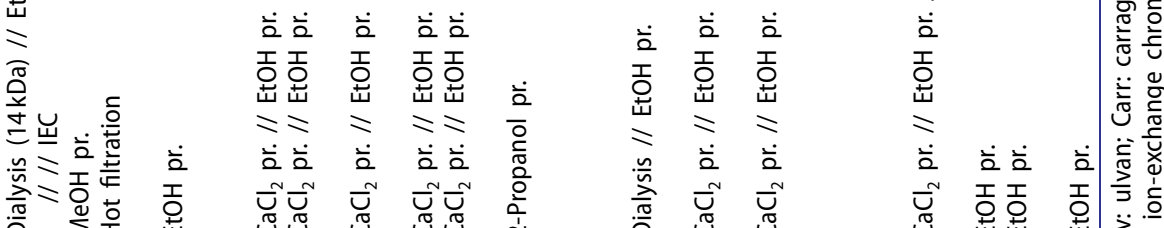

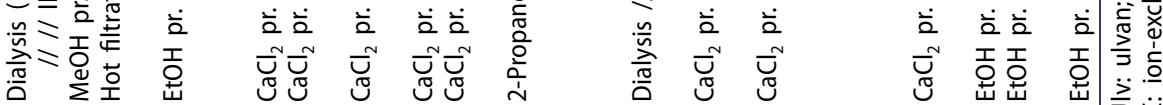

3. 要离

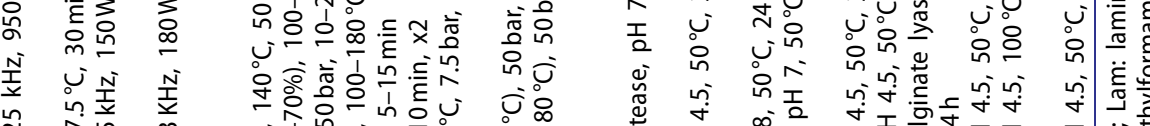

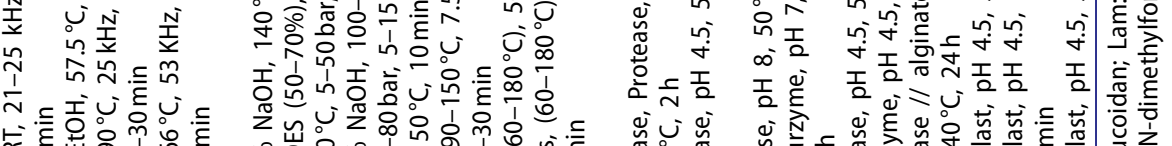

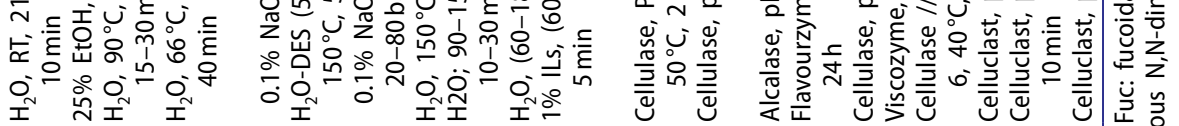

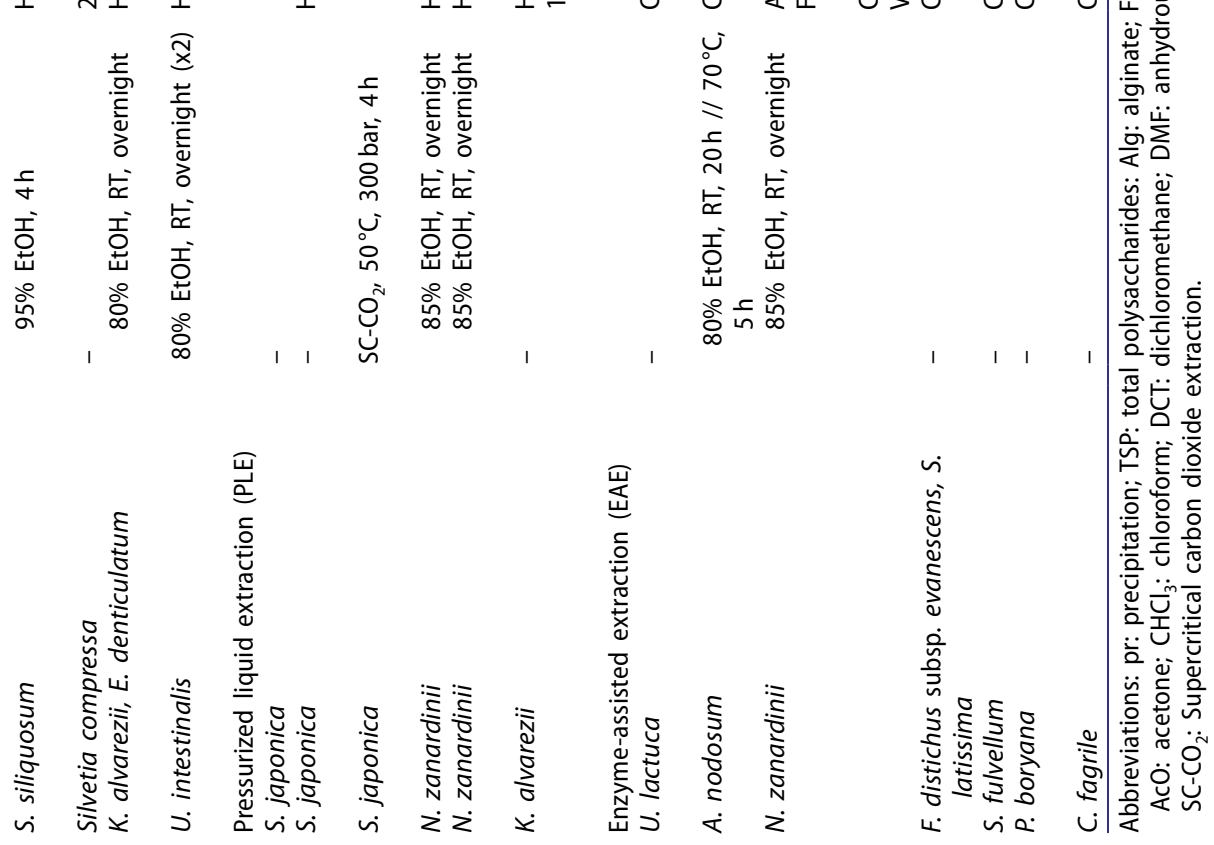


recovery rates. Thus, studies using the same species and targets, but different extraction methods were selected. For example, Alboofetileh et al. employed conventional and different innovative extractions, using water as solvent, to obtain fucoidans from $N$. zanardinii. Conventional extraction showed an extraction yield of $5.2 \%$ DW. MAE and PLE achieved higher rates, 6.17 and $13.15 \%$, respectively, while UAE was the less efficient technique, with a $3.51 \%$ of recovery. The results of EAE ranged between 5.5 to $4.2 \%$, depending on the employed enzyme (Alboofetileh, Rezaei, Tabarsa, Rittà, et al. 2019). A study assessed ulvan extraction from U. lactuca using HAE in an acidic solution ( $\mathrm{pH} 1.5-2)$ and EAE. Results showed that EAE significantly increased the extraction efficiency, compared to HAE. Specifically, traditional extraction yields ranged between 3.04 and $13.06 \%$ (80 and $90^{\circ} \mathrm{C}$, respectively), while EAE achieved a $17.15 \%$ of ulvan recovery (Yaich et al. 2017). In another study, the authors evaluated two different solvents (water and $0.1 \%$ $\mathrm{HCl}$ solution) and two different extraction techniques (HAE and UAE) for the extraction of laminarin from A. nodosum and $L$. hyperborea. In this case, UAE enhanced the efficiency of the extraction with both solvents in two seaweeds (5.28$6.24 \%$ ), compared to traditional HAE (3.25-4.6\%). Regarding solvents, water achieved better results when using HAE, while $0.1 \% \mathrm{HCl}$ was more efficient when using UAE (Kadam et al. 2015). Recently, a study compared HAE, MAE, UAE and EAE fucoidan extraction recovery from $A$. nodosum. Unlike other works, none of the innovative techniques was able to match the extraction' yield of HAE, showing the following results: $11.9,5.71,4.56$ and $3.89 \%$, respectively (Okolie et al. 2019).

Considering reported results, innovative techniques are usually efficient alternatives to traditional extraction, achieving suitable recovery rates. However, it can also be observed that it is necessary to optimize these methods and operating conditions (solvent, temperature, time, etc.) for the selected matrix to obtain the maximum extraction efficiency.

\section{Structural characterization of polysaccharides from seaweeds}

As mentioned, SP are structurally complex, with predominant monomers like galactose, rhamnose, xylose, fucose, uronic acid, etc. Thus, the structure elucidation of SP requires specialized methods to clearly analyze their composition. In fact, it seems that it is recommendable a mixture of several techniques. For example, to elucidate a water-soluble heteropolysaccharide from the algae E. prolifera, it was necessary to use up to four techniques, Fourier transform infrared spectroscopy (FTIR), high performance liquid chromatography (HPLC), multi-angle laser light scattering (MALLS), and nuclear magnetic resonance (NMR) spectroscopy (Lin et al. 2020). In general, to obtain the complete sequence of the molecule, the SP is usually degraded into oligosaccharide repeating units in a controlled manner, involving depolymerization into smaller oligosaccharides by either partial acid or enzymatic hydrolysis. Thus, the resulting oligosaccharides mixture is fractionated, and each oligosaccharide fully characterized (Amicucci et al. 2019). Table 3 collects the most used techniques for the elucidation and identification of oligosaccharides from algae. In this sense, NMR spectroscopy is one of the most used techniques to clarify the composition and structure of noncomplex SP. It helps to elucidate the monosaccharide composition and their sequence, the presence of $\alpha$ - or $\beta$-type carbohydrates and linkage features (Cheong et al. 2018). For one dimensional NMR (1H-NMR and 13 C-NMR) spectrum, a signal in the region of $5.1-5.7 \mathrm{ppm}$ is associated to the a-configuration, whereas the $\beta$-configuration occurs in the range of $4.5-4.8 \mathrm{ppm}$ in $1 \mathrm{H}-\mathrm{NMR}$ spectrum. However, SP of high $\mathrm{M}_{\mathrm{W}}$ are not proper characterized using this technique. For example, to clearly distinguish the signal of fucoidans from $\mathrm{M}_{\mathrm{W}}$ upper $20,000 \mathrm{Da}$, they have to be cleaved to be fully identified (Holtkamp et al. 2009). In this sense, gas chromatography coupled to mass spectrometry (GC-MS) is also a powerful method for structurally analyzing SP after a complete acid hydrolysis and derivatization process, due to the presence of multiple nonpolar groups with low volatility. In this process, the active hydrogen from hydroxyl groups is replaced by more nonpolar groups. The hydrolysis to release the neutral sugars is generally with trifluoroacetic acid at high temperature (for example $100^{\circ} \mathrm{C}$ for $3 \mathrm{~h}$ or $120^{\circ} \mathrm{C}$ for $90 \mathrm{~min}$ ) and after that, a reduction with $\mathrm{NaBH}_{4}$ is performed (Hentati et al. 2018). GC-MS columns are usually composed of a polysiloxane phase with lengths ranging from $30-60 \mathrm{~m}, 0.2-0.4 \mathrm{~mm}$ diameter and $0.1-0.5 \mu \mathrm{m}$ pore size (Table 3) (P. Li et al. 2018; Cheng et al. 2011; Rioux, Turgeon, and Beaulieu 2010; X. T. Xie et al. 2020; Hentati et al. 2018). For identification of different monomers, temperature gradient ranges from $60^{\circ} \mathrm{C}$ to $280^{\circ} \mathrm{C}$. It is convenient to highlight that one drawback of GC-MS is the difficulty to analyze a variety of monosaccharides due to the low sensitivity. In addition, it requires a derivatization process, extending the analysis times (Amicucci et al. 2019).

Other attempts to analyze the structure of SP comprise HPLC. There are several modes of HPLC operation for the characterization of oligosaccharides, such as ionic exchange chromatography (IEC). Given the anionic nature of SP, IEC is one of the most useful and efficient methods for separation and characterization of these $\mathrm{P}$ (Mak et al. 2013; Khajouei et al. 2018; Glasson et al. 2017; Spicer et al. 2017). Regarding detection, the refractive index is one of the most common detectors and it does not require prior derivatization of carbohydrates. Ultraviolet and fluorometric detectors are also widely used, but in these cases a prior derivatization is necessary due to the absence of chromophore or fluorophore groups in these molecules (Saravana, Cho, Patil, et al. 2018). In addition, mass spectrometry (MS) is the most powerful detection method to identify the oligosaccharide structure. The MS chromatograms provide value information concerning the molecular mass, fragmentation mode, chain length distribution and the composition of the monosaccharide units (Cheong et al. 2018). The recent development of matrix assisted lases desorption/ionization (MALDI) combined with the time of flight (TOF) separation system has resulted in the method of choice for structural characterization of oligosaccharides by many researcher groups, 
Table 3. Analytical methodology employed for the identification of algae polysaccharides.

\begin{tabular}{|c|c|c|c|c|c|}
\hline Species & SP & Composition & Column $(*)$ & $\mathrm{T}$ or $\mathrm{E}$ gradient & Ref. \\
\hline \multicolumn{6}{|c|}{ Gas chromatography-mass detection (GC-MS) } \\
\hline U. flacca & Ulvan & $\begin{array}{l}\alpha-(4 \rightarrow 1)-L-R h a \text { and } \\
\text { 4-linked- } \beta \text {-D-glucuronic } \\
\text { acid residues }\end{array}$ & $\begin{array}{l}\text { DB } 225 \text { (CPP) }\left(3010^{2} \times\right. \\
0.25)\end{array}$ & $\begin{array}{l}100-220^{\circ} \mathrm{C}\left(5^{\circ} \mathrm{C} / \mathrm{min}\right) / / \\
220^{\circ} \mathrm{C} 15 \mathrm{~min} .\end{array}$ & (P. Li et al. 2018) \\
\hline C. compressa & n.s. & $\begin{array}{l}\text { Trimethyl silylated } \\
\text { monosaccharides: CF, } \\
\text { sodium alginate } \\
\text { composed of } a-(1 \rightarrow 3) \text {, } \\
\text { a- }(1 \rightarrow 4) \text {-linked L-FucSPas } \\
\text { main backbone }\end{array}$ & $\begin{array}{l}\text { OPTIMA-1 MS (PDMS) } \\
\quad\left(30 \cdot 10^{3} \times 0.32,0.25\right)\end{array}$ & $\begin{array}{l}100^{\circ} \mathrm{C}\left(8^{\circ} \mathrm{C} / \mathrm{min}\right), 3 \mathrm{~min} / / \\
200^{\circ} \mathrm{C}\left(8^{\circ} \mathrm{C} / \mathrm{min}\right), 1 \mathrm{~min} / / \\
215^{\circ} \mathrm{C}\left(5^{\circ} \mathrm{C} / \mathrm{min}\right), 19 \mathrm{~min} .\end{array}$ & (Hentati et al. 2018) \\
\hline S. longicruris. & GI-F, laminarin & $\begin{array}{l}\text { D-xylose, D-mannose, } \\
\text { D-glucose, D-galacturonic } \\
\text { acid // D-glucuronic acid, } \\
\text { D-galactose, D-glucose } \\
\text { and D-uronic acid }\end{array}$ & $\begin{array}{r}\text { CP-Sil-5CB (PDMS) } \\
\left(60 \cdot 10^{3} \times 0.25\right)\end{array}$ & $\begin{array}{c}50^{\circ} \mathrm{C}, 1 \mathrm{~min} / / 120^{\circ} \mathrm{C}\left(20^{\circ} \mathrm{C} /\right. \\
\min ) / / 240^{\circ} \mathrm{C}\left(2{ }^{\circ} \mathrm{C} / \mathrm{min}\right) .\end{array}$ & $\begin{array}{l}\text { (Rioux, Turgeon, and } \\
\text { Beaulieu 2010) }\end{array}$ \\
\hline $\begin{array}{l}\text { P. haitanensis, } E \text {. } \\
\text { galetinae, G. } \\
\text { amansii, G. chouae, } \\
\text { G. blodgettii, G } \\
\text { lemaneiformis }\end{array}$ & n.s. & Monosaccharide, AnGal & $\begin{array}{l}\text { Rtx-5MS (dPDMS) }(30 \\
\left.10^{2} \times 0.25,0.1\right)\end{array}$ & $\begin{array}{c}60^{\circ} \mathrm{C}, 2 \mathrm{~min} / / 120^{\circ} \mathrm{C}\left(30^{\circ} \mathrm{C} /\right. \\
\min ), 1 \mathrm{~min} / / 250^{\circ} \mathrm{C} \\
\left(25^{\circ} \mathrm{C} / \mathrm{min}\right), 30 \mathrm{~min}\end{array}$ & (X. T. Xie et al. 2020) \\
\hline \multicolumn{6}{|c|}{ High performance anion exchange chromatography (HPAEC) } \\
\hline N. zanardini & Alginate & $\begin{array}{l}\text { L-guluronic and } \\
\text { D-mannuronic acids in } \\
\text { sodium alginate }\end{array}$ & $\begin{array}{l}\text { CarboPac PA-1 }(4 \times 50) \\
\text { and CarboPac PA-1 } \\
(4 \times 250)\end{array}$ & $\begin{array}{l}\text { A: } 100 \mathrm{mM} \mathrm{NaOH} / / \mathrm{B}: 1 \mathrm{M} \\
\mathrm{NaOAC}, 100 \mathrm{mM} \mathrm{NaOH} \text {. } \\
\text { Linear gradient } 0-100 \% \\
\text { of } \mathrm{B} \text { in } \mathrm{A}(60 \mathrm{~min})\end{array}$ & (Khajouei et al. 2018) \\
\hline $\begin{array}{l}\text { C. racemosa var } \\
\text { peltata }\end{array}$ & $\begin{array}{l}\text { Novel } \\
\text { water-soluble } \\
\text { SP }\end{array}$ & $\begin{array}{l}\text { Mannose, galactose, glucose, } \\
\text { galacturonic acid and } \\
\text { glucuronic acid }\end{array}$ & $\begin{array}{c}\text { CarboPac }{ }^{\mathrm{TM}} \text { PA20 } \\
(150 \times 3,6.5)\end{array}$ & n.s. & (Hao et al. 2019) \\
\hline U. ohnoi. & Ulvan & $\begin{array}{l}\text { Rhamnose, glucuronic acid, } \\
\text { iduronic acid and xylose }\end{array}$ & $\begin{array}{l}\text { CarboPac PA-1 }(4 \times 250) \\
\text { equilibrated in } \\
30 \mathrm{mM} \mathrm{NaOH} .\end{array}$ & $\begin{array}{l}\text { A: } \mathrm{NaOH}(30-10 \mathrm{mM}, \\
0-25 \mathrm{~min}) / / \mathrm{B}:(10- \\
100 \mathrm{mM}, 25-30 \mathrm{~min}) \\
50 \mathrm{~min} / / \mathrm{C}: \mathrm{NaCH}_{3} \mathrm{COO} \\
\text { 0-500 mM, 30-50 min. }\end{array}$ & (Glasson et al. 2017) \\
\hline $\begin{array}{l}\text { F. serratus, } F \text {. } \\
\text { vesiculosus, } F \text {. } \\
\text { spiralis, } P . \\
\text { canaliculata, } L . \\
\text { hyperborea, } A . \\
\text { nodosum } \\
\text { HPLC-MALDI-TOFMS }\end{array}$ & Laminarin & $\begin{array}{l}\text { Linear } \beta-(1 \rightarrow 3) \text { glucans with } \\
\text { intrachain } \beta-(1 \rightarrow 6) \\
\text { branching in laminarin } \\
\text { oligomers }\end{array}$ & $\begin{array}{l}\text { CarboPac PA-100 } \\
\qquad(250 \times 4) \text { and PA-100 } \\
\text { guard }(50 \times 4)\end{array}$ & $\begin{array}{l}A: \text { W // B: } 100 \mathrm{mM} \mathrm{NaOH} \mathrm{//}^{\mathrm{C}: 1.0 \mathrm{M} \mathrm{NaCH}_{3} \mathrm{COO}} \\
100 \mathrm{mM} \mathrm{NaOH}\end{array}$ & (Spicer et al. 2017) \\
\hline F. evanescens & Fucoidan & $\begin{array}{l}\text { ß- }(1 \rightarrow 3) \text {-linked } \\
2-O \text {-sulfonated fucose } \\
\text { residues ( } 1 \text { to } 4 \\
\text { monomers }), 2-O \text { - and } \\
4-O \text { - a- }(1 \rightarrow 4) \text { sulfonated } \\
\text { xylose and galactose } \\
\text { residues. }\end{array}$ & Silasorb C18 $(24 \times 250)$ & W: Isocratic gradient & (Anastyuk et al. 2009) \\
\hline
\end{tabular}

Abbreviations: SP: Polysaccharide; T: temperature; E: elution; n.s. not specified; CPP: cyanopropylmethyl phenylmethyl polysiloxane; GI-F: Galactofucan; PDMS: dimethyl polysiloxane; dPDMS:diphenyl dimethyl polysiloxane.

*Column order: Name $-C$ atoms (phase) ( $L$ in $\mathrm{mm} \times I D$ in $\mathrm{mm}$, particle size in $\mu \mathrm{m}$ ).

including sequencing, branching and linkage and profiling of oligosaccharides (Anastyuk et al. 2009). Advantages of MALDI over other ionization methods include its wide mass range, high sensitivity (fmol-pmol) and mass measurement accuracy. In addition, sample preparation and experiment are relatively easy to operate, and the technique is also tolerant of buffers, salts, and detergents.

\section{Modification methods of polysaccharides from seaweeds: main challenges}

Molecular modification of SP is a method commonly used to change the structure, $\mathrm{M}_{\mathrm{W}}$, and types, number, and positions of the substituent's groups of SP, with impacts on bioactivities. It can be carried out by enzymes or chemical reagents. In the enzymatic modification, the degradation of
SP occurs by catalysis with enzymes which is a highly efficient and environmentally friendly process. However, the use of this kind of modification is nowadays limited to the degradation of only certain type of SP. Perhaps the study of specific enzymes like transferase and synthase will boost the application of the enzyme technology ( $\mathrm{Li}$ et al. 2016). So far, chemical modification is the most widely used method or algae SP to bring new biological activities by changing functional groups. Despite modifying the biological activities, it can also result in SP degradation, change $M_{W}$ and improve solubility (L. Xie et al. 2020; Qiu et al. 2014; Duan et al. 2019; Safavi et al. 2019; Li et al. 2016). The main chemical modifications of SP include sulfation, carboxymethylation, phosphorylation and selenylation. The major activities and applications of these modifications are collected in Table 3. 


\subsection{Sulfation}

In regard of SP, sulfation is a reaction in which a pure SP is mixed with a sulfated reactant that allows that these sulfate groups link side hydroxyl groups of the SP chain together. The degree of sulfate groups bonding to hydroxyl groups on $\mathrm{SP}$ is monitored by adjusting the molar ratio of reactants (L. Xie et al. 2020). The sulfation modification of algae SP is mainly based on chlorosulfonic acid pyridine methods in which sulfation is carried out by dissolving the pure SP in $\mathrm{N}, \mathrm{N}$-dimethylacetamide prior adding the sulfation reagent (a mixture of chlorosulfonic acid: pyridine), in different proportions, 1:4, 1:5, 1:6, 1:7 and 1:8 (v/v) (Zhao et al. 2019; Xiao et al. 2019). Afterwards, the mixture is heated at $60-70^{\circ} \mathrm{C}$ for $2-3 \mathrm{~h}$. After sulfation, the mixture is neutralized to $\mathrm{pH}$ 7 with a solution of sodium hydroxide, for example $\mathrm{NaOH}$ $20 \%$ and then, precipitated by adding ethanol before dialyzed against distilled water for 2-3 days. Using this protocol, Jim and coworkers performed the sulfation of SP from S. thunbergii, S. japonica and E. prolifera (Jin et al. 2020). Parallel, Xiao and coworkers sulfated eight SP from S. pallidum and observed that all SFP exhibited higher hypoglycemic activity than native SP and also four of them displayed the best antioxidant effect (Xiao et al. 2019). In this case, the substitution degree of algae SFP was in a range of 0.85-1.19. Some algae SFP have shown dramatically more significant antioxidant and antitumor activities following several methods like the superoxide radical, hydroxyl radical and 3-(4,5-dimethylthiazol-2-yl)-2,5-diphenyl tetrazolium bromide (MTT) assays (Shao, Chen, and Sun 2014).

\subsection{Carboxymethylation}

The carboxymethylation modification consists in the incorporation of carboxymethyl groups into the SP chain. It is performed in two steps. First, the hydroxyl groups of SP react with sodium hydroxide to form the alkoxide groups and then, these groups react with monochloroacetic acid to generate the carboxymethyl groups by a $\mathrm{SN}_{2}$ reaction (Chakka and Zhou 2020). For example, Barros and colleagues performed carboxymethylation of ulvan from $U$. lactuca by dissolving the amount of $10 \mathrm{~g}$ of pure ulvan in $0.1 \mathrm{~L}$ of isopropanol before adding $0.05 \mathrm{~L}$ of sodium hydroxide $(40 \%, \mathrm{w} / \mathrm{w})$ at a constant flow. After that, the mixture was heating to $60^{\circ} \mathrm{C}$ for $3 \mathrm{~h}$ (under nitrogen atmosphere) after the addition of $12 \mathrm{~g}$ of monochloroacetic acid (Barros et al. 2013). Afterwards, the $\mathrm{pH}$ was neutralized to 7 with glacial acetic acid after the addition of $8.5 \mathrm{~mL}$ of cold distilled water. Finally, the resultant SP was filtered, washed with methanol: water (70:30) and anhydrous methanol before dried. Using the same scheme, Duan and coworkers were carried out the carboxymethylation of fucoidan from L. japonica (Duan et al. 2019). Authors observed that carboxymethylation enhanced the antioxidant activity of fucoidan, so that it could be used as a natural preservative.

\subsection{Phosphorylation}

The phosphorylation modification is an esterification process in which the hydroxyl groups of the branched chain are substituted by a phosphate group yielding a phosphorylated derivative (Chen et al. 2016). Common reagents for this modification are phosphoric acid, phosphoric anhydride, phosphorus trichloride and phosphates (disodium hydrogen phosphate, sodium dihydrogen phosphate, sodium tripolyphosphate, sodium trimetaphosphate, phosphorus oxychloride, sodium trimetaphosphate and polyphosphate) (Huang and Huang 2020). One of the most used phosphorylation methods in algae is the polyphosphoric acid-tributylamine-dimethyl formamide method. For example, Wang and colleagues were carried out the phosphorylation of low-molecular-weight SP from E. linza by dissolving $2 \mathrm{~g}$ of ulvan in $100 \mathrm{~mL}$ formamide and $15 \mathrm{~mL}$ tributylamine and then, it was added $6 \mathrm{~g}$ polyphosphoric acid (Z. Zhang et al. 2014). The mixture is usually stirred and then poured into ethanol. Precipitate is dissolved in water, dialyzed against distilled water and lyophilized to give phosphorylated SP. After this process, the physicochemical and biological properties of SP are altered, enhancing hydrocolloid properties.

\subsection{Selenylation}

Selenylation modification consists of the introduction of selenium into the polymeric chain of the SP. Since the insufficiency of natural seleno-polysaccharides, it is an effective measure to develop new selenium source and also, make the physiological and pharmacological function of selenium (Q. Wang et al. 2019). Selenylation highly improved the properties (antioxidant, anti-cancer, anti-diabetic, and immunomodulatory activities) respect to the native SP. Among SP-selenylation modification methods, nitric acid-sodium selenite $\left(\mathrm{HNO}_{3}-\mathrm{Na}_{2} \mathrm{SeO}_{3}\right)$ method is frequently used due to the simple reaction conditions, fast production and high selenium content of modifier (Qiu et al. 2014). As an example of this reaction, Ji and colleagues carried out the optimization of the synthesis of Seleno-SP in S. fusiforme by dissolving $1 \mathrm{~g}$ of $\mathrm{Na}_{2} \mathrm{SeO}_{3}$ and $1 \mathrm{~g}$ of SP in $100 \mathrm{~mL} \mathrm{HNO}_{3}$ (0.05\%) (Ji et al. 2013). They fixed the optimum reaction time and temperature in $8 \mathrm{~h}$ and $71^{\circ} \mathrm{C}$, respectively. After the selenylation reaction, it was added $\mathrm{Na}_{2} \mathrm{CO}_{3}$ to adjust $\mathrm{pH}$ to 5-6. In addition, it was shown that to include in the algae growth medium selenium in the form of sodium selenite $\left(\mathrm{Na}_{2} \mathrm{SeO}_{3}\right)$ at levels of $500 \mathrm{mg} / \mathrm{L}$ is a proper approach to incorporate the selenium molecule into their the structure and increase the antioxidant activities of algae SP (Sun et al. 2017).

\section{Biological properties of polysaccharides from seaweeds}

\subsection{Anticoagulant}

According to the World Health Organization (WHO), cardiovascular diseases are the first cause of human death worldwide. The formation of thrombosis is a major problem that, if not detected on time, it can result in serious hazards and ultimately, death (Owens and Mackman 2010). Currently, heparin is the main commercial antithrombotic agent. Nonetheless, it can cause several side effects, such as the development of thrombocytopenia, hemorrhagic effect, 
ineffectiveness in congenital or acquired antithrombin deficiencies and incapacity to inhibit thrombin bound to fibrin. In addition, the use of heparin may increase the risk of pollution by animal pathogens, since it is obtained from pig intestine and bovine lungs (Paluck, Nguyen, and Maynard 2016). For this reason, many researchers are interested in finding new alternative sources to obtain substitute agents with anticoagulant features. In this sense, SFP from marine algae with anticoagulant and antithrombotic activities are being investigated (Table 4).

The anticoagulant activity can be determined by partial thromboplastin time (APTT), thrombin time (TT) and prothrombin time (PT). PT is associated with extrinsic via, whereas the prolongation of APTT suggests inhibition of the intrinsic pathways of coagulant, and an increase in TT indicates the thrombin inhibition (Qin et al. 2020). For instance, arabinogalactan $(\mathrm{AB})$ obtained from $C$. linum presented high anticoagulant activity in vivo (APTT $=200 \mathrm{~s}$ and $\mathrm{TT}=60 \mathrm{~s}$ ), comparable to the effects of heparin. In a similar manner, ulvan from $U$. lactuca has been demonstrated to inhibit intrinsic and extrinsic coagulation pathways (Reis et al. 2020).

Anticoagulant responses depend on: i) chemical structure of SP, ii) $\mathrm{M}_{\mathrm{W}}$ and iii) specific sulfation patterns (Sudharsan et al. 2015). In addition, carboxyl groups may increase the anticoagulant activity by appropriate interactions with proteins involved in the coagulation cascade. A recent study suggested that the anticoagulant activity of $U$. fasciata ulvan depends on the amount of sulfate groups present in the original polymer and the content of carboxyl groups (de Carvalho et al. 2018). For example, showing longer times in the case of polycarboxylic ulvan ( $\mathrm{p}$-ulvan) compared to native ulvan (n-ulvan) when APTT, TT or PT were tested (Table 4).

Regarding $M_{W}$, generally, the higher $M_{W}$, the least anticoagulant activity. According to some authors, SFP with $\mathrm{M}_{\mathrm{W}}$ $>850 \mathrm{kDa}$, generally present low anticoagulant activity (Shanmugam and Mody 2000). However, other authors have found several polymers improved the anticoagulant activity the higher $\mathrm{M}_{\mathrm{w}}$. For example, S. fusiforme SFP with $\mathrm{M}_{\mathrm{W}}$ $227 \mathrm{kDa}$ presented higher anticoagulant effects than other low $\mathrm{M}_{\mathrm{W}}$ SFP $(36 \mathrm{kDa}$ ) (Table 4). They suggest SFP present a suitable molecular structure for interacting with proteins involved in the coagulation cascade (Sun et al. 2018; Chandía and Matsuhiro 2008).

The amount of sulfate may be an important factor which could affect in APTT and TT. For instance, it has been determined that the minimum sulfation degree from low $\mathrm{M}_{\mathrm{W}}$ fucoidan extracts to exhibit anticoagulant activity must be over 20\% (Ale, Mikkelsen, and Meyer 2011). Also, two different extracts of agar from $G$. acerosa with different sulfate content (I: $14.5 \%$; II: $27.71 \%$ ) were tested and it was found that fraction II showed higher anticoagulant activity (II: APTT $=71.1 \mathrm{~s}$, heparin $=40.05 \mathrm{~s})$ than I $($ APTT $=70.3 \mathrm{~s}$, heparin $=141.3 \mathrm{~s})($ Table 4$)($ de Queiroz et al. 2014; Chagas et al. 2020). Results were similar in another study in which ulvan extracted from $U$. conglobata with high content of sulfate (35\%) prolonged the value of APTT until $250 \mathrm{~s}$ using a concentration of $5 \mu \mathrm{g} / \mathrm{mL}$ (Mao et al. 2006).
Regarding the antithrombotic activity, it can be assessed by different methods: thrombus formation (TF), thrombus weight (TW) and clot lytic rate (CLR). According to some authors, some SFP present high antithrombotic activity although they have low anticoagulant activity. For instance, agar may inhibit thromboplastin-induced thrombus formation in rats as agar from G. acerosa $(1 \mathrm{mg} / \mathrm{kg})$ was demonstrated to reduce TF in $80 \%$ whereas heparin $(0.05 \mathrm{mg} / \mathrm{kg})$ achieved $65 \%$. However, results from anticoagulant activity were not so high (Table 4) (Chagas et al. 2020), in accordance with other works (Quinderé et al. 2014). Nonetheless, some SFP display significant antithrombotic and anticoagulant responses, for example, sulfated arabino-galactans from the green alga $C$. linum presented an important antithrombotic activity in vitro and high anticoagulant responses in vitro and in vivo (Qin et al. 2020). Moreover, carrageenan possesses important effects on platelet aggregation. In the same study, galactan-SFP $(100 \mu \mathrm{g} / \mu \mathrm{L})$ reduced $32 \%$, while heparin $(100 \mu \mathrm{g} / \mu \mathrm{L})$ only reduced $15 \%$. In another study, carrageenan from T. crinitus $(100 \mu \mathrm{g} / \mu \mathrm{L})$ reduced $55 \%$ of platelet aggregation (Byankina Barabanova et al. 2013).

\subsection{Antioxidant}

In cellular respiration, oxidizing agents called free radicals or reactive oxygen species (ROS) get accumulated (Chatterjee 2016). So, the use of antioxidants could counteract the imbalance of the oxidant/antioxidant ratio (Circu and Aw 2010). These antioxidant agents can exert their function directly by donating an electron or by breaking the oxidation chain (Filomeni, De Zio, and Cecconi 2015). In this regard, SP are accounted for significant antioxidant properties. For instance, ulvans have been reported as one of the most potent antioxidant SP. A study used a SFP extract of $U$. intestinals $(5 \mathrm{mg} / \mathrm{mL})$ with antioxidant activity that was able to remove $74 \%$ of 2.2 -diphenyl-picryl-hydrazyl radical $(\mathrm{DPPH})$ radicals and showed a reducing power of around 88\% (Rahimi, Tabarsa, and Rezaei 2016) (Table 4). However, not all SFP have high antioxidant activities, since several factors such as $M_{W}$, monomer residue composition, degree of sulfation and sulfate substitution position can significantly alter their antioxidant activity (Zhong et al. 2019). The higher $M_{W}$ of SP can lead to a reduced solubility, which complicates their penetration into cells to perform functions. Therefore, low $M_{W}$ SP present higher antioxidant activity (Choi and Kim 2013). In this sense, the degradation of SP by enzymatic methods can be a good choice to improve their antioxidant responses, since the decrease of $\mathrm{M}_{\mathrm{W}}$ of the SP could lead to the exposure of more functional groups. A study concluded the use of pectinase enzyme was able to degrade the SFP from P. haitanensis (Li et al. 2020). Other authors confirmed glucoamylase enzyme was able to degrade SP from E. prolifera (Xu et al. 2016). In addition, a new study used together pectinase and glucoamylase to degrade the fucoidan from $S$. fusiforme. In this study, enzymatically degraded S. fusiforme SP showed higher antioxidant activity than the natural S. fusiforme fucoidan (Wen et al. 2021) (Table 4). 
$\stackrel{4}{\dddot{\varpi}}$

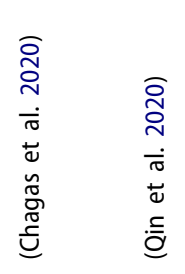

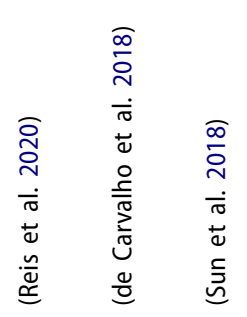

후스으응

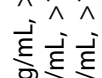
옹 홍홍

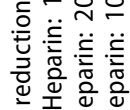

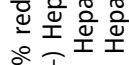

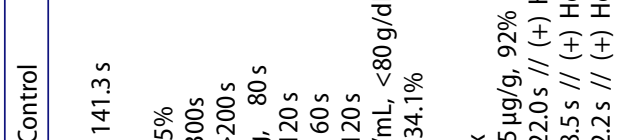

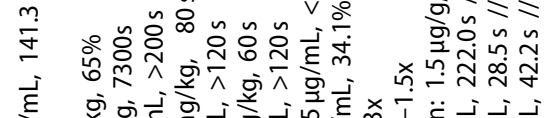

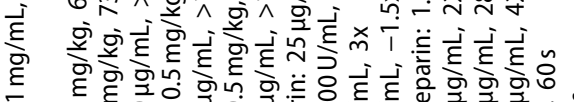

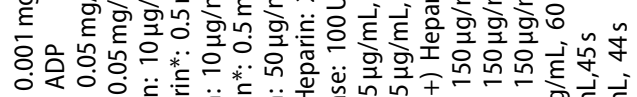

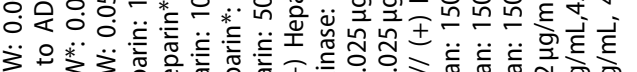

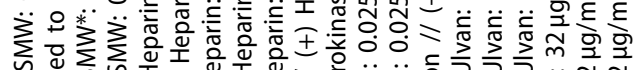

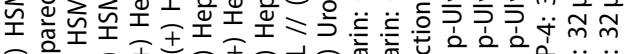

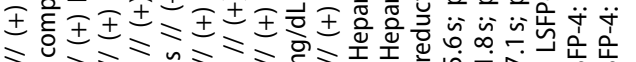

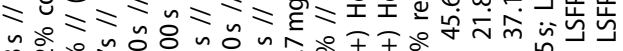

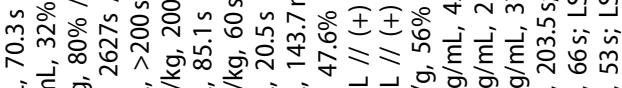

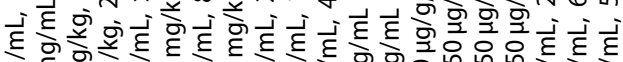

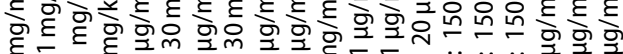

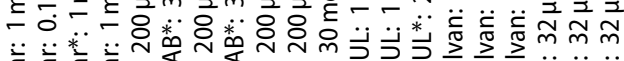

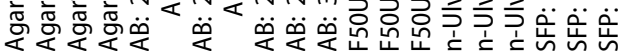

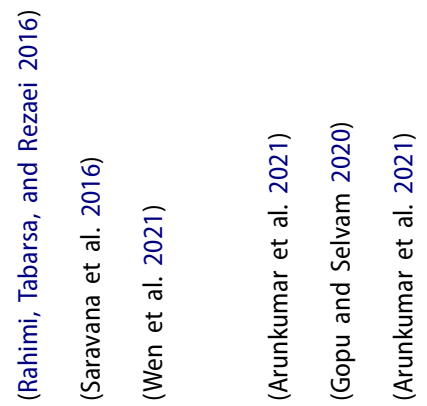

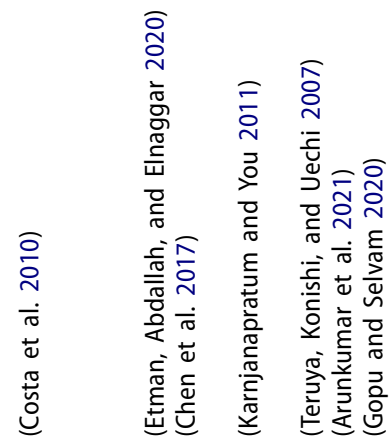

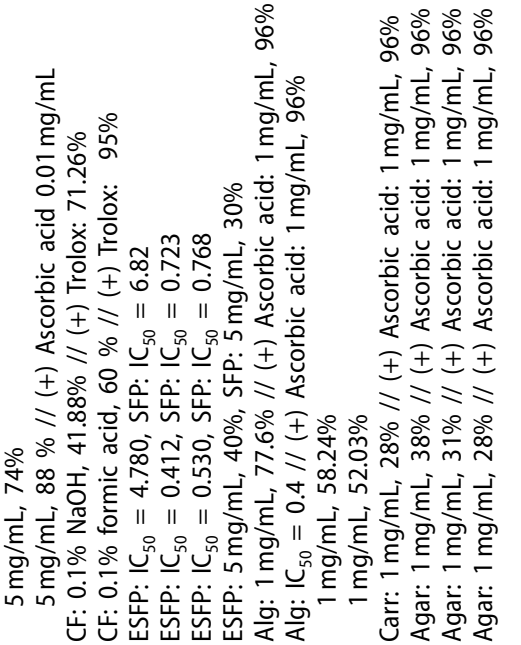

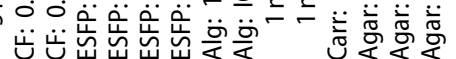

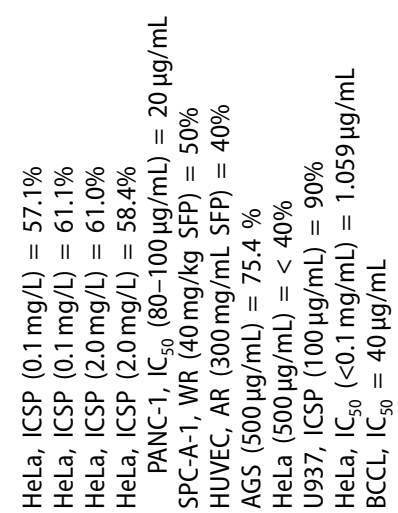

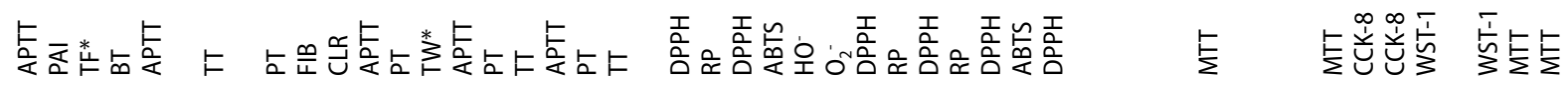
它

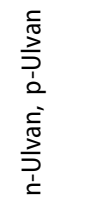

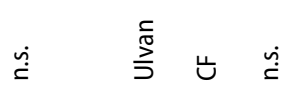

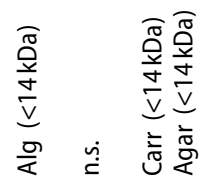

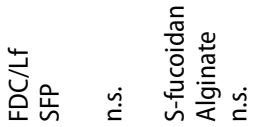
高 定

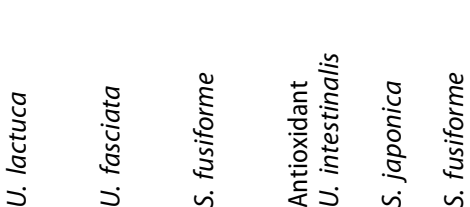

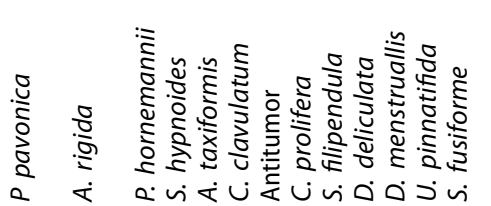

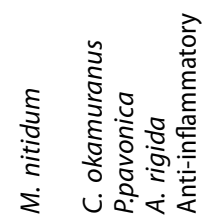



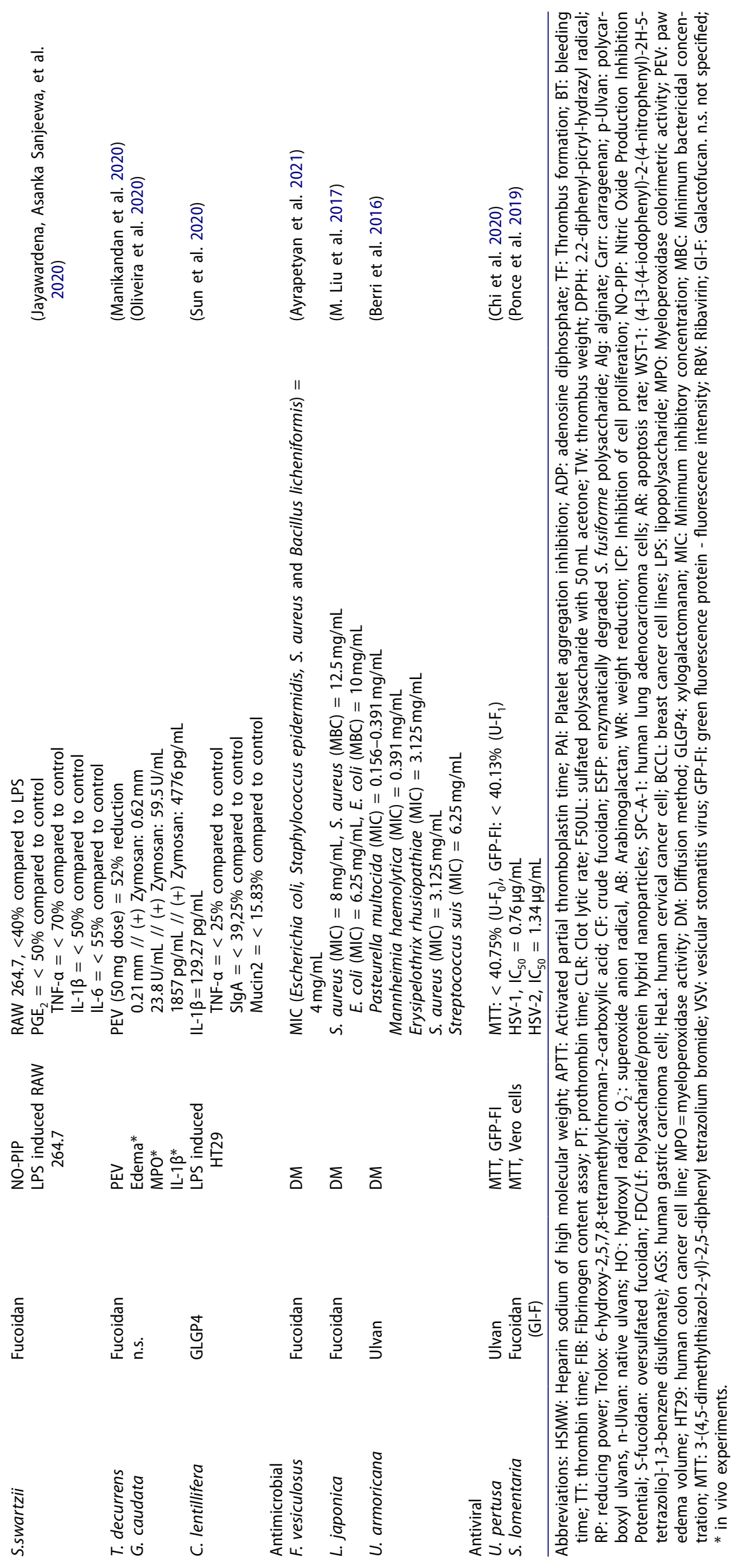
On the other hand, many studies described that degraded or chemically modified SP improved their antioxidant activities compared to the native SP. For example, a study assessing several red algae species and found that the brown algae $P$. pavonica showed higher antioxidant activity than several red algae (Table 4). This study suggest that the content of sulfate is not the main parameter that affects antioxidant response, but the type of monomers also play an important role (Arunkumar et al. 2021). Besides, different investigations have concluded high levels of uronic acid, protein and low $\mathrm{M}_{\mathrm{W}}$ can lead to stronger DPPH and ABTS scavenging activity (Chen et al. 2020). For example, the SFP extracted from red algae $A$. rigida, which contained major amounts of uronic acid and protein, showed high capacity of removing DPPH and ABTS radicals (Gopu and Selvam 2020) (Table 4).

\subsection{Antitumor}

Polysaccharides anticancer efficacy was first described in a 1946 study, in which it was discovered that some bacterial polysaccharides could weaken tumor development in cancer patients (Nauts, Swift, and Coley 1946). These compounds can inhibit tumor growth through four mechanisms: i) prevention strategy by direct consumption of active preparations; ii) the inhibition of tumor metastasis; iii) induction of tumor cell apoptosis and iv) stimulation of the immune system (Zong, Cao, and Wang 2012; Costa et al. 2010).

As previously stated, sulfate groups and $\mathrm{M}_{\mathrm{W}}$ of SFP also influence the anticancer activities. Authors suggested the anticancer activities of fucoidan and ulvan depend on the sulfate content (Karnjanapratum and You 2011). The green seaweed M. nitidum was used to extract SFP and evaluate anticancer effect against HeLa and AGS cell lines. The results concluded that native SFP $(500 \mu \mathrm{g} / \mathrm{mL})$ of $M$. nitidum showed inhibition of cell proliferation of $75.4 \%$ on AGS cells, while less than $40 \%$ on HeLa cells (Table 4). The results may be due to the content of sulfate (13.5\%) and $\mathrm{M}_{\mathrm{W}}\left(158 \times 10^{3} \mathrm{~g} / \mathrm{mol}\right)$ (Karnjanapratum and You 2011). Another study performed with four species of algae ( $C$. prolifera, S. filipendula, D. delicatula and D. menstruallis) showed there was a positive correlation between the sulfate content and the inhibition of HeLa cell proliferation. S. filipendula showed the greater inhibition with $61.1 \%$ at $0.1 \mathrm{mg} / \mathrm{L}$ concentration (Costa et al. 2010) (Table 4). The structure feature of SP is fundamental for their antiproliferative activity. Similar results were shown in a study where oversulfated fucoidan (sulfate content of $32.8 \%$ ) inhibited the proliferation of U937 cells (up to $90 \%$ at $100 \mu \mathrm{g} / \mathrm{mL}$ ), whereas native fucoidan (sulfate content of 13.5\%) did not show significant inhibition (Teruya, Konishi, and Uechi 2007) (Table 4). Another study showed that fucoidan of $S$. fusiforme was able to inhibit the proliferation of tumor cells SPC-A-1, promote the apoptosis and cell cycle arrest of HUVECs umbilical cord cell line and to inhibit endothelial growth factor VEGF-A/VEGFR2 expression (Chen et al. 2017). Also, fucoidan from $P$. pavonica reduced SPC-A-1 tumor weight up to $50 \%$ at $40 \mathrm{mg} / \mathrm{kg}$ and increased apoptosis rates up to $40 \%$ with $300 \mathrm{mg} / \mathrm{mL}$. In addition, this fucoidan extract showed inhibition against the proliferation of HeLa cells $\left(\mathrm{IC}_{50}=1.059 \mu \mathrm{g} / \mathrm{mL}\right.$ ) (Arunkumar et al. 2021), whereas SP obtained from A. rigida had significant anticancer activity against breast cancer BCCL cells $\left(\mathrm{IC}_{50}=40 \mu \mathrm{g} / \mathrm{mL}\right)$ (Gopu and Selvam 2020). In a recent study exploring the use of fucoidan nanoparticles, it was reported that found their $\mathrm{IC}_{50}(20 \mu \mathrm{g} / \mathrm{mL})$ against PANC-1 cells was 2.3 folds lower than fucoidan extracts $\left(\mathrm{IC}_{50}=\right.$ $53 \mu \mathrm{g} / \mathrm{mL}$ ) (Table 4). As such, the use of novel technologies incorporating SP may prove a suitable technology to enhance these molecules properties (Etman, Abdallah, and Elnaggar 2020).

\subsection{Immunomodulating and anti-inflammatory}

Inflammation is a defense mechanism involved in physiological and pathologic immune system responses. It consists on the liberation of many inflammatory mediators (cytokines, chemokines and reactive oxygen/nitrogen intermediates) triggering this process. The normal process of inflammation promotes the elimination of harmful stimuli and induces wound healing. However, the inflammation process can be altered by many factors and result in dysregulated inflammation, causing unusual increased liberation of inflammatory mediators. This can lead to develop other chronic diseases such as allergies, rheumatoid arthritis, Crohn's disease, type II diabetes and Alzheimer's disease, among many others (Gupta et al. 2018). Hence, both industry and academy have focused on finding suitable molecules to modulate or suppress inflammation effects. Therefore, SP have gained attention for their described anti-inflammatory properties (Fernando, Nah, and Jeon 2016). For example, agar extracted from G. caudata was administered $(3-30 \mathrm{mg} /$ $\mathrm{kg}$ ) to mice with induced arthritis, showing a significant reduction of edema and hypernociception (Table 4) (Oliveira et al. 2020). Fucoidan is also reported to be an effective anti-inflammatory molecule. However, being highly heterogeneous in its structure and composition, the extent and effectiveness of its anti-inflammatory properties may be variable. A study showed a purified fucoidan fraction from S. swartzii inhibited inflammatory mediators such as inducible nitric oxide synthase (iNOS), cyclooxygenase-2 (COX-2), nitric oxide (NO), and pro-inflammatory cytokines (Jayawardena, Asanka Sanjeewa, et al. 2020). Another study concluded that an isolated fucoidan from $T$. decurrens could reduce the expression of interleukin $1 \beta$ (IL- $1 \beta), \mathrm{COX}-2$ and matrix metallopeptidase 9 (MMP-9) as well as anti-inflammatory activity against lipopolysaccharide (LPS) induced IC-21 macrophages (Table 4) (Manikandan et al. 2020).

Furthermore, sulfation degree of the SP molecule can affect anti-inflammatory activity. Several studies demonstrated the higher sulfate content, the better anti-inflammatory responses. For example, a purified fucoidan fraction with the highest sulfate content could inhibit to a higher extent the production of inflammatory mediators and reduce the inflammatory effect under LPS stimulated conditions 
(Jayawardena et al. 2019; Sun et al. 2020). The composition of monosaccharides is also another important parameter that influences anti-inflammatory responses. Several studies found high anti-inflammatory activities in those SFP rich in fucose-rich fucoidan (Sanjeewa et al. 2018; Cui et al. 2019; Li and Shah 2016). For example, SFP from C. lentillifera, which contained galactose (43.23\%), mannose (38.73\%) and xylose $(18.04 \%)$, presented important anti-inflammatory responses (Table 4) (Sun et al. 2020).

\subsection{Antimicrobial, antiviral and antiparasitic}

Recently, different problems regarding the resistance of bacteria to drugs have increased. Therefore, many industries have been interested in the antimicrobial activities that SFP from seaweed can exert. For this purpose, some determinations such as the minimum inhibition concentration (MIC) or the minimum bactericidal concentration (MBC) are employed (Table 4).

Also, some factors such as sulfation degree, uronic acid level or $\mathrm{M}_{\mathrm{W}}$ can affect SFP antimicrobial properties. For example, fucoidan was extracted from five different brown algae (S. fusiforme, K. crassifolia, L japonica, S. honeri and $U$. pinnatifida) but only U. pinnatifida (7.8\%) and K. crassifolia (8.6\%) exhibited antimicrobial activity. In addition, in this study, two samples of commercial fucoidan from $F$. vesiculosus had different sulfate contain (14\% and $7.5 \%)$ and only the one with a high sulfate degree showed prominent antimicrobial activity (Jun et al. 2018). In the case of uronic acid level, its role is still unclear. Fucoidan from $L$. japonica was used to analyze its antimicrobial activity and the fraction which had the highest uronic acid and sulfate content, exhibited the highest antimicrobial activity (M. Liu et al. 2017). Similar results were reported in a study where the fucoidan with higher sulfate and uronic acid content showed a major antimicrobial activity degree than purified fucoidan (Ayrapetyan et al. 2021). Nevertheless, (Ashayerizadeh, Dastar, and Pourashouri 2020) concluded that a fraction of $S$. tenerrimum with less uronic acid content showed the least antimicrobial activity. At last, $\mathrm{M}_{\mathrm{W}}$ role in antimicrobial activity of SFP is not very clear. For example, a study concluded that SFP with $\mathrm{M}_{\mathrm{W}}<6 \mathrm{kDa}$ showed the highest antimicrobial activity. However, another study showed the fucoidan extract with $\mathrm{M}_{\mathrm{W}}$ of $735 \mathrm{kDa}$ showed higher antibacterial activity than extract with $343.8 \mathrm{kDa}$ (M. Liu et al. 2017).

In addition, SFP antiviral activities have been also explored. For example, I-carrageenan has antiviral activity against respiratory viruses (Eccles et al. 2015). In this case, Ghosh et al. (2009) established the following patrons that affect the antiviral activity of SP: i) degree of sulfation: generally, the higher it is, the better antiviral activity; ii) specific positioning of sulfates; iii) $\mathrm{M}_{\mathrm{w}}$ : generally, the higher $M_{W}$, the better antiviral effect. However, low $M_{W} S P$ can display a significant antiviral activity when its degree of sulfation is great, and a minimum chain length and they can inhibit the propagation of virus more efficiently.

An example of SFP with antiviral activity against human and avian influenza viruses by suppressing the viral multiplication process are ulvans (Ivanova et al. 1994). In a study, ulvan lyase was used for assisted structural analysis of ulvan from $U$. pertusa. Results of this study showed ulvan fractions with high $\mathrm{M}_{\mathrm{W}}$ (U-FO and U-F1) possessed higher antiviral activity than those with low $\mathrm{M}_{\mathrm{W}}$. Concretely, U-FO and U-F1 could reduce the infection and replication of vesicular stomatitis virus (VSV) (Chi et al. 2020) (Table 4). These results are in accordance to $M_{W}$ pattern. Similar results were found in another study (H. Liu et al. 2005). It is thought that long chains have more opportunities to interact with the viral attachment proteins and could cross-link with the virus (Ghosh et al. 2009). In another study, a galactofucan showed antiviral activity against Herpes simplex virus (HSV). Also, a positive correlation between antiviral activity and sulfate content, and a negative correlation with uronic acid content was predicted (Ponce et al. 2019).

\subsection{Anti-hyperlipidemic}

Hyperlipidemia can be considered as a lipid metabolic imbalance issue, which consist of high levels of free fatty acids, apolipoprotein B (apo B), total cholesterol (TC), triglycerides (TG) and low-density lipoprotein (LDL), together with low levels of high-density lipoprotein (HDL) Many cardiovascular and cerebrovascular diseases are originated by lipid mechanism disorder. Therefore, researches are focused in finding and obtaining polysaccharides with anti-hyperlipidemic activities from seaweed (Knouff et al. 2004; Taghizadeh et al. 2019).

Recently, several studies showed many polysaccharides from marine algae presented excellent anti-hyperlipidemic properties. Concretely, the green alga $U$. pertusa, was employed in several studies to assess hypolipidemic activity of ulvan (W. Li et al. 2018; Jiang et al. 2020). In addition, there is scientific evidence that conclude structure modifications of polysaccharides can improve the anti-hyperlipidemic activity. In particular, SP with high sulfate contain showed higher anti-hyperlipidemic responses than native ulvan (H. Qi et al. 2012). Another study used modified phosphorylated ulvans in mice with hyperlipidemia and it was demonstrated to decrease TC, TG and LDL levels and increase HDL levels with even better anti-hyperlipidemic responses than nicotinic acid used as positive control (Jiang et al. 2020).

\section{Final remarks and future perspectives}

This review explores the use of main SP, ulvan, alginates, fucoidan, laminarin, agar, carrageenans and floridean starch in terms of nutritional properties, evidence-based health benefits, and their obtaining from algae by emerging extraction techniques. SP, especially SFP, are molecules of high potential value, not present in terrestrial plants. Besides shown antioxidant, anticancer, antimicrobial, and antiviral activities, they are also associated to various health benefits including prebiotic effects and cholesterol excretion. The revised literature shows macroalgae constitute a cost-effective and useful source for recovering SP with high potential on 
innovative biomedical, functional food and technological applications.

In the biomedical field, several applications of SP have been proposed, like the improvement of drugs' formulation, particles for delivery systems and even in tissue engineering (Cosenza et al. 2017). In this field, it seems that one of the most promising molecules is fucoidan. This molecule present applications in nanomedicine as imaging agents and drug carriers due to their intrinsic properties (Chollet et al. 2016). However, to ensure a progress in this field, still there is a need for reproducible and well characterized chemical composition. Fucoidan fractions can vary considerably according to the natural source. These molecules can represent an enormous opportunity for biomedical market if alternative methods to produce SP with consistent properties can be developed, since these properties critically influence the biological activities of the compound (Liang et al. 2014). In addition, it is important to research on the mechanism of action of SFP since it is usual to observed contradicting activities. As stated, this difference in the biological effects can be due to difference in $\mathrm{M}_{W}$ and degree of branching among molecules. An understanding of the mechanism of action is key to the successful use of a SP in nanomedicine field.

In food industry, carrageenan, alginates, and agar are the most widely used SP, due to their due to their rheological properties. Agar is the most utilized in confectionary products like donuts and cakes to maintain the hydration of the products as well as in fruit jelly confections and in the meat industry as a fat reducing agent. Alginates are becoming popular for encapsulation and delivery systems of probiotics to the large intestine and colon as well as in vegetable industries for their ability to prevent the growth of microorganisms. Moreover, carrageenan is used to improve the stability and texture of different products and is also gaining interest in the improvement of formulation of gluten-free, vegetarian and vegan foods (Alba and Kontogiorgos 2018; Cosenza et al. 2017). Apart from food industry, some SP are also used in cosmetic formulations, like shampoos, moisturizers or dental-care products (Lourenço-Lopes et al. 2020).

Although the wide use of SP in industrial applications and functional foods, several issues must still be overcome. Some uses of SP are limited due to their low solubility in neutral $\mathrm{pH}$. In this sense, chemical modification of their structure is a useful process to improve their properties, and thus to enlarge the field of their potential applications. In recent years, enzymatic modification of SP seems to be a solid alternative to toxic chemical approaches. The enzymatic process include polymer $\mathrm{M}_{\mathrm{W}}$ reduction, transesterification, oxidation, glycosylation and ester formation (Cheng and $\mathrm{Gu} 2012$ ). Enzyme modification is a promising tool for obtaining more defined targeted biomolecules, although some enzymes can be expensive. Another approach that could be employed to enhance the biological properties and the potential applications of SP is the complexation with other molecules, like polyphenols (Li et al. 2021).

To sum up, this review focused on structural differences between the most relevant algae SFP, available modification methods, as well as a summary of their biological activities.
In addition, novel methods which are being developed to facilitate and improve the extraction processes of SP are also described since one issue to deal with is the need to reduce the use of chemical reagents and optimize operations to improve yields (Karaki et al. 2016). In this context, more research is needed on the extraction and purification processes of the SP.

Macroalgae species

Chlorophyta: Caulerpa (C.): C. lentillifera, C. prolifera, C. racemosa. Chaetomorpha (C.): C. linum. Codium (C.): C. fragile. Enteromorpha (E.): E. compressa, E. intestinalis, E. linza, E. prolifera. Monostroma (M.): M. nitidum. Ulothrix (U.): U. flacca. Ulva (U.): U. armoricana, U. congoblata, $U$. fasciata, U. intestinalis, U. lactuca, U. ohnoi, U. pertusa, U. prolifera, $U$. rigida, $U$. rotundata.

Rhodophyta: Amphiroa (A.): A. rigida. Asparagopsis (A.): A. taxiformis. Centroceras (C.): C. clavulatum. Chondrus (C.): C. armatus. Eucheuma (E.): E. cottoni, E. denticulatum, E. galetinae. Furcellaria (F.): F. lumbricalis. Gelidiella (G.): G. acerosa. Gelidium (G.): G. amansii, G. corneum. Gigartina (G.): G. skottsbergii. Gracilaria (G.): G. birdiae, G. blodgettii, G. caudata, G. chouae, G. gracilis, G. lemaneiformis. Gracilariopsis (G.): G. lemaneiformis, G. persica. Gelidium (G.): G. robustum, G. amansii. Hydropuntia (H.): H. cornea. Hypnea (H.): H. musciformis. Kappaphycus (K.): K. alvarezii. Mastocarpus (M.): M. pacificus. Porphyra (P.): P. boryana, $P$. haitanensis. Portieria (P.): P. hornemannii. Rhodymenia (R.): R. pseudopalmata. Sarcodia (S.): S. ceylonensis. Spyridia (S.): S. hypnoides. Tichocarpus (T.): T. crinitus

Phaeophyta: Alaria (A.): A. angusta. Ascophyllum (A.): A. nodosum. Bifurcaria (B.): B. bifurcata. Cladosiphon (C.): C. okamuranus. Coccophora (C.): C. langsdorfii. Cystoseira (C.): C. compressa. Dictyopteris (D.): D. membranacea. Dictyosiphon (D.): D. foeniculaceus. Dictyota (D.): D. deliculata, D. menstrualis. Durvillaea (D.): D. antarctica. Eisenia (E.): E. bicyclis. Fucus (F.): F. distuchus, F. evanescens, F. serratus, F. spiralis, F. vesiculosus. Kjellmaniella (K.): K. crassifolia. Laminaria (L.): L. digitata, L. hyperborea, L. japonica. Macrocystis (M.): M. pyrifera. Nizamuddinia (N.): N. zanardinii. Padina (P.): P. pavonica. Pelvetia (P.): P. canaliculata. Saccharina (S.): S. japonica, S. latissima, S. longicruris. Sargassum (S.): S. angustifolium, S. fluitans, S. filipendula, S. fusiforme, S. fulvellum, S. honeri, S. muticum, S. pallidum, S. stenophyllum, S. siliquosum, S. swartzii, S. tenerrimum, S. thunbergii. Scytosiphon (S.): S. lomentaria. Silvetia (S.): S. compressa. Solieria (S.): S. chordalis, S. filiformis. Spyridia (S.): S. filamentosa. Turbinaria (T.): T. conoides, T. decurrens, T. ornata. Undaria (U.): U. pinnafitida.

Abbreviations General Terms: AB: Arabinogalactan; ABTS: 2,2'-Azino-bis(3-ethylbenzothiazoline-6-sulfonic acid) ; apo B: Apolipoprotein B; APTT: Activated Partial Thromboplastin Time; CF: Crude Fucoidan; CLR: Clot Lytic Rate; COX-2: Cyclooxygenase-2; DPPH: 2.2-diphenyl-picryl-hydrazyl radical; DW: Dry weight; ESFP: Enzymatically degraded Sargassum fussiforme polysaccharides; HDL: High-Density Lipoprotein; HSV: Herpes simplex virus; IL-1 $\beta$ : Interleukin 1 $\beta$; iNOS: inducible nitric oxide synthase; LDL: Low-Density Lipoprotein; LPS: Lipopolysaccharide; $M_{w}$ : Molecular Weight; MBC: Minimum Bactericidal Concentration; MIC: Minimum Inhibition Concentration; MMP-9: Matrix metallopeptidase 9; MTT: 3-(4,5-dimethylthiazol-2-yl)-2,5-diphenyl tetrazolium bromide; NO: Nitric Oxide; $n$-ulvan: Native ulvan; p-ulvan: Polycarboxylic ulvan; 
PT: Prothrombin time; ROS: Reactive oxygen species; SFP: Sulfated Polysaccharides; SP: Seaweed Polysaccharides; TC: Total Cholesterol; TF: Thrombus Formation; TG: Triglycerides; TT: Thrombin Time; TW: Thrombus Weight; VSV: Vesicular Stomatitis Virus; WHO: World Health OrganizationExtraction Techniques: EAE: Enzyme-assisted extraction; MAE: Microwave-assisted extraction; PLE: Pressurized liquid extraction; UAE: Ultrasound-assisted extraction; $\mathrm{SC}-\mathrm{CO}_{2}$ : Supercritical carbon dioxide extractionldentification Techniques: FTIR: Fourier transform infrared spectroscopy; GC-MS: Gas chromatography coupled to mass spectrometry; HPLC: High performance liquid chromatography; MS: Mass spectrometry; MALDI: Matrix Assisted Laser Desorption/lonization; MALLS: Multi-angle laser light scattering; NMR: Nuclear magnetic resonance; TOF: Time of flight

\section{Acknowledgements}

The research leading to these results was supported by MICINN supporting the Ramón y Cajal grant for M.A. Prieto (RYC-2017-22891); by Xunta de Galicia for supporting the program EXCELENCIA-ED431F 2020/12, the post-doctoral grant of M. Fraga-Corral (ED481B-2019/096), the pre-doctoral grant of P. Garcia-Oliveira (ED481A-2019/295) the program Grupos de Referencia Competitiva (GRUPO AA1-GRC 2018) that supports the work of J. Echave; by University of Vigo for supporting the predoctoral grant of M. Carpena (Uvigo-00VI $131 \mathrm{H}$ 6410211) and Becas de Fundación ONCE Programme "Oportunidad al Talento" to support the work of A. Soria-Lopez. Authors are grateful to Ibero-American Program on Science and Technology (CYTEDAQUA-CIBUS, P317RT0003), to the Bio Based Industries Joint Undertaking (JU) under grant agreement No 888003 UP4HEALTH Project (H2020-BBI-JTI-2019) that supports the work of P. Otero. The JU receives support from the European Union's Horizon 2020 research and innovation program and the Bio Based Industries Consortium. The project SYSTEMIC Knowledge hub on Nutrition and Food Security, has received funding from national research funding parties in Belgium (FWO), France (INRA), Germany (BLE), Italy (MIPAAF), Latvia (IZM), Norway (RCN), Portugal (FCT), and Spain (AEI) in a joint action of JPI HDHL, JPI-OCEANS and FACCE-JPI launched in 2019 under the ERA-NET ERA-HDHL ( ${ }^{\circ}$ 696295).

\section{Disclosure statement}

The authors declare no conflict of interest.

\section{ORCID}

Paz Otero (D) http://orcid.org/0000-0001-5164-3004 M. Carpena (D) http://orcid.org/0000-0002-4819-7856

P. Garcia-Oliveira (D) http://orcid.org/0000-0003-4058-3709

J. Echave (ID http://orcid.org/0000-0002-1994-0436

P. Garcia-Perez (D) http://orcid.org/0000-0003-1798-6235

M. Fraga-Corral (D) http://orcid.org/0000-0002-5663-9239

Hui Cao (D) http://orcid.org/0000-0002-0584-4734

Shaoping Nie (D) http://orcid.org/0000-0002-2412-4679

Jianbo Xiao (D) http://orcid.org/0000-0003-3311-770X

Simal-Gandara (D) http://orcid.org/0000-0001-9215-9737

M. A. Prieto (D) http://orcid.org/0000-0002-3513-0054

\section{References}

Aarstad, O. A., A. Tøndervik, H. Sletta, and G. Skjåk-Braek. 2012. Alginate sequencing: An analysis of block distribution in alginates using specific alginate degrading enzymes. Biomacromolecules 13 (1):106-16. doi: 10.1021/bm2013026.
Abdul Khalil, H. P. S., T. K. Lai, Y. Y. Tye, S. Rizal, E. W. N. Chong, S. W. Yap, A. A. Hamzah, M. R. Nurul Fazita, and M. T. Paridah. 2018. A review of extractions of seaweed hydrocolloids: Properties and applications. Express Polymer Letters 12 (4):296-317. doi: 10.3144/expresspolymlett.2018.27.

Adrien, A., A. Bonnet, D. Dufour, S. Baudouin, T. Maugard, and N. Bridiau. 2019. Anticoagulant activity of sulfated ulvan isolated from the green macroalga Ulva rigida. Marine Drugs 17 (5):14-6. doi: $10.3390 / \mathrm{md} 17050291$.

Alba, K., and V. Kontogiorgos. 2018. Seaweed polysaccharides (agar, alginate carrageenan). In Encyclopedia of food chemistry, ed. L. Melton, F. Shahidi, and P. Varelis, 240-50. Amsterdam: Elsevier. doi: 10.1016/B978-0-08-100596-5.21587-4.

Alboofetileh, M., M. Rezaei, M. Tabarsa, M. Rittà, M. Donalisio, F. Mariatti, S. You, D. Lembo, and G. Cravotto. 2019. Effect of different non-conventional extraction methods on the antibacterial and antiviral activity of fucoidans extracted from Nizamuddinia zanardinii. International Journal of Biological Macromolecules 124:131-7. doi: 10.1016/j.ijbiomac.2018.11.201.

Alboofetileh, M., M. Rezaei, M. Tabarsa, S. You, F. Mariatti, and G. Cravotto. 2019. Subcritical water extraction as an efficient technique to isolate biologically-active fucoidans from Nizamuddinia zanardinii. International Journal of Biological Macromolecules 128:244-53. doi: 10.1016/j.ijbiomac.2019.01.119.

Ale, M. T., J. D. Mikkelsen, and A. S. Meyer. 2011. Important determinants for fucoidan bioactivity: A critical review of structure-function relations and extraction methods for fucose-containing sulfated polysaccharides from brown seaweeds. Marine Drugs 9 (10):2106-30. doi: $10.3390 / \mathrm{md} 9102106$.

Alves, C., S. Pinteus, T. Simões, A. Horta, J. Silva, C. Tecelão, and R. Pedrosa. 2016. Bifurcaria bifurcata: A key macro-alga as a source of bioactive compounds and functional ingredients. International Journal of Food Science \& Technology 51 (7):1638-46. doi: 10.1111/ijfs.13135.

Amicucci, M. J., A. G. Galermo, A. Guerrero, G. Treves, E. Nandita, M. J. Kailemia, S. M. Higdon, T. Pozzo, J. M. Labavitch, A. B. Bennett, et al. 2019. Strategy for structural elucidation of polysaccharides: Elucidation of a maize mucilage that harbors diazotrophic bacteria. Analytical Chemistry 91 (11):7254-65. doi: 10.1021/acs. analchem.9b00789.

Ammar, H., Hadj, S. Lajili, R. Ben Said, D. Le Cerf, A. Bouraoui, and H. Majdoub. 2015. Physico-chemical characterization and pharmacological evaluation of sulfated polysaccharides from three species of Mediterranean brown algae of the genus Cystoseira. Daru: Journal of Faculty of Pharmacy, Tehran University of Medical Sciences 23 (1):1-11. doi: 10.1186/s40199-015-0089-6.

Anastyuk, S. D., N. M. Shevchenko, E. L. Nazarenko, P. S. Dmitrenok, and T. N. Zvyagintseva. 2009. Structural analysis of a fucoidan from the brown alga Fucus evanescens by MALDI-TOF and tandem ESI mass spectrometry. Carbohydrate Research 344 (6):779-87. doi: 10.1016/j.carres.2009.01.023

Armisén, R., and F. Galatas. 2009. Agar. In Handbook of hydrocolloids, 2nd ed., 82-107. Eds.: G.O. Phillips and P.A. Williams. Elsevier: Amsterdam, The Netherlands. doi: 10.1533/9781845695873.82.

Arunkumar, K., R. Raja, V. B. S. Kumar, A. Joseph, T. Shilpa, and I. S. Carvalho. 2021. Antioxidant and cytotoxic activities of sulfated polysaccharides from five different edible seaweeds. Journal of Food Measurement and Characterization 15 (1):567-76. doi: 10.1007/ s11694-020-00661-4.

Ashayerizadeh, O., B. Dastar, and P. Pourashouri. 2020. Study of antioxidant and antibacterial activities of depolymerized fucoidans extracted from Sargassum tenerrimum. International Journal of Biological Macromolecules 151:1259-66. doi: 10.1016/j.ijbiomac.2019.10.172.

Ayrapetyan, O. N., E. D. Obluchinskaya, E. V. Zhurishkina, Y. A Skorik, D. V. Lebedev, A. A. Kulminskaya, and I. M. Lapina. 2021. Antibacterial properties of fucoidans from the brown algae Fucus vesiculosus 1. of the Barents Sea. Biology 10 (1):1-17. doi: 10.3390/ biology10010067.

Barkia, I., N. Saari, and S. R. Manning. 2019. Microalgae for high-value products towards human health and nutrition. Marine Drugs 17 (5):1-29. doi: 10.3390/md17050304. 
Barros, A. A. A., A. Alves, C. Nunes, M. A. Coimbra, R. A. Pires, and R. L. Reis. 2013. Acta biomaterialia carboxymethylation of ulvan and chitosan and their use as polymeric components of bone cements. Acta Biomaterialia 9 (11):9086-97. doi: 10.1016/j.actbio.2013.06.036.

Beaumont, M., R. Tran, G. Vera, D. Niedrist, A. Rousset, R. Pierre, V. P. Shastri, and A. Forget. 2021. Hydrogel-forming algae polysaccharides: From seaweed to biomedical applications. Biomacromolecules 22 (3):1027-52. doi: 10.1021/acs.biomac.0c01406.

Bedoux, G., E. Caamal-Fuentes, R. Boulho, C. Marty, N. Bourgougnon, Y. Freile-Pelegrín, and D. Robledo. 2017. Antiviral and cytotoxic activities of polysaccharides extracted from four tropical seaweed species. Natural Product Communications 12 (6):1934578X1701200602. doi: 10.1177/1934578X1701200602.

Berri, M., C. Slugocki, M. Olivier, E. Helloin, I. Jacques, H. Salmon, H. Demais, M. Le Goff, and P. N. Collen. 2016. Marine-sulfated polysaccharides extract of Ulva armoricana green algae exhibits an antimicrobial activity and stimulates cytokine expression by intestinal epithelial cells. Journal of Applied Phycology 28 (5):2999-3008. doi: 10.1007/s10811-016-0822-7.

Bhardwaj, M., P. T K, S. Mani, M. R, V. K. Sali, and H. R. Vasanthi. 2020. Sulfated polysaccharide from Turbinaria ornata suppress lipopolysaccharide-induced inflammatory response in RAW 264.7 mcrophages. International Journal of Biological Macromolecules 164:4299-305. doi: 10.1016/j.ijbiomac.2020.09.036.

Bilan, M. I., A. A. Grachev, A. S. Shashkov, N. E. Nifantiev, and A. I. Usov. 2006. Structure of a fucoidan from the brown seaweed Fucus serratus L. Carbohydrate Research 341 (2):238-45. doi: 10.1016/j.carres.2005.11.009.

Bilan, M. I., and A. I. Usov. 2008. Structural analysis of fucoidans. Natural Product Communications 3 (10):1934578X0800301011. doi: 10.1177/1934578X0800301011.

Bittkau, K. S., S. Neupane, and S. Alban. 2020. Initial evaluation of six different brown algae species as source for crude bioactive fucoidans. Algal Research 45:101759. doi: 10.1016/j.algal.2019.101759.

Borazjani, N. J., M. Tabarsa, S. You, and M. Rezaei. 2017. Effects of extraction methods on molecular characteristics, antioxidant properties and immunomodulation of alginates from Sargassum angustifolium. International Journal of Biological Macromolecules 101:70311. doi: 10.1016/j.ijbiomac.2017.03.128.

Bouissil, S., Z. El Alaoui-Talibi, G. Pierre, P. Michaud, C. El Modafar, and C. Delattre. 2020. Use of alginate extracted from Moroccan brown algae to stimulate natural defense in date palm roots. Molecules 25 (3):720. doi: 10.3390/molecules25030720.

Byankina Barabanova, A. O., E. V. Sokolova, S. D. Anastyuk, V. V. Isakov, V. P. Glazunov, A. V. Volod'ko, I. M. Yakovleva, T. F. Solov'eva, and I. M. Yermak. 2013. Polysaccharide structure of tetrasporic red seaweed Tichocarpus crinitus. Carbohydrate Polymers 98 (1):26-35. doi: 10.1016/j.carbpol.2013.04.063.

Cao, C., Q. Huang, B. Zhang, C. Li, and X. Fu. 2018. Physicochemical characterization and in vitro hypoglycemic activities of polysaccharides from Sargassum pallidum by microwave-assisted aqueous two-phase extraction. International Journal of Biological Macromolecules 109:357-68. doi: 10.1016/j.ijbiomac.2017.12.096.

Cardoso, M. J., R. R. Costa, and J. F. Mano. 2016. Marine origin polysaccharides in drug delivery systems. Marine Drugs 14 (2):1-27. doi: $10.3390 / \mathrm{md} 14020034$.

Chagas, F. D. d. S., G. C. Lima, V. I. N. Dos Santos, L. E. C. Costa, W. M. de Sousa, V. G. Sombra, D. F. de Araújo, F. C. N. Barros, E. Marinho-Soriano, J. P. de Andrade Feitosa, et al. 2020. Sulfated polysaccharide from the red algae Gelidiella acerosa: Anticoagulant, antiplatelet and antithrombotic effects. International Journal of Biological Macromolecules 159:415-21. doi: 10.1016/j.ijbiomac.2020.05.012.

Chakka, V. P., and T. Zhou. 2020. Carboxymethylation of polysaccharides: Synthesis and bioactivities. International Journal of Biological Macromolecules 165 (Pt B):2425-31. doi: 10.1016/j.ijbiomac.2020.10.178.

Chandía, N. P., and B. Matsuhiro. 2008. Characterization of a fucoidan from Lessonia vadosa (Phaeophyta) and its anticoagulant and elicitor properties. International Journal of Biological Macromolecules 42 (3):235-40. doi: 10.1016/j.ijbiomac.2007.10.023.
Chatterjee, S. 2016. Oxidative stress, inflammation, and disease Oxidative stress and biomaterials. Elsevier Inc.: Amsterdam, The Netherlands. doi: 10.1016/B978-0-12-803269-5.00002-4.

Chen, H., L. Zhang, X. Long, P. Li, S. Chen, W. Kuang, and J. Guo. 2017. Sargassum fusiforme polysaccharides inhibit VEGF-A-related angiogenesis and proliferation of lung cancer in vitro and in vivo. Biomedicine \& Pharmacotherapy = Biomedecine \& Pharmacotherapie 85:22-7. doi: 10.1016/j.biopha.2016.11.131.

Chen, R., X. Ren, W. Yin, J. Lu, L. Tian, L. Zhao, R. Yang, and S. Luo. 2020. Ultrasonic disruption extraction, characterization and bioactivities of polysaccharides from wild Armillaria mellea. International Journal of Biological Macromolecules 156:1491-502. doi: 10.1016/j.ijbiomac.2019.11.196.

Chen, Y., F. Yao, K. Ming, D. Wang, Y. Hu, and J. Liu. 2016. Polysaccharides from traditional Chinese medicines: Extraction, purification, modification, and biological activity. Molecules 21 (12):1705. doi: 10.3390/molecules21121705.

Cheng, D., B. Liang, M. Li, and M. Jin. 2011. Influence of laminarin polysaccahrides on oxidative damage. International Journal of Biological Macromolecules 48 (1):63-6. doi: 10.1016/j.ijbiomac.2010.09.011.

Cheng, H. N., and Q. M. Gu. 2012. Enzyme-catalyzed modifications of polysaccharides and poly(ethylene glycol). Polymers 4 (2):131130. doi: 10.3390/polym4021311.

Cheong, K. L., H. M. Qiu, H., Du, Y. Liu, and B. M. Khan. 2018. Oligosaccharides derived from red seaweed: Production, properties, and potential health and cosmetic applications. Molecules 23 (10):2451. doi: 10.3390/molecules23102451.

Chi, Y., M. Zhang, X. Wang, X. Fu, H. Guan, and P. Wang. 2020. Ulvan lyase assisted structural characterization of ulvan from Ulva pertusa and its antiviral activity against Vesicular stomatitis virus. International Journal of Biological Macromolecules 157:75-82. doi: 10.1016/j.ijbiomac.2020.04.187.

Choi, J.-i., and H.-J. Kim. 2013. Preparation of low molecular weight fucoidan by gamma-irradiation and its anticancer activity. Carbohydrate Polymers 97 (2):358-62. doi: 10.1016/j.carbpol.2013.05.002.

Chollet, L., P. Saboural, C. Chauvierre, J.-n. Villemin, D. Letourneur, and F. Chaubet. 2016. Fucoidans in nanomedicine. Marine Drugs 14 (8):145. doi: $10.3390 / \mathrm{md} 14080145$.

Ciancia, M., P. V. Fernández, and F. Leliaert. 2020. Diversity of sulfated polysaccharides from cell walls of coenocytic green algae and their structural relationships in view of green algal evolution. Frontiers in Plant Science 11:554585. doi: 10.3389/fpls.2020.554585.

Ciko, A. M., S. Jokić, D. Šubarić, and I. Jerković. 2018. Overview on the application of modern methods for the extraction of bioactive compounds from marine macroalgae. Marine Drugs 16 (10):348. doi: $10.3390 / \mathrm{md} 16100348$.

Circu, M. L., and T. Y. Aw. 2010. Reactive oxygen species, cellular redox systems, and apoptosis. Free Radical Biology \& Medicine 48 (6):749-62. doi: 10.1016/j.freeradbiomed.2009.12.022.

Cong, Q., H. Chen, W. Liao, F. Xiao, P. Wang, Y. Qin, Q. Dong, and K. Ding. 2016. Structural characterization and effect on anti-angiogenic activity of a fucoidan from Sargassum fusiforme. Carbohydrate Polymers 136:899-907. doi: 10.1016/j.carbpol.2015.09.087.

Correc, G., A. O. Barabanova, R. Tuvikene, K. Truus, I. Yermak, and W. Helbert. 2012. Comparison of the structures of hybrid $\kappa$-/ $\beta$-carrageenans extracted from Furcellaria lumbricalis and Tichocarpus crinitus. Carbohydrate Polymers 88 (1):31-6. doi: 10.1016/j.carbpol.2011.11.052.

Cosenza, V. A., D. A. Navarro, N. M. A. Ponce, and C. A. Stortz. 2017. Seaweed polysaccharides: structure and applications. In Industrial applications of renewable biomass products, ed. S. Goyanes and N. D'Accorso, 75-116. Cham: Springer. doi: 10.1007/978-3-319-61288-1.

Costa, L. S., G. P. Fidelis, S. L. Cordeiro, R. M. Oliveira, D. A. Sabry, R. B. G. Câmara, L. T. D. B. Nobre, M. S. S. P. Costa, J. Almeida-Lima, E. H. C. Farias, et al. 2010. Biological activities of sulfated polysaccharides from tropical seaweeds. Biomedicine \& Pharmacotherapy 64 (1):21-8. doi: 10.1016/j.biopha.2009.03.005.

Cui, M., J. Wu, S. Wang, H. Shu, M. Zhang, K. Liu, and K. Liu. 2019. Characterization and anti-inflammatory effects of sulfated polysac- 
charide from the red seaweed Gelidium pacificum Okamura. International Journal of Biological Macromolecules 129:377-85. doi: 10.1016/j.ijbiomac.2019.02.043.

Cui, Y., L. Zhu, Y. Li, S. Jiang, Q. Sun, E. Xie, H. Chen, Z. Zhao, W. Qiao, J. Xu, et al. 2021. Structure of a laminarin-type $\beta$-(1 $\rightarrow 3)$-glucan from brown algae Sargassum henslowianum and its potential on regulating gut microbiota. Carbohydrate Polymers 255:117389. doi: 10.1016/j.carbpol.2020.117389.

de Carvalho, M. M., R. A. de Freitas, D. R. B. Ducatti, L. G. Ferreira, A. G. Gonçalves, F. G. Colodi, E. Mazepa, E. M. Aranha, M. D. Noseda, and M. E. R. Duarte. 2018. Modification of ulvans via periodate-chlorite oxidation: Chemical characterization and anticoagulant activity. Carbohydrate Polymers 197:631-40. doi: 10.1016/j. carbpol.2018.06.041.

De Jesus Raposo, M. F., A. M. B. De Morais, and R. M. S. C. De Morais. 2015. Marine polysaccharides from algae with potential biomedical applications. Marine Drugs 13 (5):2967-3028. doi: $10.3390 / \mathrm{md} 13052967$.

De Jesus Raposo, M. F., A. M. B. De Morais, and R. M. S. C. Bernardo De Morais. 2013. Bioactivity and applications of sulphated polysaccharides from marine microalgae. Marine Drugs 11 (1):233-52. doi: $10.3390 / \mathrm{md} 11010233$.

de Queiroz, I. N., Lino, J. A. G. Rodrigues, A. L. G. Quinderé, M. L. Holanda, M. G. Pereira, and N. M. B. Benevides. 2014. Inhibition of coagulation proteases and thrombosis and sub-chronic toxicological study of a sulfated polysaccharidic fraction from the red alga Gelidiella acerosa. Acta Scientiarum. Biological Sciences 36 (4):393-401. doi: 10.4025/actascibiolsci.v36i4.23704.

Deghrigue Abid, M., S. Lajili, H. Hadj Ammar, D. Cherif, N. Eltaief, H. Majdoub, and A. Bouraoui. 2019. Chemical and biological properties of sodium alginates isolated from tow brown algae Dictyopteris membranaceae and Padina pavonica. Trends Journal of Sciences Research 4 (2):62-7. doi: 10.31586/Pharmacology.0402.03.

Dobrinčić, A., Sandra Balbino, Z. Zorić, Sandra Pedisić, D. Bursać Kovačević, I. Elez Garofulić, and V. Dragović-Uzelac. 2020. Advanced technologies for the extraction of marine brown algal polysaccharides. Marine Drugs 18 (3):168. doi: 10.3390/md18030168.

Draget, K. I. 2009. Alginates. In Handbook of Hydrocolloids, 2nd ed., ed. G. O. Phillips and P. A. Williams, 807-28. Amsterdam: Elsevier. doi: $10.1533 / 9781845695873.807$.

Duan, Z., W. Duan, F. Li, Y. Li, P. Luo, and H. Liu. 2019. Effect of carboxymethylation on properties of fucoidan from Laminaria japonica: Antioxidant activity and preservative effect on strawberry during cold storage. Postharvest Biology and Technology 151:127-33. doi: 10.1016/j.postharvbio.2019.02.008.

Duarte, M. E. R., M. A. Cardoso, M. D. Noseda, and A. S. Cerezo. 2001. Structural studies on fucoidans from the brown seaweed. Carbohydrate Research 333 (4):281-93. doi: 10.1016/ S0008-6215(01)00149-5.

Eccles, R., B. Winther, S. L. Johnston, P. Robinson, M. Trampisch, and S. Koelsch. 2015. Efficacy and safety of iota-carrageenan nasal spray versus placebo in early treatment of the common cold in adults: The ICICC trial. Respiratory Research 16 (1):1-11. doi: 10.1186/ s12931-015-0281-8.

Etman, S. M., O. Y. Abdallah, and Y. S. R. Elnaggar. 2020. Novel fucoidan based bioactive targeted nanoparticles from Undaria pinnatifida for treatment of pancreatic cancer. International Journal of Biological Macromolecules 145:390-401. doi: 10.1016/j.ijbiomac.2019.12.177.

Farias, E. H. C., V. H. Pomin, A.-P. Valente, H. B. Nader, H. A. O. Rocha, and P. A. S. Mourão. 2008. A preponderantly 4-sulfated, 3-linked galactan from the green alga Codium isthmocladum. Glycobiology 18 (3):250-9. doi: 10.1093/glycob/cwm139.

Fernando, I. P. S., J.-W. Nah, and Y.-J. Jeon. 2016. Potential anti-inflammatory natural products from marine algae. Environmental Toxicology and Pharmacology 48:22-30. doi: 10.1016/j.etap.2016.09.023.

Filomeni, G., D. De Zio, and F. Cecconi. 2015. Oxidative stress and autophagy: The clash between damage and metabolic needs. Cell Death and Differentiation 22 (3):377-88. doi: 10.1038/cdd.2014.150.

Flórez-Fernández, N., H. Domínguez, and M. D. Torres. 2019. A green approach for alginate extraction from Sargassum muticum brown seaweed using ultrasound-assisted technique. International Journal of Biological Macromolecules 124:451-9. doi: 10.1016/j.ijbiomac.2018.11.232.

Garcia-Vaquero, M., G. Rajauria, B. Tiwari, T. Sweeney, and J. O'Doherty. 2018. Extraction and yield optimisation of fucose, glucans and associated antioxidant activities from Laminaria digitata by applying response surface methodology to high intensity ultrasound-assisted extraction. Marine Drugs 16 (8):257. doi: $10.3390 / \mathrm{md} 16080257$

Garcia-Vaquero, M., V. Ummat, B. Tiwari, and G. Rajauria. 2020. Exploring ultrasound, microwave and ultrasound-microwave assisted extraction technologies to increase the extraction of bioactive compounds and antioxidants from brown macroalgae. Marine Drugs 18 (3):172. doi: $10.3390 / \mathrm{md} 18030172$.

Garcia-Vaquero, M., G. Rajauria, J. V. O’Doherty, and T. Sweeney. 2017. Polysaccharides from macroalgae: Recent advances, innovative technologies and challenges in extraction and purification. Food Research International (Ottawa, Ont.) 99 (Pt 3):1011-20. Elsevier Ltd: doi: 10.1016/j.foodres.2016.11.016.

Garcia-Vaquero, M., G. Rajauria, and B. Tiwari. 2020. Conventional extraction techniques: Solvent extraction. In Sustainable seaweed technologies, ed. M. D. Torres, S. Kraan, and H. Dominguez, 17189. Elsevier Inc. doi: 10.1016/B978-0-12-817943-7.00006-8

George, M., and T. E. Abraham. 2006. Polyionic hydrocolloids for the intestinal delivery of protein drugs: Alginate and chitosan-A review. Journal of Controlled Release: Official Journal of the Controlled Release Society 114 (1):1-14. doi: 10.1016/j.jconrel.2006.04.017.

Gereniu, C. R. N., P. S. Saravana, and B.-S. Chun. 2018. Recovery of carrageenan from Solomon Islands red seaweed using ionic liquid-assisted subcritical water extraction. Separation and Purification Technology 196:309-17. doi: 10.1016/j.seppur.2017.06.055.

Ghosh, T., K. Chattopadhyay, M. Marschall, P. Karmakar, P. Mandal, and B. Ray. 2009. Focus on antivirally active sulfated polysaccharides: From structure-activity analysis to clinical evaluation. Glycobiology 19 (1):2-15. doi: 10.1093/glycob/cwn092.

Glasson, C. R. K., I. M. Sims, S. M. Carnachan, R. de Nys, and M. Magnusson. 2017. A cascading biorefinery process targeting sulfated polysaccharides (ulvan) from Ulva ohnoi. Algal Research 27:38391. doi: 10.1016/j.algal.2017.07.001.

Gomez, C. G., M. V. Pérez Lambrecht, J. E. Lozano, M. Rinaudo, and M. A. Villar. 2009. Influence of the extraction-purification conditions on final properties of alginates obtained from brown algae (Macrocystis pyrifera). International Journal of Biological Macromolecules 44 (4):365-71. doi: 10.1016/j.ijbiomac.2009.02.005.

Gomez, L. P., C. Alvarez, M. Zhao, U. Tiwari, J. Curtin, M. Garcia-Vaquero, and B. K. Tiwari. 2020. Innovative processing strategies and technologies to obtain hydrocolloids from macroalgae for food applications. Carbohydrate Polymers 248:116784. doi: 10.1016/j. carbpol.2020.116784.

Gómez-Ordóñez, E., A. Jiménez-Escrig, and P. Rupérez. 2014. Bioactivity of sulfated polysaccharides from the edible red seaweed Mastocarpus stellatus. Bioactive Carbohydrates and Dietary Fibre 3 (1):29-40. doi: 10.1016/j.bcdf.2014.01.002.

Gomez-Zavaglia, A., M. A. Prieto Lage, C. Jimenez-Lopez, J. C. Mejuto, and J. Simal-Gandara. 2019. The potential of seaweeds as a source of functional ingredients of prebiotic and antioxidant value. Antioxidants 8 (9). doi: 10.3390/antiox 8090406.

Gopu, M., and K. Selvam. 2020. Polysaccharides from marine red algae Amphiroa rigida and their biomedical potential: An in-vitro study. Biocatalysis and Agricultural Biotechnology 29:101769. doi: 10.1016/j.bcab.2020.101769.

Grünewald, N., and S. Alban. 2009. Optimized and standardized isolation and structural characterization of anti-inflammatory sulfated polysaccharides from the red alga Delesseria sanguinea (Hudson) Lamouroux (Ceramiales, Delesseriaceae). Biomacromolecules 10 (11):2998-3008. doi: 10.1021/bm900501g.

Gupta, S. C., A. B. Kunnumakkara, S. Aggarwal, and B. B. Aggarwal. 2018. Inflammation, a double-edge sword for cancer and other age-related diseases. Frontiers in Immunology 9:2160. doi: 10.3389/ fimmu.2018.02160. 
Hao, H., Y. Han, L. Yang, L. Hu, X. Duan, X. Yang, and R. Huang. 2019. Structural characterization and immunostimulatory activity of a novel polysaccharide from green alga Caulerpa racemosa var peltata. International Journal of Biological Macromolecules 134:891900. doi: 10.1016/j.ijbiomac.2019.05.084.

He, J., Y. Xu, H. Chen, and P. Sun. 2016. Extraction, structural characterization, and potential antioxidant activity of the polysaccharides from four seaweeds. International Journal of Molecular Sciences 17 (12):1988. doi: 10.3390/ijms17121988.

Hentati, F., C. Delattre, A. V. Ursu, J. Desbrières, D. Le Cerf, C. Gardarin, S. Abdelkafi, P. Michaud, and G. Pierre. 2018. Structural characterization and antioxidant activity of water-soluble polysaccharides from the Tunisian brown seaweed Cystoseira compressa. Carbohydrate Polymers 198:589-600. doi: 10.1016/j.carbpol.2018.06.098.

Hentati, F., L. Tounsi, D. Djomdi, G. Pierre, C. Delattre, A. V. Ursu, I. Fendri, S. Abdelkafi, and P. Michaud. 2020. Bioactive polysaccharides from seaweeds. Molecules 25 (14):3152. doi: 10.3390/molecules 25143152 .

Hmelkov, A. B., T. N. Zvyagintseva, N. M. Shevchenko, A. B. Rasin, and S. P. Ermakova. 2018. Ultrasound-assisted extraction of polysaccharides from brown alga Fucus evanescens. Structure and biological activity of the new fucoidan fractions. Journal of Applied Phycology 30 (3):2039-46. doi: 10.1007/s10811-017-1342-9.

Holtkamp, A. D., S. Kelly, R. Ulber, and S. Lang. 2009. Fucoidans and fucoidanases-focus on techniques for molecular structure elucidation and modification of marine polysaccharides. Applied Microbiology and Biotechnology 82 (1):1-11. doi: 10.1007/s00253-008-1790-x.

Huang, H., and G. Huang. 2020. Extraction, separation, modification, structural characterization, and antioxidant activity of plant polysaccharides. Chemical Biology \& Drug Design 96 (5):1209-22. doi: $10.1111 /$ cbdd.13794.

Hughes, M. H., H. J. Prado, M. C. Rodríguez, K. Michetti, P. I. Leonardi, and M. C. Matulewicz. 2018. Carrageenans from Sarcothalia crispata and Gigartina skottsbergii: Structural analysis and interpolyelectrolyte complex formation for drug controlled release. Marine Biotechnology (New York, N.Y.) 20 (6):706-17. doi: 10.1007/s10126-018-9842-4

Hurtado, M. Á., M. Manzano-Sarabia, E. Hernández-Garibay, I. Pacheco-Ruíz, and J. A. Zertuche-González. 2011. Latitudinal variations of the yield and quality of agar from Gelidium robustum (Gelidiales, Rhodophyta) from the main commercial harvest beds along the western coast of the Baja California Peninsula, Mexico. Journal of Applied Phycology 23 (4):727-34. doi: 10.1007/ s10811-010-9572-0.

Imbs, T. I., Ermakova, S. P. O. S. Malyarenko (Vishchuk), V. V. Isakov, and T. N. Zvyagintseva. 2016. Structural elucidation of polysaccharide fractions from the brown alga Coccophora langsdorfii and in vitro investigation of their anticancer activity. Carbohydrate Polymers 135:162-8. doi: 10.1016/j.carbpol.2015.08.062.

Ivanova, V., R. Rouseva, M. Kolarova, J. Serkedjieva, R. Rachev, and N. Manolova. 1994. Isolation of a polysaccharide with antiviral effect from Ulva lactuca. Preparative Biochemistry 24 (2):83-97. doi: 10.1080/10826069408010084.

Jacobsen, C., A.-D M. Sørensen, S. L. Holdt, C. C. Akoh, and D. B. Hermund. 2019. Source, extraction, characterization, and applications of novel antioxidants from seaweed. Annual Review of Food Science and Technology 10 (1):541-68. doi: 10.1146/ annurev-food-032818-121401.

Jayawardena, T. U., Asanka Sanjeewa, K. K. D. P. Nagahawatta, H. G. Lee, Y. A. Lu, A. P. J. P. Vaas, D. T. U. Abeytunga, C. M. Nanayakkara, D. S. Lee, and Y. J. Jeon. 2020. Anti-inflammatory effects of sulfated polysaccharide from Sargassum swartzii in macrophages via blocking TLR/NF-Kb signal transduction. Marine Drugs 18 (12). doi: $10.3390 / \mathrm{md} 18120601$.

Jayawardena, T. U., I. P. Shanura Fernando, W. Woo Lee, K. K. Asanka Sanjeewa, H. S. Kim, D. S. Lee, and Y. J. Jeon. 2019. Isolation and purification of fucoidan fraction in Turbinaria ornata from the Maldives; inflammation inhibitory potential under LPS stimulated con- ditions in in-vitro and in-vivo models. International Journal of Biological Macromolecules 131:614-23. doi: 10.1016/j.ijbiomac.2019.03.105.

Jayawardena, T. U., Wang, L. K. K. Asanka Sanjeewa, S. I. Kang, J. S. Lee, and Y. J. Jeon. 2020. Antioxidant potential of sulfated polysaccharides from Padina boryana; protective effect against oxidative stress in in vitro and in vivo zebrafish model. Marine Drugs 18 (4):212. doi: $10.3390 / \mathrm{md} 18040212$.

Ji, Y.-B., F. Dong, M. Yu, L. Qin, and D. Liu. 2013. Optimization of synthesis of seleno-Sargassum fusiforme (Harv.) Setch. Polysaccharide by response surface methodology, its characterization, and antioxidant activity. Journal of Chemistry 2013:1-9. doi: 10.1155/2013/493524.

Jiang, N., B. Li, X. Wang, X. Xu, X. Liu, W. Li, X. Chang, H. Li, and H. Qi. 2020. The antioxidant and antihyperlipidemic activities of phosphorylated polysaccharide from Ulva pertusa. International Journal of Biological Macromolecules 145:1059-65. doi: 10.1016/j. ijbiomac.2019.09.198

Jiao, G., G. Yu, J. Zhang, and H. S. Ewart. 2011. Chemical structures and bioactivities of sulfated polysaccharides from marine algae. Marine Drugs 9 (2):196-233. doi: 10.3390/md9020196.

Jin, W., D. Jiang, W. Zhang, C. Wang, K. Xia, F. Zhang, and R. J. Linhardt. 2020. Interactions of fibroblast growth factors with sulfated galactofucan from Saccharina japonica. International Journal of Biological Macromolecules 160:26-34. doi: 10.1016/j.ijbiomac.2020.05.183.

Jin, W., W. Zhang, J. Wang, S. Ren, N. Song, D. Duan, and Q. Zhang 2014. Characterization of laminaran and a highly sulfated polysaccharide from Sargassum fusiforme. Carbohydrate Research 385:58-64. doi: 10.1016/j.carres.2013.12.009.

Jönsson, M., Allahgholi, L. Roya, R. R. Sardari, G. O. Hreggviosson, and E. Nordberg Karlsson. 2020. Extraction and modification of macroalgal polysaccharides for current and next-generation applications. Molecules 25 (4). doi: 10.3390/molecules 25040930.

Jun, J. Y., M. J. Jung, I. H. Jeong, K. Yamazaki, Y. Kawai, and B. M. Kim. 2018. Antimicrobial and antibiofilm activities of sulfated polysaccharides from marine algae against dental plaque bacteria. Marine Drugs 16 (9). doi: 10.3390/md16090301.

Kadam, S. U., C. P. O'Donnell, D. K. Rai, M. B. Hossain, C. M. Burgess, D. Walsh, and B. K. Tiwari. 2015. Laminarin from Irish brown seaweeds Ascophyllum nodosum and Laminaria hyperborea: Ultrasound assisted extraction, characterization and bioactivity. Marine Drugs 13 (7):4270-80. doi: 10.3390/md13074270.

Kadam, S. U., B. K. Tiwari, and C. P. O'Donnell. 2015. Extraction, structure and biofunctional activities of laminarin from brown algae. International Journal of Food Science \& Technology 50 (1):24-31. doi: $10.1111 /$ ijfs. 12692 .

Karaki, N., A. Aljawish, C. Humeau, L. Muniglia, and J. Jasniewski. 2016. Enzymatic modification of polysaccharides: Mechanisms, properties, and potential applications: A review. Enzyme and Microbial Technology 90:1-18. doi: 10.1016/j.enzmictec.2016.04.004.

Karnjanapratum, S., and S. G. You. 2011. Molecular characteristics of sulfated polysaccharides from Monostroma nitidum and their in vitro anticancer and immunomodulatory activities. International Journal of Biological Macromolecules 48 (2):311-8. doi: 10.1016/j. ijbiomac.2010.12.002

Khajouei, R. A., J. Keramat, N. Hamdami, A.-V. Ursu, C. Delattre, C. Laroche, C. Gardarin, D. Lecerf, J. Desbrières, G. Djelveh, et al. 2018. Extraction and characterization of an alginate from the Iranian brown seaweed Nizimuddinia zanardini. International Journal of Biological Macromolecules 118 (Pt A):1073-81. doi: 10.1016/j.ijbiomac.2018.06.154.

Kidgell, J. T., S. M. Carnachan, M. Magnusson, R. J. Lawton, I. M. Sims, S. F. R. Hinkley, R. de Nys, and C. R. K. Glasson. 2021. Are all ulvans equal? A comparative assessment of the chemical and gelling properties of ulvan from blade and Filamentous ulva. Carbohydrate Polymers 264:118010. doi: 10.1016/j.carbpol.2021.118010.

Knouff, C., O. Briand, S. Lestavel, V. Clavey, M. Altenburg, and N. Maeda. 2004. Defective VLDL metabolism and severe atherosclerosis in mice expressing human apolipoprotein $\mathrm{E}$ isoforms but lacking 
the LDL receptor. Biochimica et Biophysica Acta 1684 (1-3):8-17. doi: 10.1016/j.bbalip.2004.03.004.

Kopplin, G., A. M. Rokstad, H. Mélida, V. Bulone, G. Skjåk-Braek, and F. Lillelund Aachmann. 2018. Structural Characterization of Fucoidan from Laminaria hyperborea: Assessment of Coagulation and Inflammatory Properties and Their Structure-Function Relationship. ACS Applied Bio Materials 1 (6):1880-92. doi: 10.1021/ acsabm. 8 b00436.

Kosanić, M., B. Ranković, and T. Stanojković. 2015. Biological activities of two macroalgae from Adriatic Coast of Montenegro. Saudi Journal of Biological Sciences 22 (4):390-7. doi: 10.1016/j. sjbs.2014.11.004.

Kraan, S. 2012. Algal polysaccharides, novel applications and outlook. Carbohydrates - Comprehensive Studies on Glycobiology and Glycotechnology 32:137-44. doi: 10.5772/51572.

Kravchenko, A. O., S. D. Anastyuk, V. P. Glazunov, E. V. Sokolova, V. V. Isakov, and I. M. Yermak. 2020. Structural characteristics of carrageenans of red alga Mastocarpus pacificus from Sea of Japan. Carbohydrate Polymers 229:115518. doi: 10.1016/j.carbpol.2019.115518.

Lahaye, M., and B. Ray. 1996. Cell-wall polysaccharides from the marine green. Carbohydrate Research 283 (283):161-73. doi: 10.1016/0008-6215(95)00407-6.

Lee, S.-H., C.-I. Ko, G. Ahn, S. You, J.-S. Kim, M. S. Heu, J. Kim, Y. Jee, and Y.-J. Jeon. 2012. Molecular characteristics and anti-inflammatory activity of the fucoidan extracted from Ecklonia cava. Carbohydrate Polymers 89 (2):599-606. doi: 10.1016/j.carbpol.2012.03.056.

Lee, W.-K., Y.-Y. Lim, A. T.-C. Leow, P. Namasivayam, J. Ong Abdullah, and C.-L. Ho. 2017. Biosynthesis of agar in red seaweeds: A review. Carbohydrate Polymers 164:23-30. doi: 10.1016/j.carbpol.2017.01.078.

Li, B., S. Liu, R. Xing, K. Li, R. Li, Y. Qin, X. Wang, Z. Wei, and P. Li. 2013. Degradation of sulfated polysaccharides from Enteromorpha prolifera and their antioxidant activities. Carbohydrate Polymers 92 (2):1991-6. doi: 10.1016/j.carbpol.2012.11.088

Li, L., R. Ni, Y. Shao, and S. Mao. 2014. Carrageenan and its applications in drug delivery. Carbohydrate Polymers 103 (1):1-11. doi: 10.1016/j.carbpol.2013.12.008.

Li, P., S. Wen, K. Sun, Y. Zhao, and Y. Chen. 2018. Structure and bioactivity screening of a low molecular weight ulvan from the green alga Ulothrix flacca. Marine Drugs 16 (8):281. doi: 10.3390/ md16080281.

Li, S., Q. Xiong, X. Lai, X. Li, M. Wan, J. Zhang, Y. Yan, M. Cao, L. $\mathrm{Lu}$, J. Guan, et al. 2016. Molecular modification of polysaccharides and resulting bioactivities. Comprehensive Reviews in Food Science and Food Safety 15 (2):237-50. doi: 10.1111/1541-4337.12161.

Li, S., D. Lei, Z. Zhu, J. Cai, M. Manzoli, L. Jicsinszky, G. Grillo, and G. Cravotto. 2021. Ultrasonics sonochemistry complexation of maltodextrin-based inulin and green tea polyphenols via different ultrasonic pretreatment. Ultrasonics Sonochemistry 74 (68):105568. doi: $10.1016 /$ j.ultsonch.2021.105568.

Li, S., and N. P. Shah. 2016. Characterization, anti-inflammatory and antiproliferative activities of natural and sulfonated exo-polysaccharides from Streptococcus thermophilus ASCC 1275. Journal of Food Science 81 (5):M1167-M1176. doi: 10.1111/1750-3841.13276.

Li, W., K. Wang, N. Jiang, X. Liu, M. Wan, X. Chang, D. Liu, H. Qi, and S. Liu. 2018. Antioxidant and antihyperlipidemic activities of purified polysaccharides from Ulva pertusa. Journal of Applied Phycology 30 (4):2619-27. doi: 10.1007/s10811-018-1475-5.

Li, Y.-T., Y.-F. Huo, F. Wang, C. Wang, Q. Zhu, Y.-B. Wang, L.-L. Fu, and T. Zhou. 2020. Improved antioxidant and immunomodulatory activities of enzymatically degraded Porphyra haitanensis polysaccharides. Journal of Food Biochemistry 44 (5):e13189. doi: 10.1111/ jfbc. 13189.

Liang, W., X. Mao, X. Peng, and S. Tang. 2014. Effects of sulfate group in red seaweed polysaccharides on anticoagulant activity and cytotoxicity. Carbohydrate Polymers 101 (1):776-85. doi: 10.1016/j.carbpol.2013.10.010.
Lin, G.-p., D.-s. Wu, X.-w. Xiao, Q.-y. Huang, H.-b. Chen, D. Liu, H.-q. Fu, X.-h. Chen, and C. Zhao. 2020. Structural characterization and antioxidant effect of green alga Enteromorpha prolifera polysaccharide in Caenorhabditis elegans via modulation of MicroRNAs. International Journal of Biological Macromolecules 150:1084-92. doi: 10.1016/j.ijbiomac.2019.10.114.

Liu, H., M. Geng, X. Xin, F. Li, Z. Zhang, J. Li, and J. Ding. 2005. Multiple and multivalent interactions of novel anti-AIDS drug candidates, sulfated polymannuronate (SPMG)-derived oligosaccharides, with Gp120 and their anti-HIV activities. Glycobiology 15 (5):50110. doi: $10.1093 /$ glycob/cwi031.

Liu, J., X. Zhan, J. Wan, Y. Wang, and C. Wang. 2015. Review for carrageenan-based pharmaceutical biomaterials: Favourable physical features versus adverse biological effects. Carbohydrate Polymers 121:27-36. doi: 10.1016/j.carbpol.2014.11.063.

Liu, M., Y. Liu, M.-J. Cao, G.-M. Liu, Q. Chen, L. Sun, and H. Chen. 2017. Antibacterial activity and mechanisms of depolymerized fucoidans isolated from Laminaria japonica. Carbohydrate Polymers 172:294-305. doi: 10.1016/j.carbpol.2017.05.060.

Liu, X., B. Liu, X. Wei, Y. Shi, A. Jia, and C. Wang. 2020. Structural elucidation of fucoidans from Sargassum pallidum. Journal of Applied Phycology 33 (1):523-31. doi: 10.1007/s10811-020-02287-x.

Lorbeer, A. J., S. Charoensiddhi, J. Lahnstein, C. Lars, C. M. M. Franco, V. Bulone, and W. Zhang. 2017. Sequential extraction and characterization of fucoidans and alginates from Ecklonia radiata, Macrocystis pyrifera, Durvillaea potatorum, and Seirococcus axillaris. Journal of Applied Phycology 29 (3):1515-26. doi: 10.1007/ s10811-016-0990-5.

Lourenço-Lopes, C., M. Fraga-Corral, C. Jimenez-Lopez, A. G. Pereira, P. Garcia-Oliveira, M. Carpena, M. A. Prieto, and J. Simal-Gandara. 2020. Metabolites from macroalgae and its applications in the cosmetic industry: A circular economy approach. Resources 9 (9):101. doi: 10.3390/RESOURCES9090:101.

Madany, M. A., M. S. Abdel-Kareem, A. K. Al-Oufy, M. Haroun, and S. A. Sheweita. 2021. The biopolymer ulvan from Ulva fasciata: Extraction towards nanofibers fabrication. International Journal of Biological Macromolecules 177:401-12. doi: 10.1016/j.ijbiomac.2021.02.047.

Mak, W., N. Hamid, T. Liu, J. Lu, and W. L. White. 2013. Fucoidan from New Zealand Undaria pinnatifida: Monthly variations and determination of antioxidant activities. Carbohydrate Polymers 95 (1):606-14. doi: 10.1016/j.carbpol.2013.02.047.

Manikandan, R., D. Parimalanandhini, K. Mahalakshmi, M. Beulaja, M. Arumugam, S. Janarthanan, S. Palanisamy, S. You, and N. M. Prabhu. 2020. Studies on isolation, characterization of fucoidan from brown algae Turbinaria decurrens and evaluation of it's in vivo and in vitro anti-inflammatory activities. International Journal of Biological Macromolecules 160:1263-76. doi: 10.1016/j.ijbiomac.2020.05.152.

Mao, W., X. Zang, Y. Li, and H. Zhang. 2006. Sulfated polysaccharides from marine green algae Ulva conglobata and their anticoagulant activity. Journal of Applied Phycology 18 (1):9-14. doi: 10.1007/ s10811-005-9008-4.

Martín, L. A., María, C. Rodríguez, María, C. Matulewicz, E. N. Fissore, L. N. Gerschenson, and P. I. Leonardi. 2013. Seasonal variation in agar composition and properties from Gracilaria gracilis (Gracilariales, Rhodophyta) of the Patagonian Coast of Argentina. Phycological Research 61 (3):163-71. doi: 10.1111/pre.12000.

Martinez-Garcia, M., M. C. A. Stuart, and M. J. E. C. van der Maarel. 2016. Characterization of the highly branched glycogen from the thermoacidophilic red microalga Galdieria sulphuraria and comparison with other glycogens. International Journal of Biological Macromolecules 89:12-8. doi: 10.1016/j.ijbiomac.2016.04.051.

McKim, J. M., J. A. Willoughby, W. R. Blakemore, and M. L. Weiner 2019. Clarifying the confusion between poligeenan, degraded carrageenan, and carrageenan: A review of the chemistry, nomenclature, and in vivo toxicology by the oral route. Critical Reviews in Food Science and Nutrition 59 (19):3054-73. doi: 10.1080/10408398.2018.1481822. 
Menshova, R. V., S. D. Anastyuk, S. P. Ermakova, N. M. Shevchenko, V. I. Isakov, and T. N. Zvyagintseva. 2015. Structure and anticancer activity in vitro of sulfated galactofucan from brown alga Alaria Angusta. Carbohydrate Polymers 132:118-25. doi: 10.1016/j.carbpol.2015.06.020.

Mohammed, A. S. A., M. Naveed, and N. Jost. 2021. Polysaccharides; classification, chemical properties, and future perspective applications in fields of pharmacology and biological medicine (a review of current applications and upcoming potentialities). Journal of Polymers and the Environment 29 (8):2359-71. doi: 10.1007/ s10924-021-02052-2.

Morelli, A., and F. Chiellini. 2010. Ulvan as a new type of biomaterial from renewable resources: Functionalization and hydrogel preparation. Macromolecular Chemistry and Physics 211 (7):821-32. doi: 10.1002/macp.200900562.

Nauts, H. C., W. E. Swift, and B. L. Coley. 1946. The treatment of malignant tumors by bacterial toxins as developed by the Late William B. Coley, M.D., reviewed in the light of modern research. Cancer Research 6 (4):205-16.

Navarro del Hierro, J., A. Gutiérrez-Docio, P. Otero, G. Reglero, and D. Martin. 2020. Characterization, antioxidant activity, and inhibitory effect on pancreatic lipase of extracts from the edible insects Acheta domesticus and Tenebrio molitor. Food Chemistry 309:125742. doi: $10.1016 /$ j.foodchem.2019.125742.

Nguyen, T. T., M. D. Mikkelsen, V. Ha Nguyen Tran, V. T. D. Trang, N. Rhein-Knudsen, J. Holck, A. B. Rasin, H. T. T. Cao, T. Tran Thi, A. S. Van, et al. 2020. Enzyme-assisted fucoidan extraction from brown macroalgae Fucus distichus Subsp. evanescens and Saccharina latissima. Marine Drugs 18 (6):296. doi: 10.3390/md18060296.

Okolie, C. L., B. Mason, A. Mohan, N. Pitts, and C. C. Udenigwe. 2019. The comparative influence of novel extraction technologies on in vitro prebiotic-inducing chemical properties of fucoidan extracts from Ascophyllum nodosum. Food Hydrocolloids 90:462-71. doi: 10.1016/j.foodhyd.2018.12.053.

Olatunji, O. 2020. Starch. In Aquatic biopolymers, 1st ed., ed. O. Olatunji, 287-310. Cham: Springer. doi: 10.1007/978-3-030-34709-3_13.

Oliveira, F. F. B. d., R. D. Bingana, P. A. F. Morais, S. R. B. D. Oliveira, A. L. D. R. Barbosa, L. d. S. Chaves, P. d. O. C. Alencar, P. M. G. Soares, M. H. L. P. Souza, A. L. P. Freitas, et al. 2020. Sulfated polysaccharide from Gracilaria caudata reduces hypernociception and inflammatory response during arthritis in rodents. International Journal of Biological Macromolecules 161:1061-9. doi: 10.1016/j. ijbiomac.2020.06.060.

Otero, P., A. Gutierrez-Docio, J. Navarro del Hierro, G. Reglero, and D. Martin. 2020. Extracts from the edible insects Acheta domesticus and Tenebrio molitor with improved fatty acid profile due to ultrasound assisted or pressurized liquid extraction. Food Chemistry 314:126200. doi: 10.1016/j.foodchem.2020.126200.

Otero, P., M. I. López-Martínez, and M. R. García-Risco. 2019. Application of pressurized liquid extraction (PLE) to obtain bioactive fatty acids and phenols from Laminaria ochroleuca collected in Galicia (NW Spain). Journal of Pharmaceutical and Biomedical Analysis 164:86-92. doi: 10.1016/j.jpba.2018.09.057.

Otero, P., S. E. Quintana, G. Reglero, T. Fornari, and M. R. García-Risco. 2018. Pressurized liquid extraction (PLE) as an innovative green technology for the effective enrichment of Galician algae extracts with high quality fatty acids and antimicrobial and antioxidant properties. Marine Drugs 16 (5). doi: 10.3390/md16050156.

Owens, A. P., and N. Mackman. 2010. Tissue factor and thrombosis: The clot starts here. Thrombosis and Haemostasis 104 (3):432-9. doi: 10.1160/TH09-11-0771.

Paluck, S. J., T. H. Nguyen, and H. D. Maynard. 2016. Heparin-mimicking polymers: Synthesis and biological applications. Biomacromolecules 17 (11):3417-40. doi: 10.1021/acs.biomac.6b01147.

Pangestuti, R., and D. Kurnianto. 2017. Green seaweeds-derived polysaccharides ulvan: Occurrence, medicinal value and potential applications. Seaweed polysaccharides: Isolation, biological and biomedical applications. Elsevier Inc. doi: 10.1016/B978-0-12-809816-5.00011-6.

Patil, N. P., V. Le, A. D. Sligar, L. Mei, D. Chavarria, E. Y. Yang, and A. B. Baker. 2018. Algal polysaccharides as therapeutic agents for atherosclerosis. Frontiers in Cardiovascular Medicine 5:1-18. doi:10.3389/fcvm.2018.00:153

Pereira, A. G., P. Otero, J. Echave, A. Carreira-Casais, F. Chamorro, N. Collazo, A. Jaboui, C. Lourenço-Lopes, J. Simal-Gandara, and M. A. Prieto. 2021. Xanthophylls from the sea: Algae as source of bioactive carotenoids. Marine Drugs 19 (4):188.

Polikovsky, M., F. Fernand, M. Sack, W. Frey, G. Müller, and A. Golberg. 2016. Towards marine biorefineries: Selective proteins extractions from marine macroalgae Ulva with pulsed electric fields. Innovative Food Science \& Emerging Technologies 37:194-200. doi: 10.1016/j.ifset.2016.03.013

Ponce, N. M. A., Flores, M. L. Carlos, A. Pujol, M. B. Becerra, D. A Navarro, O. Córdoba, E. B. Damonte, and C. A. Stortz. 2019. Fucoidans from the phaeophyta Scytosiphon lomentaria: Chemical analysis and antiviral activity of the galactofucan component. Carbohydrate Research 478:18-24. doi: 10.1016/j.carres.2019.04.004.

Prabhu, M., A. Chemodanov, R. Gottlieb, M. Kazir, O. Nahor, M. Gozin, A. Israel, Y. D. Livney, and A. Golberg. 2019. Starch from the sea: The green macroalga Ulva ohnoi as a potential source for sustainable starch production in the marine biorefinery. Algal Research 37:215-27. doi: 10.1016/j.algal.2018.11.007.

Prabhu, M. S., K. Levkov, Y. D. Livney, A. Israel, and A. Golberg. 2019. High-voltage pulsed electric field preprocessing enhances extraction of starch, proteins, and ash from marine macroalgae Ulva ohnoi. ACS Sustainable Chemistry \& Engineering 7 (20):17453-63. doi: 10.1021/acssuschemeng.9b04669.

Qi, H., X. Liu, J. Zhang, Y. Duan, X. Wang, and Q. Zhang. 2012. Synthesis and antihyperlipidemic activity of acetylated derivative of ulvan from Ulva pertusa. International Journal of Biological Macromolecules 50 (1):270-2. doi: 10.1016/j.ijbiomac.2011.11.006.

Qi, J., and S. M. Kim. 2017. Characterization and immunomodulatory activities of polysaccharides extracted from green alga Chlorella ellipsoidea. International Journal of Biological Macromolecules 95:106-14. doi: 10.1016/j.ijbiomac.2016.11.039.

Qin, L., M. He, Y. Yang, Z. Fu, C. Tang, Z. Shao, J. Zhang, and W. Mao. 2020. Anticoagulant-active sulfated arabinogalactan from Chaetomorpha linum: Structural characterization and action on coagulation factors. Carbohydrate Polymers 242:116394. doi: 10.1016/j.carbpol.2020.116394.

Qiu, S., J. Chen, T. Qin, Y. Hu, D. Wang, Q. Fan, C. Zhang, X. Chen, X. Chen, C. Liu, et al. 2014. Effects of selenylation modification on immune-enhancing activity of garlic polysaccharide. PLoS One 9 (1):e86377. doi: 10.1371/journal.pone.0086377.

Quinderé, A. L. G., G. R. C. Santos, S. N. M. C. G. Oliveira, B. F. Glauser, B. P. Fontes, I. N. L. Queiroz, N. M. B. Benevides, V. H. Pomin, and P. A. S. Mourão. 2014. Is the antithrombotic effect of sulfated galactans independent of serpin?Journal of Thrombosis and Haemostasis: JTH 12 (1):43-53. doi: 10.1111/jth.12448.

Rahimi, F., M. Tabarsa, and M. Rezaei. 2016. Ulvan from green algae Ulva intestinalis: Optimization of ultrasound-assisted extraction and antioxidant activity. Journal of Applied Phycology 28 (5):2979-90. doi: 10.1007/s10811-016-0824-5.

Ray, B. 2006. Polysaccharides from Enteromorpha compressa: Isolation, purification and structural features. Carbohydrate Polymers 66 (3):408-16. doi: 10.1016/j.carbpol.2006.03.027.

Reis, S. E., R. G. C. Andrade, C. M. Accardo, L. F. Maia, L. F. C. Oliveira, H. B. Nader, J. A. K. Aguiar, and V. P. Medeiros. 2020. Influence of sulfated polysaccharides from Ulva lactuca L. upon Xa and IIa coagulation factors and on venous blood clot formation. Algal Research 45:101750. doi: 10.1016/j.algal.2019.101750.

Ren, B., C. Chen, C. Li, X. Fu, L. You, and R. H. Liu. 2017 Optimization of microwave-assisted extraction of Sargassum thunbergii polysaccharides and its antioxidant and hypoglycemic activities. Carbohydrate Polymers 173:192-201. doi: 10.1016/j.carbpol.2017.05.094.

Rioux, L. E., S. L. Turgeon, and M. Beaulieu. 2007. Characterization of polysaccharides extracted from brown seaweeds. Carbohydrate Polymers 69 (3):530-7. doi: 10.1016/j.carbpol.2007.01.009.

Rioux, L.-E., S. L. Turgeon, and M. Beaulieu. 2010. Structural characterization of laminaran and galactofucan extracted from the brown 
seaweed Saccharina longicruris. Phytochemistry 71 (13):1586-95. doi: $10.1016 /$ j.phytochem.2010.05.021.

Robic, A., D. Bertrand, J. F. Sassi, Y. Lerat, and M. Lahaye. 2009. Determination of the chemical composition of ulvan, a cell wall polysaccharide from Ulva Spp. (Ulvales, Chlorophyta) by FT-IR and chemometrics. Journal of Applied Phycology 21 (4):451-6. doi: 10.1007/s10811-008-9390-9.

Robic, A., J. F. Sassi, and M. Lahaye. 2008. Impact of stabilization treatments of the green seaweed Ulva rotundata (Chlorophyta) on the extraction yield, the physico-chemical and rheological properties of ulvan. Carbohydrate Polymers 74 (3):344-52. doi: 10.1016/j.carbpol.2008.02.020.

Robic, A., C. Gaillard, J.-F. Sassi, Y. Lerat, and M. Lahaye. 2009. Ultrastructure of ulvan: A polysaccharide from green seaweeds. Biopolymers 91 (8):652-64. doi: 10.1002/bip.21195.

Robin, A., M. Sack, A. Israel, W. Frey, G. Müller, and A. Golberg. 2018 Deashing macroalgae biomass by pulsed electric field treatment. Bioresource Technology 255:131-9. doi: 10.1016/j.biortech.2018.01.089.

Rodríguez, M. C., M. C. Matulewicz, M. D. Noseda, D. R. B. Ducatti, and P. I. Leonardi. 2009. Agar from Gracilaria gracilis (Gracilariales, Rhodophyta) of the Patagonic coast of Argentina-content, structure and physical properties. Bioresource Technology 100 (3):1435-41. doi: 10.1016/j.biortech.2008.08.025.

Safavi, S. V., A. A. Kenari, M. Tabarsa, and M. Esmaeili. 2019. Effect of sulfated polysaccharides extracted from marine macroalgae (Ulva intestinalis and Gracilariopsis persica) on growth performance, fatty acid profile, and immune response of rainbow trout (Oncorhynchus mykiss). Journal of Applied Phycology 31 (6):4021-35. doi: 10.1007/ s10811-019-01902-w.

Salehi, P., Y. Dashti, F. M. Tajabadi, F. Safidkon, and R. Rabei. 2011. Structural and compositional characteristics of a sulfated galactan from the red alga Gracilariopsis persica. Carbohydrate Polymers 83 (4):1570-4. doi: 10.1016/j.carbpol.2010.10.017.

Saluri, M., K. Liis Kaljuvee, T. Paalme, I. Reile, and R. Tuvikene. 2021. Structural variability and rheological properties of furcellaran. Food Hydrocolloids 111:106227. doi: 10.1016/j.foodhyd.2020.106227.

Sanjeewa, K. K A., I. P. S. Fernando, S.-Y. Kim, H.-S. Kim, G. Ahn, Y. Jee, and Y.-J. Jeon. 2018. In vitro and in vivo anti-inflammatory activities of high molecular weight sulfated polysaccharide; containing fucose separated from Sargassum horneri: Short communication. International Journal of Biological Macromolecules 107:803-7. doi: 10.1016/j.ijbiomac.2017.09.050.

Saravana, P. S., Y.-J. Cho, Y.-B. Park, H.-C. Woo, and B.-S. Chun. 2016. Structural, antioxidant, and emulsifying activities of fucoidan from Saccharina japonica using pressurized liquid extraction. Carbohydrate Polymers 153:518-25. doi: 10.1016/j.carbpol.2016.08.014.

Saravana, P. S., Y. N. Cho, M. P. Patil, Y. J. Cho, G. D. Kim, Y. B. Park, H. C. Woo, and B. S. Chun. 2018. Hydrothermal degradation of seaweed polysaccharide: Characterization and biological activities. Food Chemistry 268:179-87. doi: 10.1016/j.foodchem.2018.06.077.

Saravana, P. S., Y. N. Cho, H. C. Woo, and B. S. Chun. 2018. Green and efficient extraction of polysaccharides from brown seaweed by adding deep eutectic solvent in subcritical water hydrolysis. Journal of Cleaner Production 198:1474-84. doi: 10.1016/j.jclepro.2018.07.151.

Saravana, P. S., A. Tilahun, C. Gerenew, V. D. Tri, N. H. Kim, G. D. Kim, H. C. Woo, and B. S. Chun. 2018. Subcritical water extraction of fucoidan from Saccharina japonica: Optimization, characterization and biological studies. Journal of Applied Phycology 30 (1):579-90. doi: 10.1007/s10811-017-1245-9.

Schiener, P., K. D. Black, M. S. Stanley, and D. H. Green. 2015. The seasonal variation in the chemical composition of the kelp species Laminaria digitata, Laminaria hyperborea, Saccharina latissima and Alaria esculenta. Journal of Applied Phycology 27 (1):363-73. doi: 10.1007/s10811-014-0327-1.

Shang, X. c., D. Chu, J. x. Zhang, Y. f. Zheng, and Y. Li. 2021. Microwave-assisted extraction, partial purification and biological activity in vitro of polysaccharides from Bladder-Wrack (Fucus vesiculosus) by using deep eutectic solvents. Separation and Purification Technology 259:118169. doi: 10.1016/j.seppur. 2020.118169 .
Shanmugam, M., and K. H. Mody. 2000. Heparinoid-active sulphated polysaccharides from marine algae as potential blood anticoagulant agents. Current Science 79 (12):1672-83.

Shao, L.-L., J. Xu, M.-J. Shi, X.-L. Wang, Y.-T. Li, L.-M. Kong, R. C. Hider, and T. Zhou. 2017. Preparation, antioxidant and antimicrobial evaluation of hydroxamated degraded polysaccharides from Enteromorpha prolifera. Food Chemistry 237:481-7. doi: 10.1016/j. foodchem.2017.05.119.

Shao, P., X. Chen, and P. Sun. 2014. Chemical characterization, antioxidant and antitumor activity of sulfated polysaccharide from Sargassum horneri. Carbohydrate Polymers 105 (1):260-9. doi: 10.1016/j.carbpol.2014.01.073.

Shao, P., M. Qin, L. Han, and P. Sun. 2014. Rheology and characteristics of sulfated polysaccharides from chlorophytan seaweeds Ulva fasciata. Carbohydrate Polymers 113:365-72. doi: 10.1016/j.carbpol.2014.07.008

Shen, P., Z. Yin, G. Qu, and C. Wang. 2018. Fucoidan and its health benefits. Bioactive seaweeds for food applications: Natural ingredients for healthy diets. Amsterdam: Elsevier Inc. doi: 10.1016/ B978-0-12-813312-5.00011-X.

Shi, M.-J., X. Wei, J. Xu, B.-J. Chen, D.-Y. Zhao, S. Cui, and T. Zhou. 2017. Carboxymethylated degraded polysaccharides from Enteromorpha prolifera: Preparation and in vitro antioxidant activity. Food Chemistry 215:76-83. doi: 10.1016/j.foodchem.2016.07.151.

Shimonaga, T., M. Konishi, Y. Oyama, S. Fujiwara, A. Satoh, N. Fujita, C. Colleoni, A. Buléon, J.-L. Putaux, S. G. Ball, et al. 2008. Variation in storage alpha-glucans of the porphyridiales (Rhodophyta). Plant \& Cell Physiology 49 (1):103-16. doi: 10.1093/pcp/pcm 172.

Shin, H. J., S. J. Oh, S. I. Kim, H. Won Kim, and J.-H. Son. 2009 Conformational characteristics of B -glucan in laminarin probed by terahertz spectroscopy. Applied Physics Letters 94 (11):111911-4. doi: $10.1063 / 1.3100778$.

Skriptsova, A. V., N. M. Shevchenko, T. N. Zvyagintseva, and T. I. Imbs. 2010. Monthly changes in the content and monosaccharide composition of fucoidan from Undaria pinnatifida (Laminariales, Phaeophyta). Journal of Applied Phycology 22 (1):79-86. doi: 10.1007/ s10811-009-9438-5.

Sousa, A. M. M., C. M. R. Rocha, and M. P. Gonçalves. 2020. Agar In Handbook of hydrocolloids, ed. G. O. Phillips and P. A. Williams, 3rd ed., 731-65. Amsterdam: Woodhead Publishing, Elsevier. doi: 10.1016/B978-0-12-820104-6.00014-0.

Souza, B. W. S., M. A. Cerqueira, A. I. Bourbon, A. C. Pinheiro, J. T. Martins, J. A. Teixeira, M. A. Coimbra, and A. A. Vicente. 2012. Chemical characterization and antioxidant activity of sulfated polysaccharide from the red seaweed Gracilaria birdiae. Food Hydrocolloids. 27 (2):287-92. doi: 10.1016/j.foodhyd.2011.10.005.

Spicer, S. E., J. M. M. Adams, D. S. Thomas, J. A. Gallagher, and A. L. Winters. 2017. Novel rapid method for the characterisation of polymeric sugars from macroalgae. Journal of Applied Phycology 29 (3):1507-13. doi: 10.1007/s10811-016-0995-0.

Stephanie, B., D. Eric, F. M. Sophie, B. Christian, and G. Yu. 2010. Carrageenan from Solieria chordalis (Gigartinales): Structural analysis and immunological activities of the low molecular weight fractions. Carbohydrate Polymers 81 (2):448-60. doi: 10.1016/j.carbpol.2010.02.046.

Subash, A., G. Veeraraghavan, V. K. Sali, M. Bhardwaj, and H. R. Vasanthi. 2016. Attenuation of inflammation by marine algae Turbinaria ornata in cotton pellet induced granuloma mediated by fucoidan like sulphated polysaccharide. Carbohydrate Polymers 151:1261-8. doi: 10.1016/j.carbpol.2016.06.077.

Sudharsan, S., N. Subhapradha, P. Seedevi, V. Shanmugam, P. Madeswaran, A. Shanmugam, and A. Srinivasan. 2015. Antioxidant and anticoagulant activity of sulfated polysaccharide from Gracilaria debilis (Forsskal). International Journal of Biological Macromolecules 81:1031-8. doi: 10.1016/j.ijbiomac.2015.09.046.

Sun, X., Yu Zhong, H. Luo, and Y. Yang. 2017. Selenium-containing polysaccharide-protein complex in se-enriched Ulva fasciata induces mitochondria-mediated apoptosis in A549 human lung cancer cells. Marine Drugs 15 (7):215. doi: 10.3390/md15070215. 
Sun, Y., X. Chen, S. Liu, H. Yu, R. Li, X. Wang, Y. Qin, and P. Li. 2018. Preparation of low molecular weight Sargassum fusiforme polysaccharide and its anticoagulant activity. Journal of Oceanology and Limnology 36 (3):882-91. doi: 10.1007/s00343-018-7089-6.

Sun, Y., Z. Liu, S. Song, B. Zhu, L. Zhao, J. Jiang, N. Liu, J. Wang, and X. Chen. 2020. Anti-inflammatory activity and structural identification of a sulfated polysaccharide CLGP4 from Caulerpa lentillifera. International Journal of Biological Macromolecules 146:931-8. doi: 10.1016/j.ijbiomac.2019.09.216.

Tabarsa, M., S. G. You, E. Hashem Dabaghian, and U. Surayot. 2018. Water-soluble polysaccharides from Ulva intestinalis: Molecular properties, structural elucidation and immunomodulatory activities. Journal of Food and Drug Analysis 26 (2):599-608. doi: 10.1016/j. jfda.2017.07.016.

Taghizadeh, E., R. Mardani, D. Rostami, H. Taghizadeh, H. Bazireh, and S. M. G. Hayat. 2019. Molecular mechanisms, prevalence, and molecular methods for familial combined hyperlipidemia disease: A review. Journal of Cellular Biochemistry 120 (6):8891-8. doi: $10.1002 /$ jcb. 28311 .

Tang, W., D. Liu, J. Yi Yin, and S. P. Nie. 2020. Consecutive and progressive purification of food-derived natural polysaccharide: Based on material, extraction process and crude polysaccharide. Trends in Food Science \& Technology 99:76-87. doi: 10.1016/j.tifs.2020.02.015.

Tanna, B., and A. Mishra. 2019. Nutraceutical potential of seaweed polysaccharides: Structure, bioactivity, safety, and toxicity. Comprehensive Reviews in Food Science and Food Safety 18 (3):81731. doi: 10.1111/1541-4337.12441.

Teruya, T., T. Konishi, and S. Uechi. 2007. Anti-proliferative activity of oversulfated fucoidan from commercially cultured Cladosiphon okamuranus TOKIDA in U937 cells §. International Journal of Biological Macromolecules 41 (3):221-6. doi: 10.1016/j.ijbiomac.2007.02.010

Vázquez-Delfín, E., D. Robledo, and Y. Freile-Pelegrín. 2014. Microwave-assisted extraction of the carrageenan from Hypnea musciformis (Cystocloniaceae, Rhodophyta). Journal of Applied Phycology 26 (2):901-7. doi: 10.1007/s10811-013-0090-8.

Vázquez-Rodríguez, B., J. A. Gutiérrez-Uribe, M. Antunes-Ricardo, L. Santos-Zea, and L. E. Cruz-Suárez. 2020. Ultrasound-assisted extraction of phlorotannins and polysaccharides from Silvetia compressa (Phaeophyceae). Journal of Applied Phycology 32 (2):1441-53. doi: 10.1007/s10811-019-02013-2.

Wang, J., Q. Zhang, Z. Zhang, and Z. Li. 2008. Antioxidant activity of sulfated polysaccharide fractions extracted from Laminaria japonica. International Journal of Biological Macromolecules 42 (2):12732. doi: 10.1016/j.ijbiomac.2007.10.003.

Wang, L., J. Y. Oh, J. Hwang, J. Y. Ko, Y.-j. Jeon, and B. Ryu. 2019. In vitro and in vivo antioxidant activities of polysaccharides isolated from celluclast-assisted extract of an edible brown seaweed, Sargassum fulvellum. Antioxidants 8:493. doi: 10.3390/antiox8100493.

Wang, L., J. Y. Oh, J. G. Je, T. U. Jayawardena, Y.-S. Kim, J. Y. Ko, X. Fu, and Y.-J. Jeon. 2020. Protective effects of sulfated polysaccharides isolated from the enzymatic digest of Codium fragile against hydrogen peroxide-induced oxidative stress in in vitro and in vivo models. Algal Research 48:101891. 101891. doi: 10.1016/j.algal.2020.101891.

Wang, Q., Y. Zuo, T. Chen, W. Zheng, and Y. Yang. 2019. Effects of selenium on antioxidant enzymes and photosynthesis in the edible seaweed Gracilaria lemaneiformis. Journal of Applied Phycology 31 (2):1303-10. doi: 10.1007/s10811-018-1647-3.

Wang, S.-H., C.-Y. Huang, C.-Y. Chen, C.-C. Chang, C.-Y. Huang, C.-D. Dong, and J.-S. Chang. 2020. Structure and biological activity analysis of fucoidan isolated from Sargassum siliquosum. ACS Omega 5 (50):32447-55. doi: 10.1021/acsomega.0c04591.

Wang, S. H., C. Y. Huang, C. Y. Chen, C. C. Chang, C. Y. Huang, C. D. Dong, and J. S. Chang. 2021. Isolation and purification of brown algae fucoidan from Sargassum siliquosum and the analysis of anti-lipogenesis activity. Biochemical Engineering Journal 165:107798. doi: $10.1016 /$ j.bej.2020.107798.

Wang, X., D. Duan, and X. Fu. 2016. Enzymatic desulfation of the red seaweeds agar by Marinomonas arylsulfatase. International Journal of Biological Macromolecules 93 (Pt A):600-8. doi: 10.1016/j. ijbiomac.2016.08.031.
Wang, Y., S. Luo, Z. Xu, L. Liu, S. Feng, T. Chen, L. Zhou, M. Yuan, Y. Huang, and C. b. Ding. 2021. The potential antioxidant ability of hydroxytyrosol on Caenorhabditis elegans against oxidative damage via the insulin signaling pathway. Arabian Journal of Chemistry 14 (6):103149. doi: 10.1016/j.arabjc.2021.103149.

Wen, W., Q. Si, Q. Yang, S. Min, H. Xiao, L. Wang, Y. Zhu, and T. Zhou. 2021. Enzymatic degradation, antioxidant and immunoregulatory activities of polysaccharides from brown algae Sargassum fusiforme. Journal of Food Measurement and Characterization 15 (2):1960-72. doi: 10.1007/s11694-020-00776-8.

Xiao, H., X. Fu, C. Cao, C. Li, C. Chen, and Q. Huang. 2019. Sulfated modification, characterization, antioxidant and hypoglycemic activities of polysaccharides from Sargassum pallidum. International Journal of Biological Macromolecules 121:407-14. doi: 10.1016/j. ijbiomac.2018.09.197.

Xie, L., M. Shen, Y. Hong, H. Ye, L. Huang, and J. Xie. 2020. Chemical modifications of polysaccharides and their anti-tumor activities. Carbohydrate Polymers 229:115436. doi: 10.1016/j.carbpol.2019.115436.

Xie, X. T., X. Zhang, Y. Liu, X. Q. Chen, and K. L. Cheong. 2020. Quantification of 3,6-anhydro-galactose in red seaweed polysaccharides and their potential skin-whitening activity. 3 Biotech 10 (4):189. doi: 10.1007/s13205-020-02175-8.

Xu, J., L. L. Xu, Q. W. Zhou, S. X. Hao, T. Zhou, and H. J. Xie. 2016 Enhanced in vitro antioxidant activity of polysaccharides from Enteromorpha prolifera by enzymatic degradation. Journal of Food Biochemistry 40 (3):275-83. doi: 10.1111/jfbc.12218.

Xu, S.-Y., X. Huang, and K.-L. Cheong. 2017. Recent advances in marine algae polysaccharides: Isolation, structure, and activities. Marine Drugs 15 (12):388. doi: 10.3390/md15120388.

Yaich, H., A. Ben, F. Abbes, M. Bouaziz, S. Besbes, A. Richel, C. Blecker, H. Attia, and H. Garna. 2017. Effect of extraction procedures on structural, thermal and antioxidant properties of Ulvan from Ulva lactuca collected in Monastir Coast. International Journal of Biological Macromolecules 105 (Pt 2):1430-9. doi: 10.1016/j.ijbiomac.2017.07.141.

Yaich, H., H. Garna, S. Besbes, J. P. Barthélemy, M. Paquot, C. Blecker, and H. Attia. 2014. Impact of extraction procedures on the chemical, rheological and textural properties of ulvan from Ulva lactuca of Tunisia Coast. Food Hydrocolloids. 40:53-63. doi: 10.1016/j.foodhyd.2014.02.002.

Yermak, I. M., A. O. Barabanova, D. L. Aminin, V. N. Davydova, E. V. Sokolova, T. F. Solov'Eva, Y. H. Kim, and K. S. Shin. 2012. Effects of structural peculiarities of carrageenans on their immunomodulatory and anticoagulant activities. Carbohydrate Polymers 87 (1):713-20. doi: 10.1016/j.carbpol.2011.08.053

Youssouf, L., L. Lallemand, P. Giraud, F. Soulé, A. Bhaw-Luximon, O. Meilhac, C. L. D'Hellencourt, D. Jhurry, and J. Couprie. 2017. Ultrasound-assisted extraction and structural characterization by NMR of alginates and carrageenans from seaweeds. Carbohydrate Polymers 166:55-63. doi: 10.1016/j.carbpol.2017.01.041.

Yu, G., B. Yang, W. Ren, X. Zhao, J. Zhang, and C. Barrow. 2007. A comparative analysis of four kinds of polysaccharides purified from Furcellaria lumbricalis. Journal of Ocean University of China 6 (1):16-20. doi: 10.1007/s11802-007-0016-7.

Yuan, Y., X. Xu, C. Jing, P. Zou, C. Zhang, and Y. Li. 2018. Microwave assisted hydrothermal extraction of polysaccharides from Ulva prolifera: Functional properties and bioactivities. Carbohydrate Polymers 181:902-10. doi: 10.1016/j.carbpol.2017.11.061.

Zargarzadeh, M., A. J. R. Amaral, C. A. Custódio, and J. F. Mano 2020. Biomedical applications of laminarin. Carbohydrate Polymers 232:115774. doi: 10.1016/j.carbpol.2019.115774.

Zhang, Y., X. Fu, D. Duan, J. Xu, and X. Gao. 2019. Preparation and characterization of agar, agarose, and agaropectin from the red alga Ahnfeltia plicata. Journal of Oceanology and Limnology 37 (3):81524. doi: 10.1007/s00343-019-8129-6.

Zhang, Z., X. Wang, M. Zhao, and H. Qi. 2014. O-acetylation of low-molecular-weight polysaccharide from Enteromorpha linza with antioxidant activity. International Journal of Biological Macromolecules 69:39-45. doi: 10.1016/j.ijbiomac.2014.04.058.

Zhao, G., X. Zhai, M. Qu, C. Tong, and W. Li. 2019. Sulfated modification of the polysaccharides from Crassostrea gigas and their 
antioxidant and hepatoprotective activities through metabolomics analysis. International Journal of Biological Macromolecules 129:38695. doi: 10.1016/j.ijbiomac.2019.02.053.

Zhong, Q., B. Wei, S. Wang, S. Ke, J. Chen, H. Zhang, and H. Wang. 2019. The antioxidant activity of polysaccharides derived from ma- rine organisms: An overview. Marine Drugs 17 (12):674. doi: $10.3390 / \mathrm{md} 17120674$

Zong, A. H., Cao, and F. Wang. 2012. Anticancer polysaccharides from natural resources: A review of recent research. Carbohydrate Polymers 90 (4):1395-410. doi: 10.1016/j.carbpol.2012.07.026. 